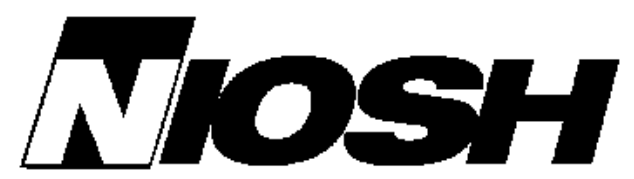

\title{
Test Results of Collision Warning Systems for Surface Mining Dump Trucks
}

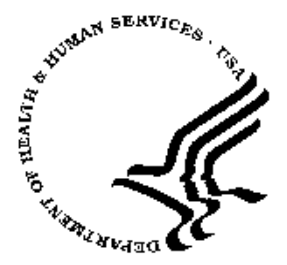

U.S. DEPARTMENT OF HEALTH AND HUMAN SERVICES Public Health Service

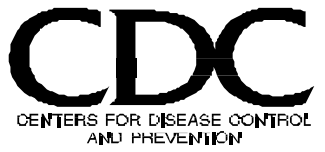


Report of Investigations 9652

\title{
Test Results of Collision Warning Systems for Surface Mining Dump Trucks
}

\author{
By Todd M. Ruff
}

U.S. DEPARTMENT OF HEALTH AND HUMAN SERVICES

Public Health Service

Centers for Disease Control and Prevention

National Institute for Occupational Safety and Health

Pittsburgh Research Laboratory

Pittsburgh, PA

May 2000 
International Standard Serial Number ISSN 1066-5552 


\section{CONTENTS}

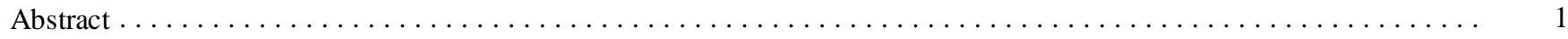

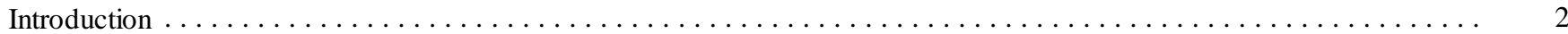

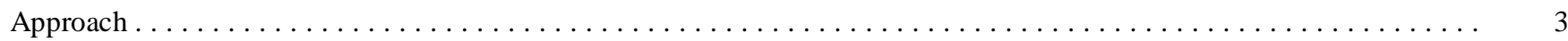

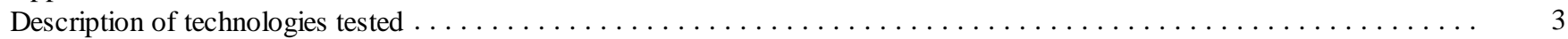

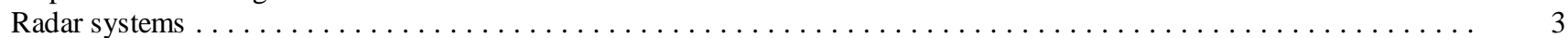

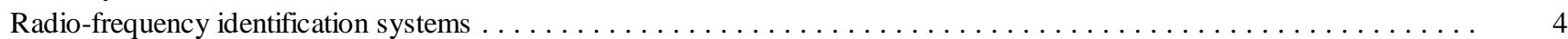

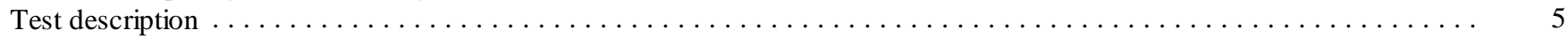

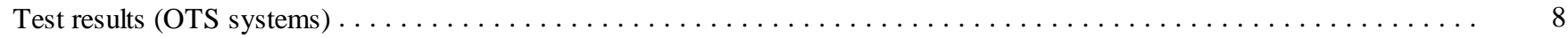

System 1-Radar Backup Alarm System $201 \ldots \ldots \ldots \ldots$

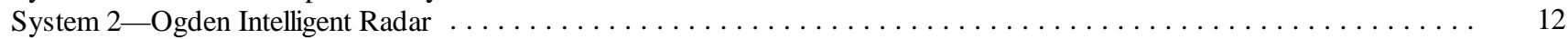

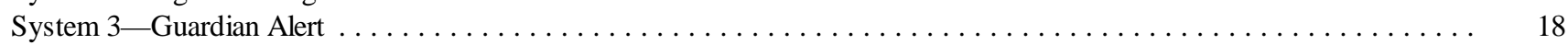

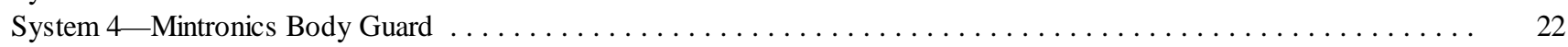

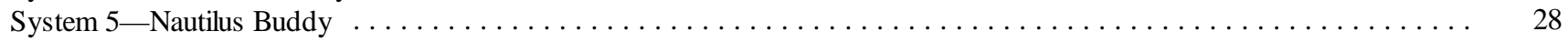

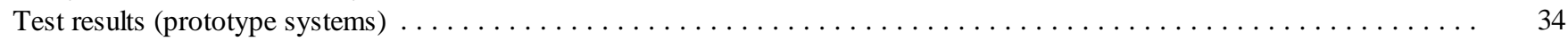

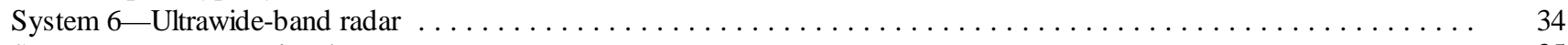

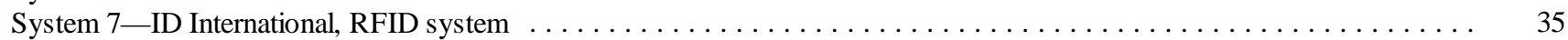

System 8 -Pittsburgh Research Laboratory HASARD system . . . . . . . . . . . . . . . . . . . . . . $\ldots 38$

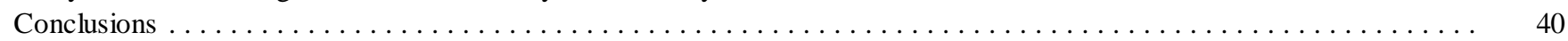

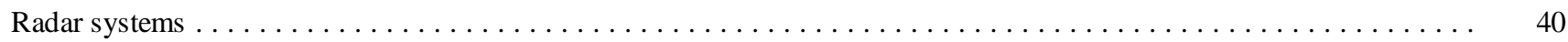

Radio-frequency identification systems $\ldots \ldots \ldots \ldots \ldots$

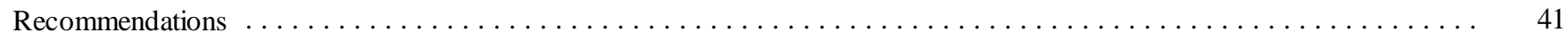

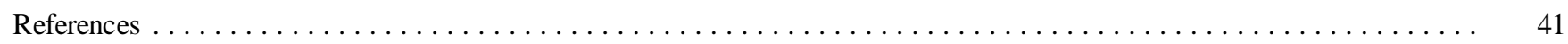

Appendix A: Collision warning system test description $\ldots \ldots \ldots \ldots$

\section{ILLUSTRATIONS}

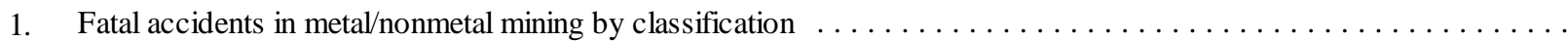

2. FMCW radar-based collision warning system manufactured by Ogden Safety Systems showing antenna and

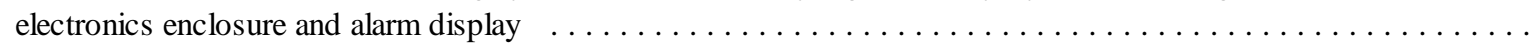

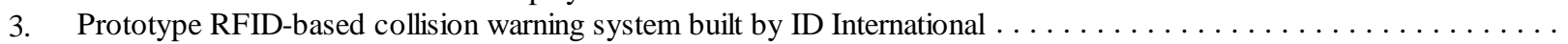

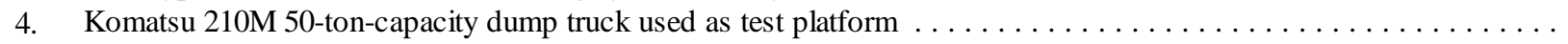

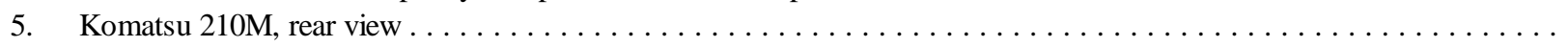

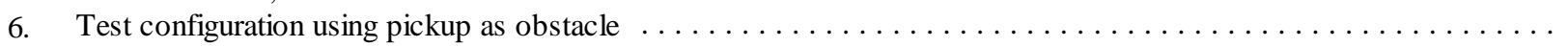

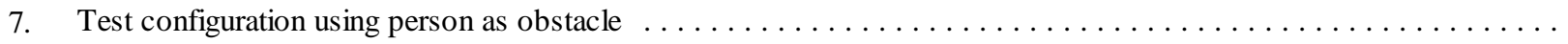

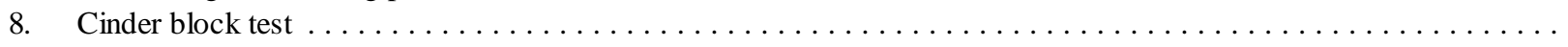

9. Doppler radar system manufactured by R. F. Knapp showing antenna and processing electronics and alarm display

10. Test results for Knapp System 201, narrow beam, and person $\ldots \ldots \ldots \ldots \ldots \ldots \ldots \ldots \ldots \ldots \ldots \ldots \ldots$

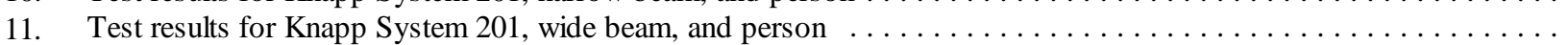

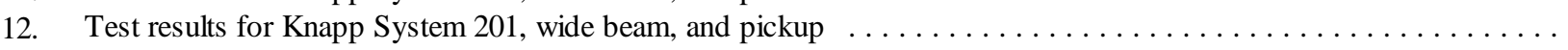

13. Test results for Knapp System 201, wide beam, and pickup perpendicular to dump truck $\ldots \ldots \ldots \ldots \ldots$

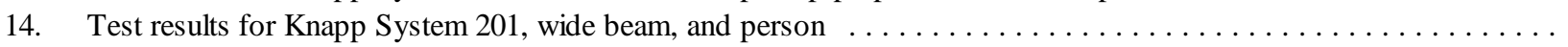

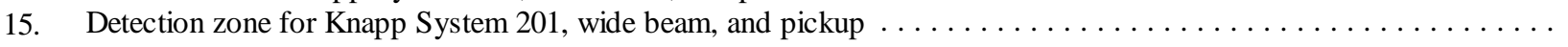

16. Detection zone for Knapp System 201, wide beam, and pickup perpendicular to dump truck $\ldots \ldots \ldots \ldots \ldots$

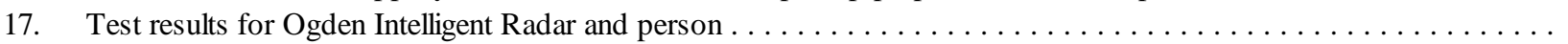

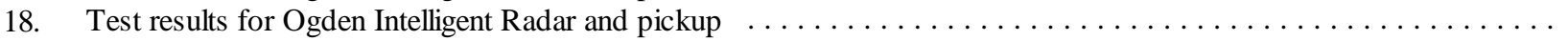

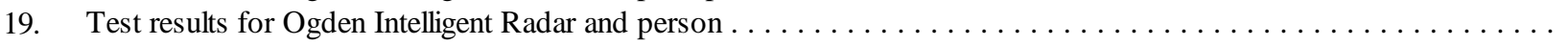

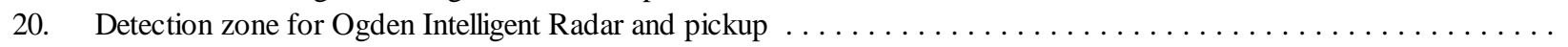

21. Guardian Alert radar system showing antenna and electronics enclosure and alarm display $\ldots \ldots \ldots \ldots \ldots$

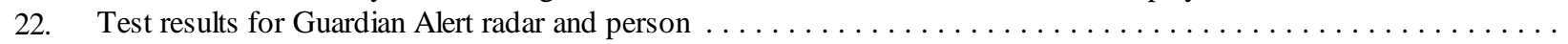

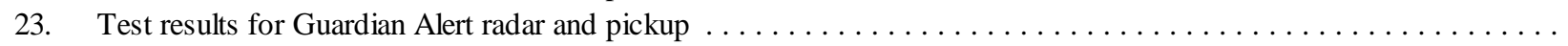




\section{ILLUSTRATIONS-Continued}

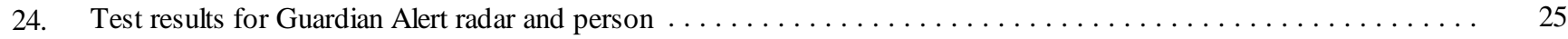

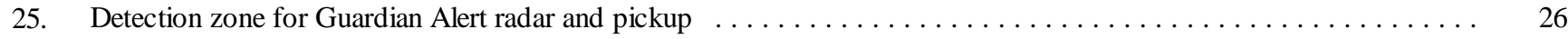

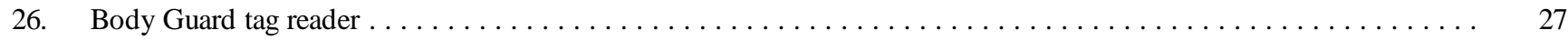

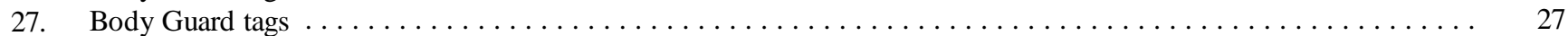

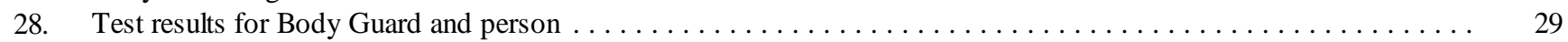

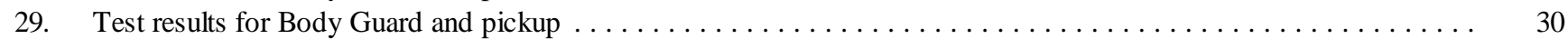

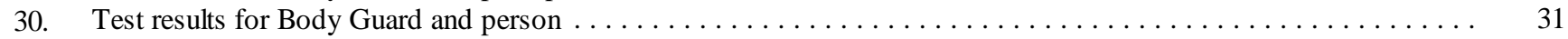

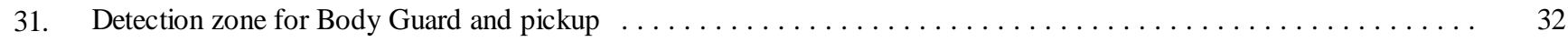

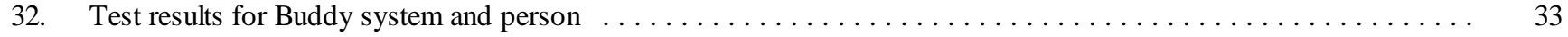

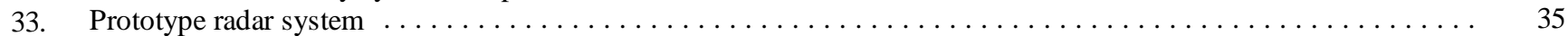

34. Test results for Multispectral ultrawide-band radar prototype and person $\ldots \ldots \ldots \ldots 36$

35. Detection zone for Multispectral ultrawide-band radar prototype and pickup $\ldots \ldots \ldots 37$

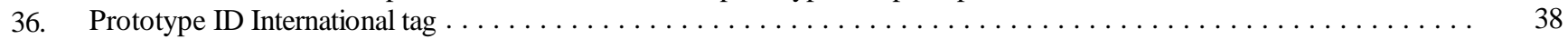

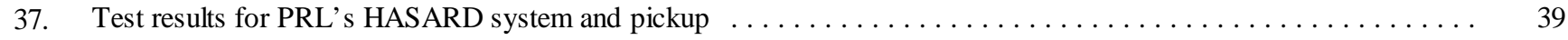

A-1. Example of size of detection zones for sensors mounted on front bumper and rear axle of off-road dump truck .... 42

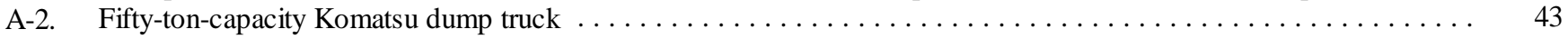

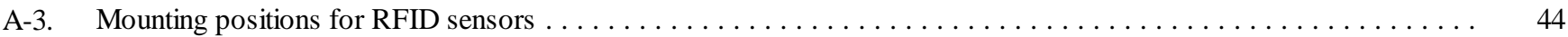

\section{TABLES}

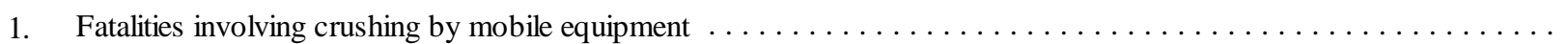

\section{UNIT OF MEASURE ABBREVIATIONS USED IN THIS REPORT}

$\begin{array}{llll}\mathrm{cm} & \text { centimeter } & \mathrm{MHz} & \text { megahertz } \\ \mathrm{dB} & \text { decibel } & \mathrm{mi} / \mathrm{h} & \text { mile per hour } \\ \mathrm{ft} & \text { foot } & \mathrm{ms} & \text { millisecond } \\ \mathrm{in} & \text { inch } & \mathrm{mW} & \text { milliwatt } \\ \mathrm{kHz} & \text { kilohertz } & \mathrm{ns} & \text { nanosecond } \\ \mathrm{km} / \mathrm{h} & \text { kilometer per hour } & \mathrm{V} & \text { volt } \\ \mathrm{m} & \text { meter } & & \\ \end{array}$




\title{
TEST RESULTS OF COLLISION WARNING SYSTEMS FOR SURFACE MINING DUMP TRUCKS
}

\author{
By Todd M. Ruff'
}

\begin{abstract}
An average of 13 mine workers are killed each year by being run over or pinned by mobile mining equipment. At surface mines, these accidents commonly involve large dump trucks that drive over a smaller vehicle or a person that is in the dump truck's blind spot. One method of detecting a person or another vehicle in a blind spot is to use some type of sensor technology such as radar or radio-frequency identification (RFID). Researchers at the Spokane Research Laboratory of the National Institute for Occupational Safety and Health tested a number of commercially available and experimental sensors that monitor obstacles in a vehicle's blind spots. None of the sensors had been previously applied to the specific problem of rigid-frame surface mining trucks. This report documents the procedures and results of tests conducted after RFID and radar systems were mounted on a 50-toncapacity dump truck. It was determined that both RFID and radar technology show promise for detecting obstacles in the blind spots of mining equipment; however, more development work is needed to meet the unique requirements of mining equipment and the mine environment.
\end{abstract}

${ }^{1}$ Electrical engineer, Spokane Research Laboratory, National Institute for Occupational Safety and Health, Spokane, WA. 


\section{INTRODUCTION}

For the 5-year period between 1994 and 1998, powered haulage accounted for the majority of fatal accidents in metal/nonmetal mines (table 1; figure 1). According to the Mine Safety and Health Administration (MSHA 1999), approximately $20 \%$ of these fatalities involved the off-road dump trucks used in surface mining.

In 1998, 13 miners were killed in metal/nonmetal and coal mines when they were run over or pinned by mobile equipment. An average of 13 workers were killed per year in such types of accidents in the previous 3 years also. Over half of these accidents could have been avoided if the equipment operator had been adequately warned of an impending collision (table 1). Many of these avoidable accidents involved dump trucks that ran over a worker or a small vehicle hidden from view in the blind spot of the truck. Despite the requirement for audible backup alarms, these accidents are still occurring with unsettling frequency. In fact, at the time of this report, MSHA was considering regulations that would require the use of some type of blind spot sensor (30 CFR Parts 56, 57, 77, 1998).

Researchers at the Spokane Research Laboratory (SRL) of the National Institute for Occupational Safety and Health (NIOSH) are investigating sensor technologies that can be used to detect the presence of an obstacle in the blind spot of a piece of mining equipment and provide a warning to the equipment operator. A preliminary analysis indicated that such technology is available and is being used in other industries. However, applying these technologies to off-road dump trucks and other mining equipment has proven to be more of a challenge than first expected.

Table 1.-Fatalities involving crushing by mobile equipment

\begin{tabular}{lcc}
\hline Year & $\begin{array}{c}\text { Total no. of fatalities (figures do not include } \\
\text { rollovers) }\end{array}$ & $\begin{array}{c}\text { No. of fatalities that could have been avoided } \\
\text { using collision warning system. }\end{array}$ \\
\hline $1998 \ldots \ldots \ldots \ldots \ldots$ & 13 & 6 \\
$1997 \ldots \ldots \ldots \ldots \ldots$ & 9 & 7 \\
$1996 \ldots \ldots \ldots \ldots \ldots$ & 15 & 8 \\
$1995 \ldots \ldots \ldots \ldots \ldots$ & 16 & 9 \\
\hline
\end{tabular}

Source: MSHA Fatal Alert Bulletins (http://www.msha.gov)

\section{4-1998 Fatal Accidents}

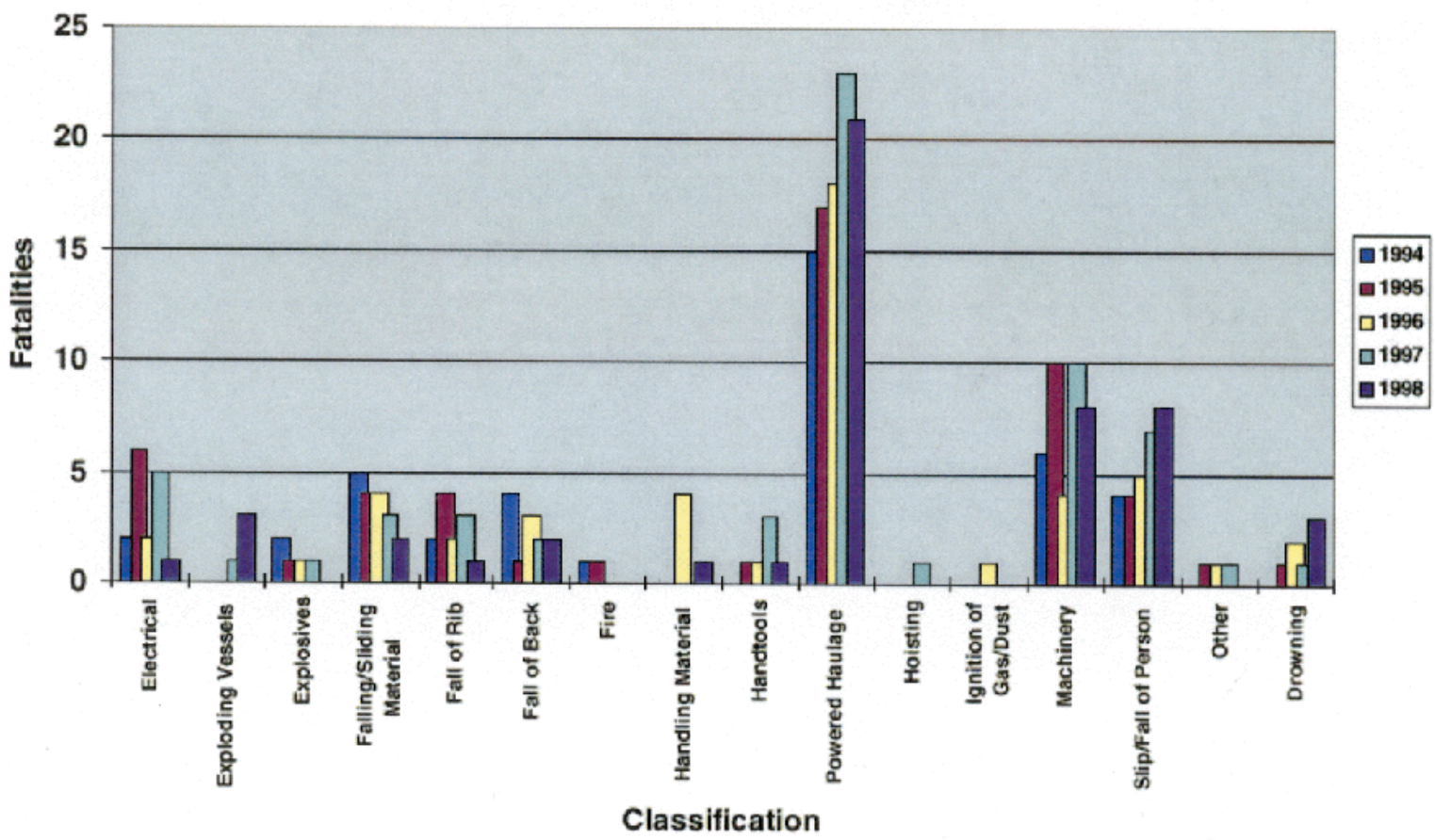

Figure 1.-Fatal accidents in metal/nonmetal mining by classification. (Source: MSHA)

\section{APPROACH}


A collision warning system consists of some type of sensor that detects the presence of an object, an interface that provides an audible and/or visual alarm to the equipment operator, and wiring between the two. Potential sensor technologies include ultrasonic echo detection, infrared reflection, radar (radio detection and ranging), video cameras, and radio-frequency identification (RFID) systems.

A product search was conducted to determine the availability of collision warning systems that could be applied to the mining problem. We found many systems being used on long-haul trucks, passenger cars, light trucks, vans, buses, and to a limited extent, construction equipment. A few foreign systems are specifically manufactured for mining equipment.

Next, SRL researchers talked with mining personnel, equipment manufacturers, and engineers at MSHA to determine why existing collision warning systems are not being used extensively by the mining industry. They indicated that the main factors are (1) lack of field testing and research to determine the effectiveness of these systems, (2) poor reliability because of high false alarm rates, and (3) poor reliability and high maintenance because of the harsh mining environment. Based on this information, researchers decided that further product development and extensive field tests were needed before collision warning systems would be widely embraced.

The next step was to narrow the selection of the collision warning systems to those that showed promise for surface mining applications. While other technologies are available, such as infrared, ultrasonic, and video, the evaluations were limited to radio-frequency devices (radar and RFID). This decision was based on earlier research [Johnson et al. 1986] and experience. Radio-frequency devices are more robust and can handle the harsh conditions of surface mining. They are not affected by adverse weather, heat or sunlight, dust, or moderate amounts of dirt and mud buildup on the sensor. The other technologies may be able to address the particular challenges of surface mining as they are improved, but for this study, only radio-frequency devices were tested.

Five off-the-shelf (OTS) systems were purchased or borrowed for evaluation at SRL. Two more prototype systems were developed under contract as alternatives to OTS systems. Another prototype system being developed for underground coal mining was also evaluated. Four of the systems are based on radar technology, and four are based on RFID.

Preliminary tests of these systems in the lab showed the need for testing each system on actual mining machines. Moving parts and the amount of steel present on large mining equipment may have detrimental effects on the operation of a collision warning system. The only way to ensure that a system operates reliably is to mount it on the actual machine and under actual operating conditions.

\section{DESCRIPTION OF TECHNOLOGIES TESTED}

\section{RADAR SYSTEMS}

Radar technology is one of the most established methods of obstacle detection. Many types of radar are used in collision warning systems, including pulsed or ultrawide-band, Doppler, and frequency-modulated continuous wave (FMCW). Most operate in the microwave frequencies within the $\mathrm{C}, \mathrm{X}$, or $\mathrm{K}$ bands. Some of the newer systems for highway applications operate at even higher frequencies.

A radar system operates by emitting electromagnetic energy and detecting this energy when it is reflected from an object or target. Information about the target, such as range and direction of movement, can be acquired by analyzing this reflected energy [Skolnik 1990]. The technology is well suited to collision avoidance applications because it is not affected by rain, snow, dust, or even a moderate buildup of mud on the antennas.

Many collision warning systems are based on radar technology. The systems consist of a radar antenna(s), processing electronics, and an operator interface or alarm display (figure 2). The radar unit is mounted on the vehicle and directed toward the area to be monitored. If an object of sufficient crosssectional area is within the beam pattern of the radar antenna, the signal is reflected to the unit and is processed. If certain criteria are met, an alarm is generated. The type of alarm varies with the type of display.

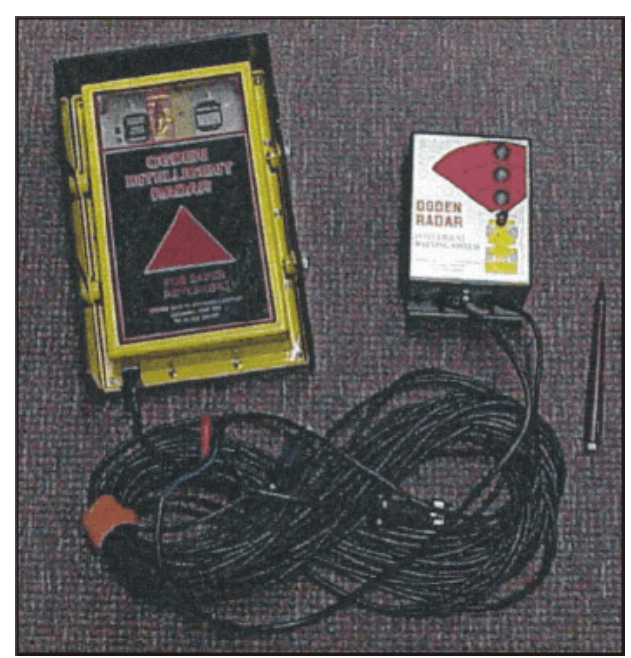

Figure 2.-FMCW radar-based collision warning system manufactured by Ogden Safety Systems showing antenna and electronic enclosure (left) and alarm display (right). 
The most common type of radar used in collision warning systems employs Doppler shift detection. These systems only detect relative movement of objects by sensing a frequency shift in the reflected signal. For the system to activate an alarm, either the object within the transmitted beam pattern must move toward the stationary vehicle, or the vehicle must move toward the object. If both object and vehicle are not moving, no alarm is activated. This has the advantage of providing alarms only when a vehicle is moving and a collision is imminent. However, it has the disadvantage of not providing an alarm that allows sufficient time to stop if a stationary object is very close to a vehicle that starts moving. Other types of radar, such as FMCW, can be configured to operate in this manner also.

Pulsed radar is also used for collision warning systems. Because of the pulsed nature of the output signal, the average power output by the radar is extremely low (microwatts). Also, time of flight for the reflected signal is easily measured, and accurate range information can be provided as long as the detected object is not immediately next to the antennas. Systems using this type of radar can sense the presence of an object whether there is relative motion or not.

\section{RADIO-FREQUENCY IDENTIFICATION SYSTEMS ${ }^{2}$}

Several companies have applied RFID systems to the collision avoidance problem. The systems typically consist of a tag reader, tags, and an operator interface or alarm display (figure 3). The tag reader detects radio transmissions from a tag if the tag is within its reading range. The tag reader is mounted on the mine equipment, while tags are mounted on any item that is to be avoided. These items can include other vehicles, pedestrian workers, power and utility poles, or even a building. The small cost and small size of most tags allows them to be mounted on hard hats, personnel belts, or anywhere on the exterior of a vehicle. The nature of radio-frequency signals makes this technology ideal for harsh environments because radio transmissions are not adversely affected by harsh weather, dust, or moderate amounts of mud buildup on the antennas. However, radio signals can be affected by interference from multipath effects and other radio signal sources.

${ }^{2}$ RFID can also be referred to as radio signal detection. Traditional RFID uses transmission of digital codes for identification functions. Digital codes may or may not be implemented in collision avoidance applications. Only the detection of the correct radio signal is required.

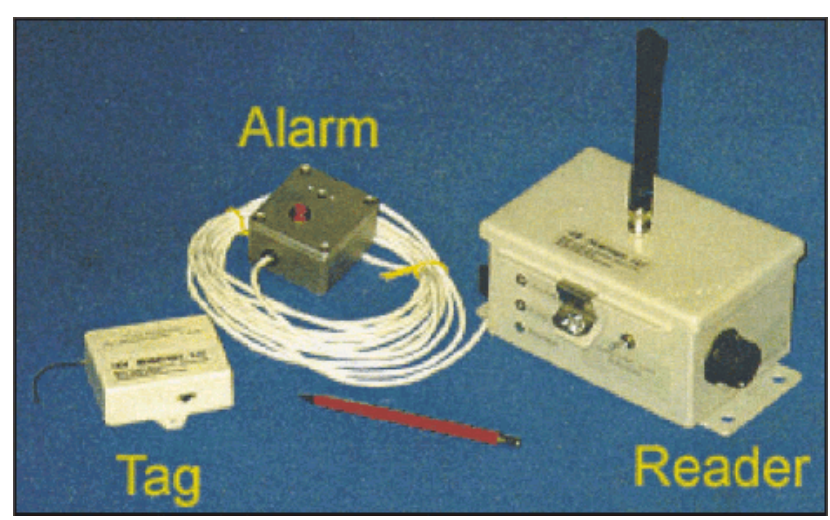

Figure 3.-Prototype RFID-based collision warning system built by ID International.

There are two types of tags: passive and active. Each has advantages and disadvantages. For passive tags, the tag reader constantly transmits a signal that activates a tag if it is within range. The tag then answers with a unique signal that is detected by the tag reader. The advantages of passive tags are that there is no requirement for external power, they need little maintenance, and they are very inexpensive. The disadvantage is that they often have a more limited reading range than active tags.

With active tags, the reader can be passive and just listen for the unique transmissions from the tag. The tag usually transmits constantly and requires external power. The advantages of these tags is an increased reading range and more functionality. The disadvantages include the need for batteries and increased cost and size when compared to passive tags.

If a reader detects a tag within its reading range, signal processing software analyzes the signal to determine signal strength and integrity. If the acquired signal meets alarm criteria, then an audible and/or visual alarm is indicated at the alarm display. The alarm thus warns an operator that a tag is in proximity to the equipment.

At least three companies are currently working on RFID systems for collision avoidance in mines. Two of these companies have OTS systems available for remote-controlled equipment (mainly load-haul-dump units, or LHD's) used in underground mines. All three companies were in the process of developing a system for surface mine haulage trucks when this report was published. 


\section{TEST DESCRIPTION}

Tests of the collision warning systems were designed based on experience gained from previous tests, some aspects of SAE J1741 Discriminating Backup Alarm Standard [Society for Automotive Engineers (SAE) 1998], and guidance from MSHA. A detailed test description is found in appendix A. The systems were to be tested on a rigid-frame, off-road dump truck that represented those used in industry as closely as possible. Because of the number of systems to be tested and the amount of time required, the tests could not be conducted at an operating mine. Therefore, a dump truck was rented, and the tests were conducted at a remote auxiliary site of SRL.

The largest dump truck available for rental in the Spokane area was a 50-ton-capacity Komatsu 210M Haulpak ${ }^{3}$ (figures 4 and 5). Unfortunately, although this truck has similar features and is commonly used in sand and gravel operations, it is smaller than most trucks used in surface mining, where 190- or 240-ton trucks are common. While not an ideal representation of the larger trucks, the 50-ton truck did provide an adequate platform for the tests.

Each collision warning system was mounted on the truck according to the manufacturer's suggestions and with the requirement that the sensor be accessible and unobtrusive during the truck's operation. To monitor the rear blind spot of the truck, the sensor was mounted near the light bar above the rear axle. To monitor the front blind spot, the sensor was mounted near the front bumper or on the grill.

${ }^{3}$ Mention of specific products or manufacturers does not imply endorsement by the National Institute for Occupational Safety and Health.
The test area was approximately $61 \mathrm{~m}$ long by $30 \mathrm{~m}$ wide (200 by $100 \mathrm{ft}$ ). It was cleared of debris and graded flat. The surface of the test area was dirt and gravel with no large rocks or ruts. This gave researchers a clear field for testing the collision warning systems under ideal conditions. Obstacles and other debris were then added as each test progressed.

The obstacles to be detected by the collision warning system consisted of either a person or a pickup truck. Two scenarios were tested for each obstacle: (1) the dump truck was driven toward the stationary obstacle and (2) the obstacle moved toward the stationary dump truck (figures 6 and 7). A detection zone was then recorded that showed in which areas the obstacle was consistently detected and an alarm was sounded. When needed, a second zone was recorded that indicated the area in which an obstacle was detected sporadically, i.e., less than $100 \%$ of the time but more than $10 \%$. The detection zone was recorded by placing the obstacle on the points of a grid at 76-cm (2.5-ft) spacings in the dump truck's blind spot. As the dump truck or obstacle was moved, the state of the system's alarm was noted for each position.

The alarm display for each system was mounted near the sensor or antennas. This allowed researchers to monitor the alarm easily. Normally the alarm display would be mounted in the cab with the operator.

It is critical that the audible alarm be easily distinguished from all background engine noises and other warning buzzers. Also, it is important that any lights or LED's be visible in any lighting condition. The alarm's effectiveness in the cab was not tested because most of the collision warning systems were not designed for surface mining haulage equipment. Each

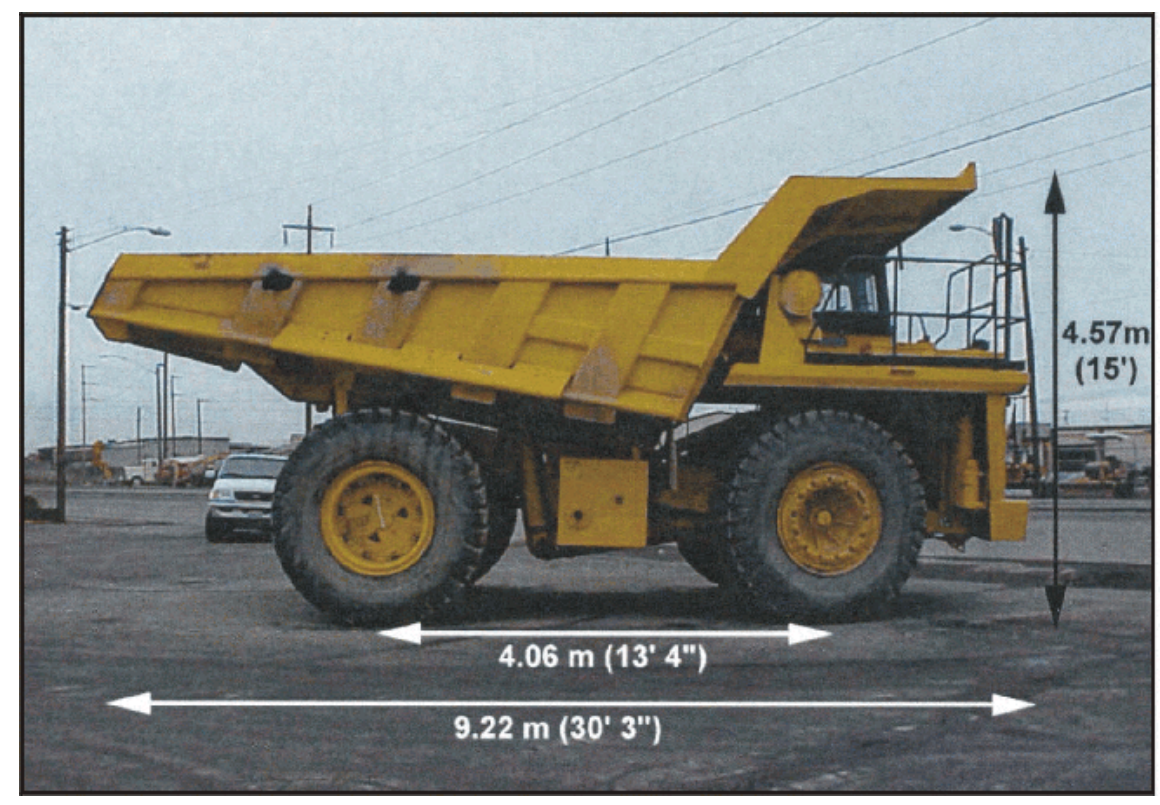

Figure 4.-Komatsu 210M 50-ton-capacity dump truck used as test platform. 
manufacturer will have to develop an appropriate alarm display to meet the demands of this application. Guidelines for developing warning signals can be found in SAE J1741 and in U.S. Department of Transportation reports [Harpster et al. 1996; Huey et al. 1997].

According to SAE J1741, it is desirable that a collision warning system ignore an object the size of a cinder block in the blind spot of the dump truck (figure 8). While this may or may not be important to a mine implementing a collision warning system, researchers tested each OTS radar system to see how it reacted to a cinder block. RFID-based systems were not tested with the cinder block because the block would obviously be ignored if no tag were attached to it.

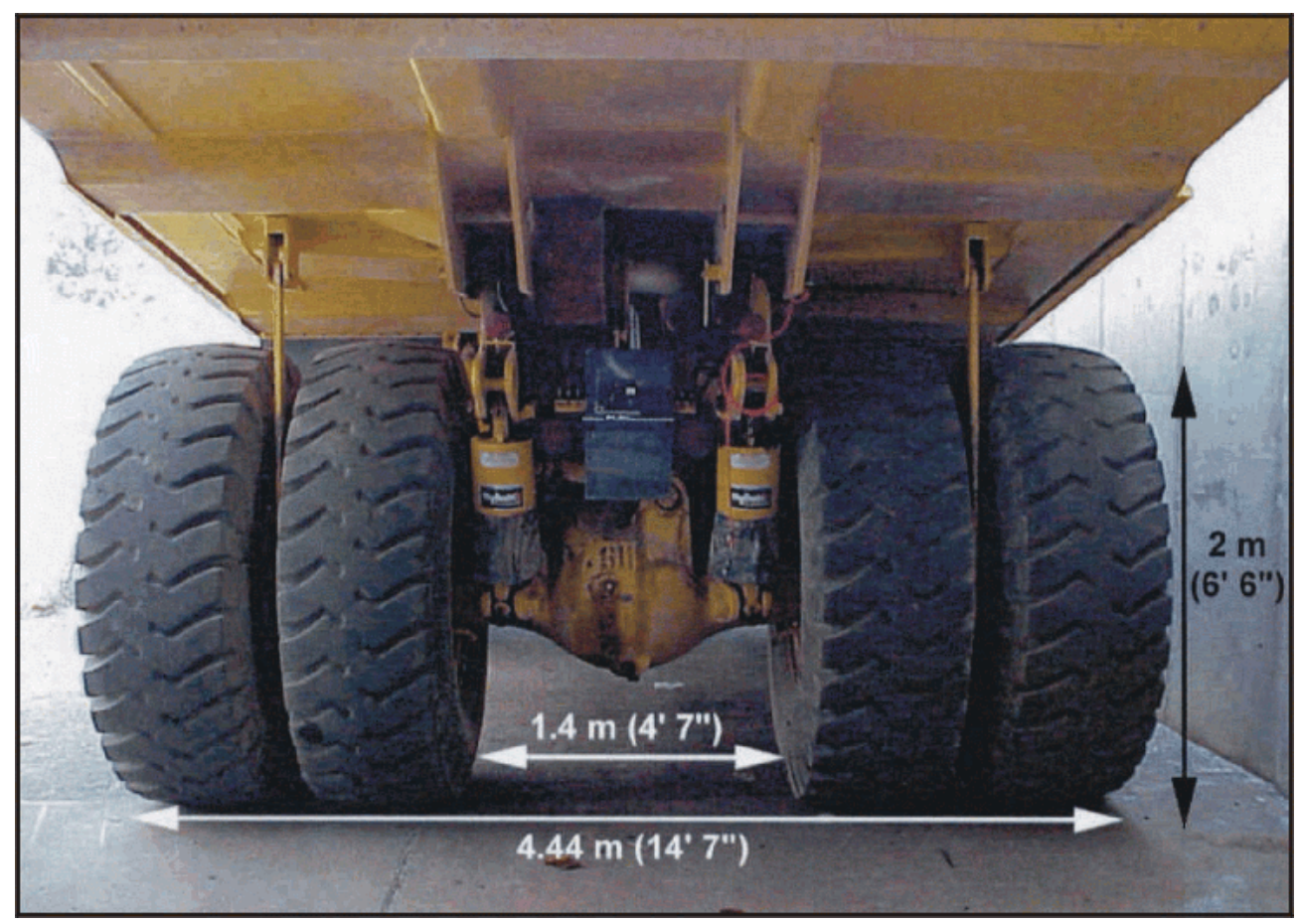

Figure 5.-Komatsu 210M, rear view.

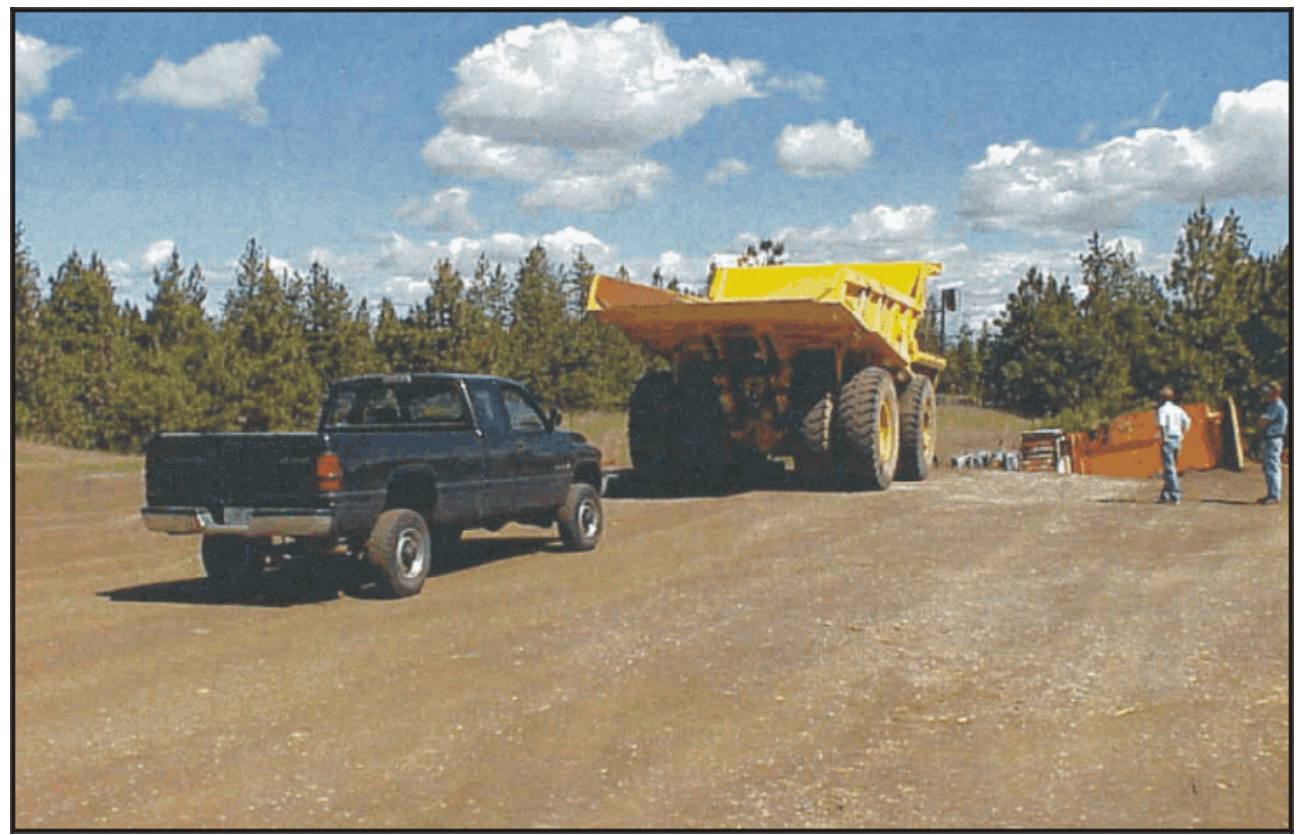

Figure 6.-Test configuration using pickup as obstacle. 


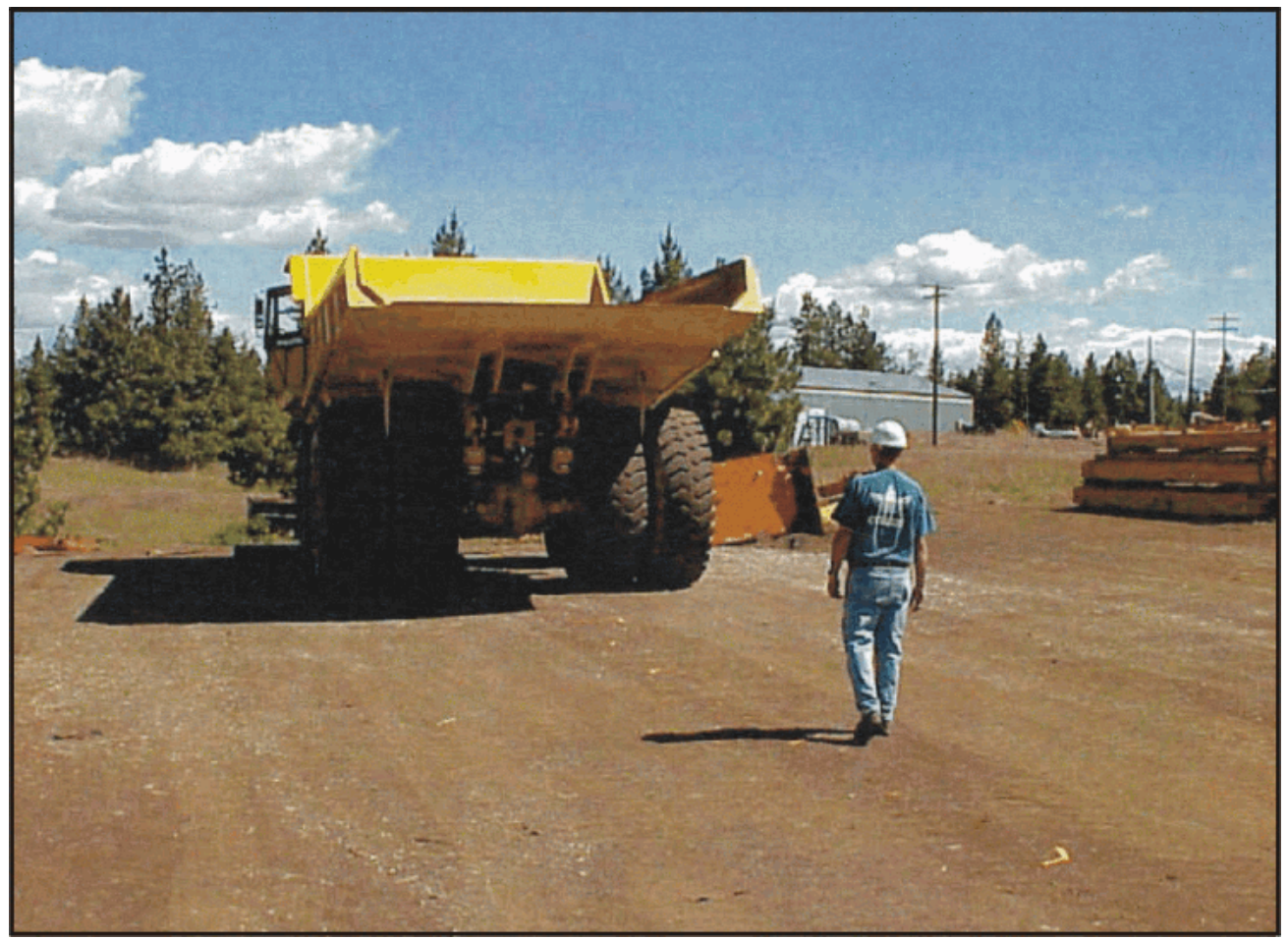

Figure 7.-Test configuration using person as obstacle.

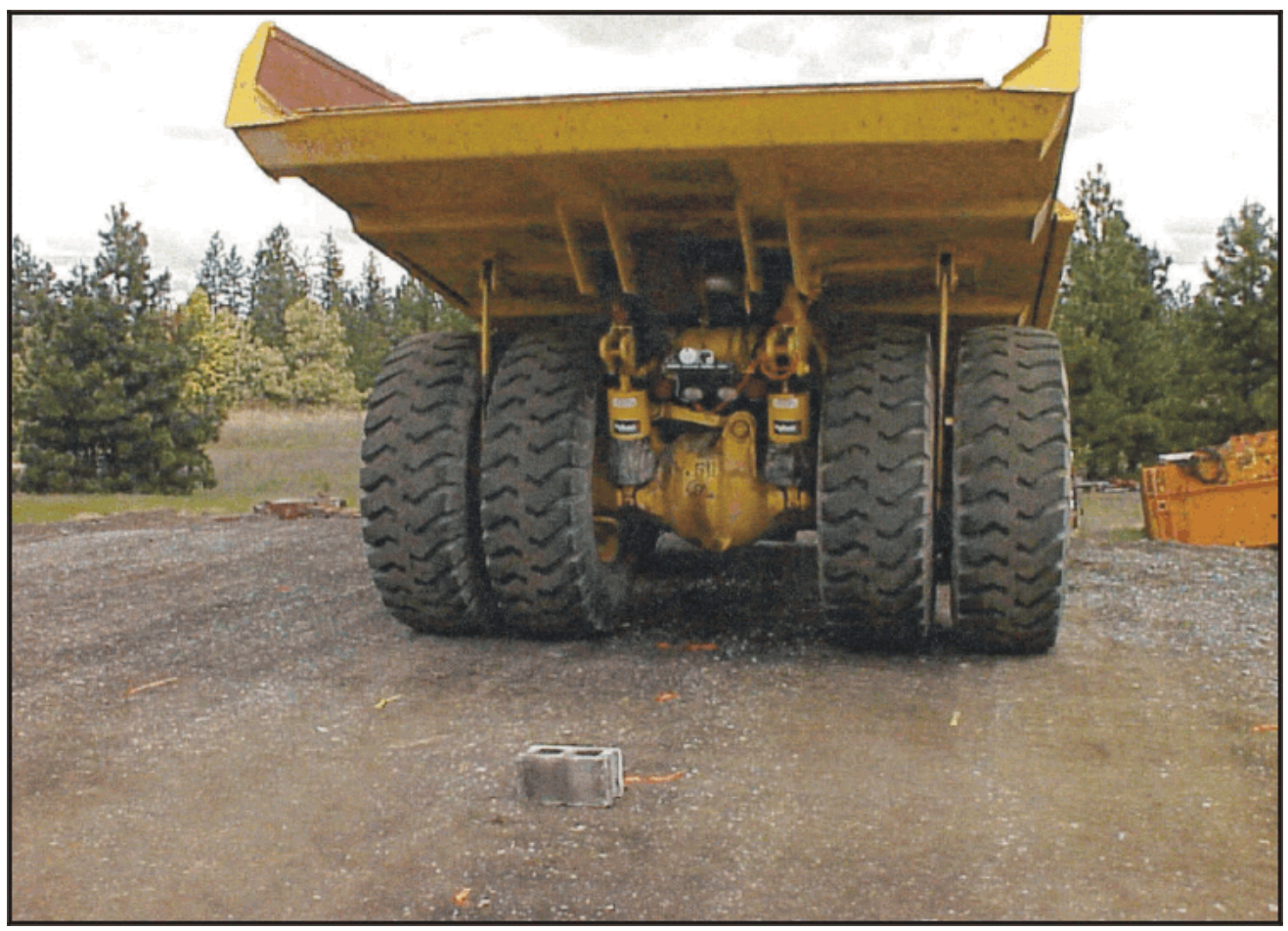

Figure 8.-Cinder block test. 


\section{TEST RESULTS (OTS SYSTEMS)}

\section{SYSTEM 1- RADAR BACKUP ALARM SYSTEM 201}

Manufacturer:

\section{R. F. Knapp Company, Spirit Lake, Idaho}

\section{Description:}

The system uses microwave radar technology in which Doppler shift is sensed. The antenna and processing electronics are contained in a polyvinyl-chloride (PVC)-type plastic enclosure. The alarm display consists of a light and a buzzer, both of which are simple on-off indicators. The system is shown in figure 9.

\section{Current Applications:}

The system is currently used on construction equipment that includes front-end loaders, cranes, and over-the-road trucks.

\section{Rear Blind Spot Test Results:}

The system was mounted on the rear of the dump truck in a location $20 \mathrm{~cm}(8 \mathrm{in})$ in front of the light bar and just above the axle at a height of $1.7 \mathrm{~m}$ (68 in) from the ground. The alarm display was also mounted on the light bar so researchers could easily monitor the state of the alarm. Normally the alarm display would be located in the cab of the dump truck.

Two models were tested, a narrow-beam system and a standard wide-beam system. The narrow-beam system did not have wide enough coverage to detect a person immediately behind the outermost tires of the truck (figure 10A), so the widebeam sensor was used for the rest of the tests. The narrow-beam sensor is more appropriate for narrower equipment, or two units could be placed side-by-side for an even wider coverage area on a larger truck [Boldt and Backer 1997].

The wide-beam radar system was mounted on the rear of the truck in the same location as the narrow-beam system. However, when the truck was moved, false alarms were set off when the system detected the rotation of the truck's tires. This problem was solved by moving the radar unit another $25 \mathrm{~cm}$ (10 in) away from the light bar so that the detection zone started just beyond the tires (figure $11 B$ ). On a larger truck, there may not be a mounting location with sufficient offset to allow the radar unit to ignore tire rotation. Boldt and Backer [1997] note this problem and possible solutions that involve installing multiple narrow-beam sensors.

The system was tested for false alarms in a clear field. False alarms did occur if the radar unit was tilted downward too far, and it was suspected that the radar unit was detecting the ground. The angle of tilt needed to ignore the ground depends on the ground surface and its composition. In this situation, a downward tilt of $5^{\circ}$ or less was enough to eliminate false

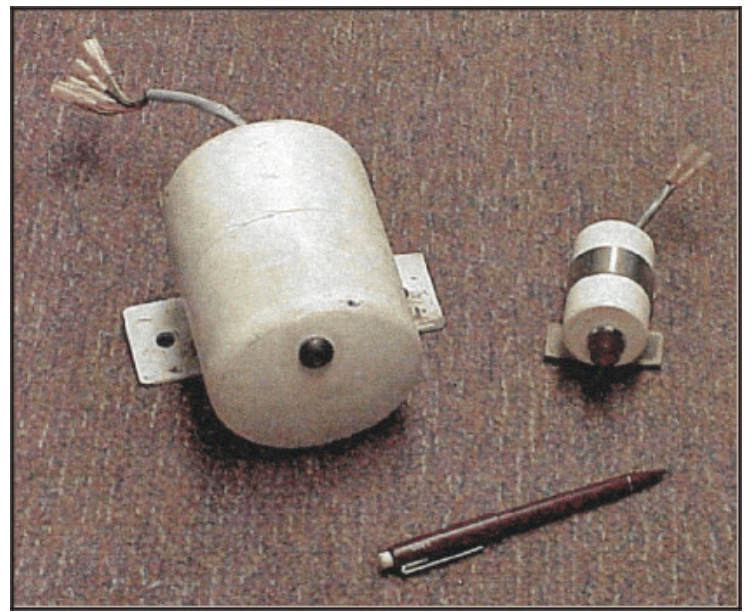

Figure 9.-Doppler radar system manufactured by R. F. Knapp showing antenna and processing electronics (left) and alarm display (right).

alarms. Both the height of the radar unit and the angle of tilt would have to be adjusted for ground conditions and each type of equipment at a mine. There were also occasional false alarms (usually just a single beep of the alarm display) from unknown sources. According to Boldt and Backer, this also can be eliminated by using higher mounting locations and adjusting the radar unit's tilt.

Figure $11 A$ shows the results of tests with the wide-beam sensor when a person was used as the obstacle. This system reliably detected a person in the recorded detection zone when the truck moved toward the person or the person moved toward the truck. However, there were occasional alarms when the distance between the target and the radar unit was increased. Usually with Doppler-based systems, an alarm is desired only when the distance decreases because this is the dangerous situation. The maximum distance that a person was detected was $6.9 \mathrm{~m}(22.5 \mathrm{ft})$ when the range of the system was set at approximately $75 \%$. Range settings above this amount resulted in more false alarms.

Figure $12 A$ shows test results when a pickup was used as the obstacle. The "reliable detection zone" indicates the area in which the pickup was detected consistently, i.e., if the front bumper of the pickup was within the indicated zone, detection was consistent. This test was conducted with the pickup facing the rear of the dump truck, an orientation that resulted in the least amount of cross-sectional area that could reflect radar energy. The maximum distance over which the pickup was detected was $18.3 \mathrm{~m}(60 \mathrm{ft})$. The minimum distance occurred directly in front of the radar. As seen in figure $12 A$, the rear of the pickup truck was detected as long as it remained in front of the sensor, accounting for the detection areas that extend down the sides of the dump truck. In other words, if a pickup truck is parked so that its front bumper is within this zone, it will be detected when the dump truck moves. 


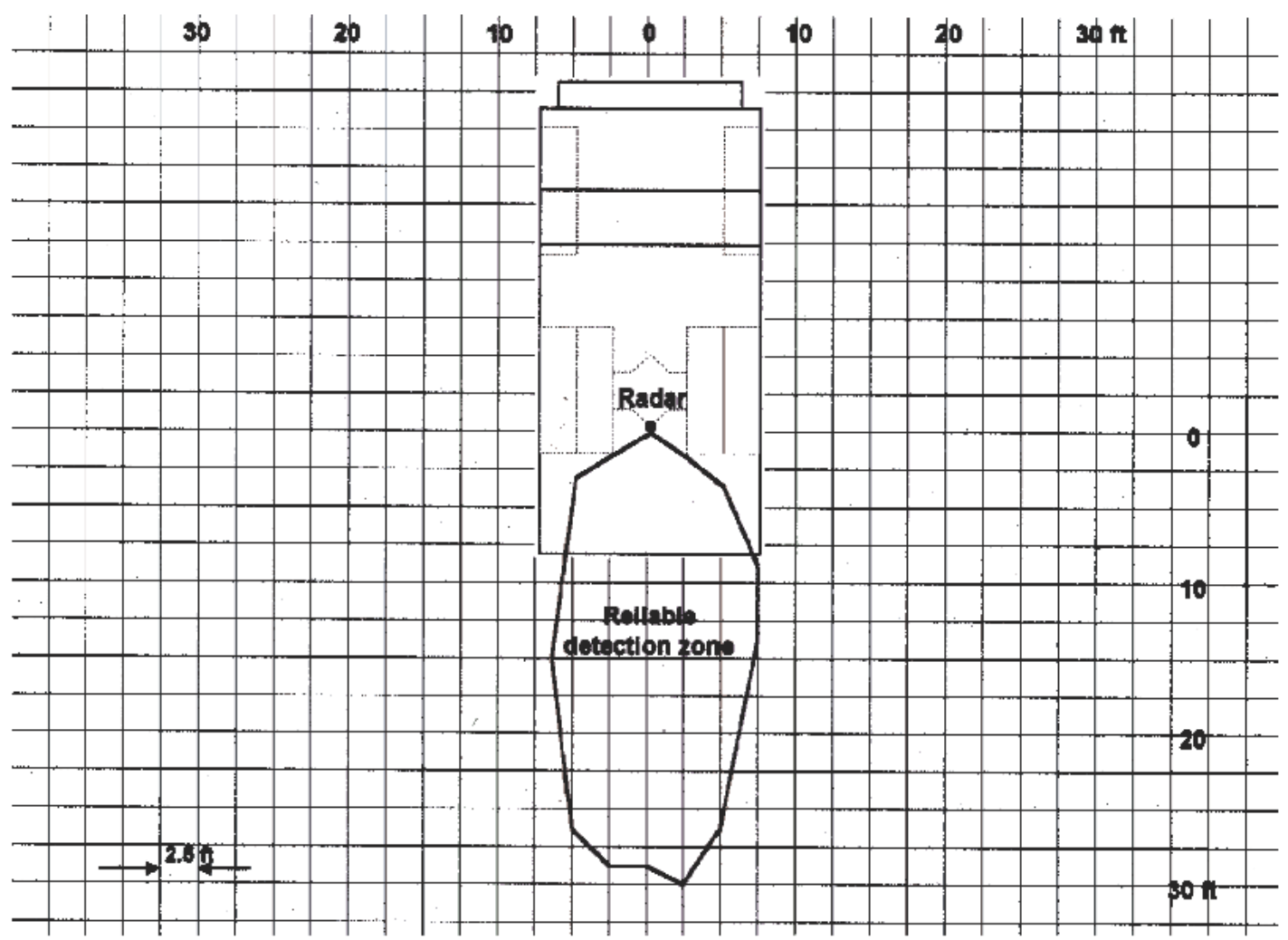

$\boldsymbol{A}$

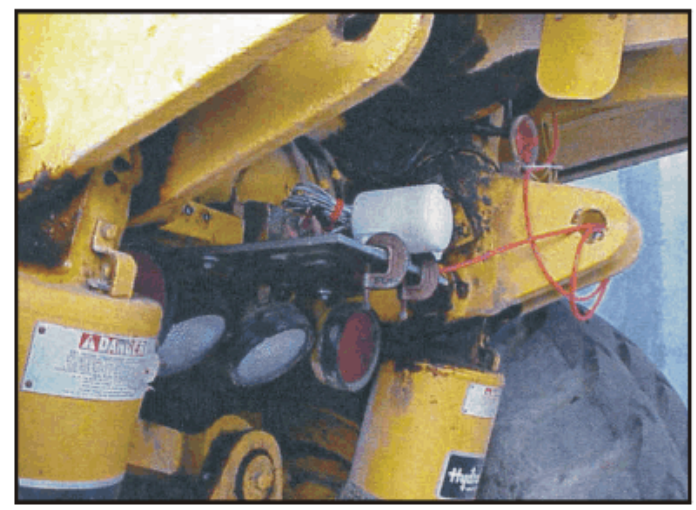

B

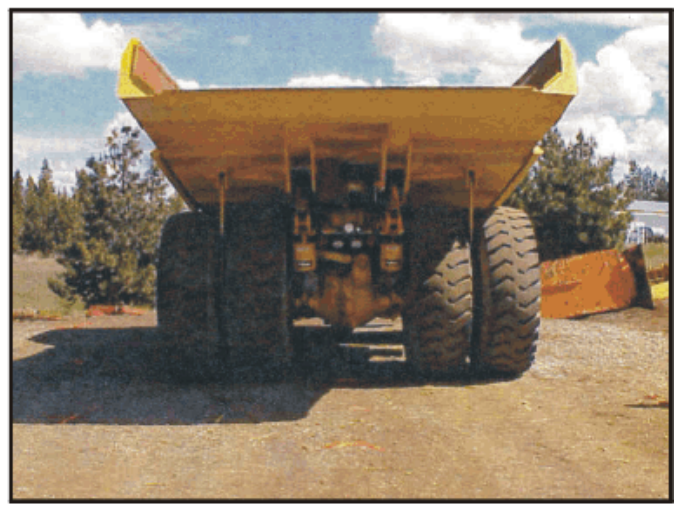

C

Settings: $\quad$ Range set to maximum.

Mounting: $\quad$ Radar mounted near light bar at height of $1.7 \mathrm{~m}$ (68 in), offset of $20 \mathrm{~cm}$ (8 in), and downward tilt of $10^{\circ}$.

Target detected: Person.

Figure 10.-Test results for Knapp System 201, narrow beam, and person. A, Detection zone; B, mounting position; $C$, rear view of truck. 


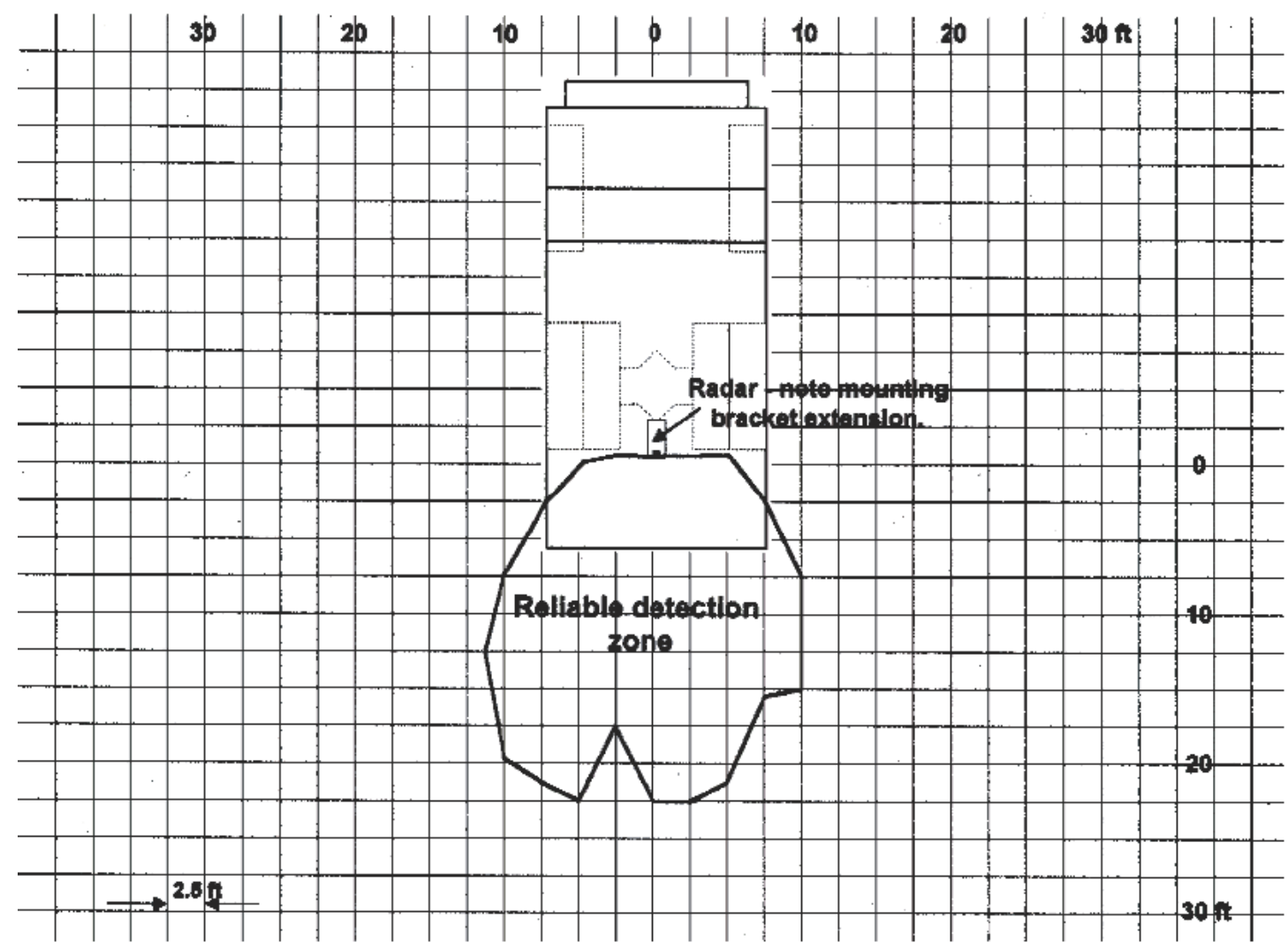

$\boldsymbol{A}$

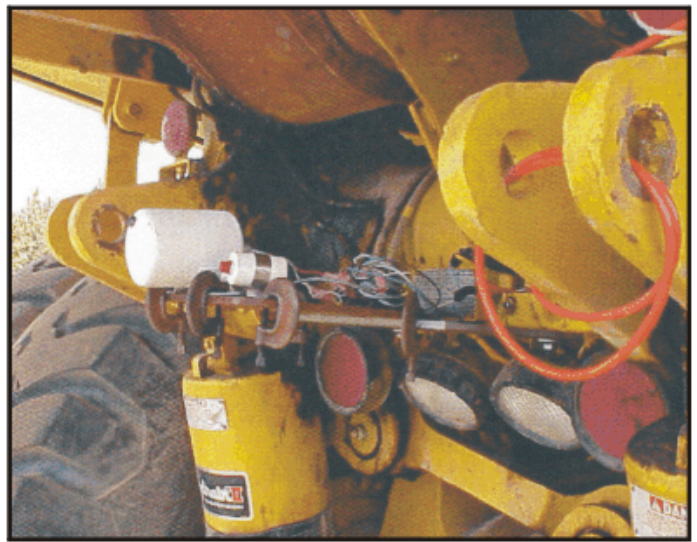

$\boldsymbol{B}$

Settings:

Mounting:

Target detected: Person.

Figure 11.-Test results for Knapp System 201, wide beam, and person. $A$, Detection zone; $B$, mounting position; $C$, view behind truck.

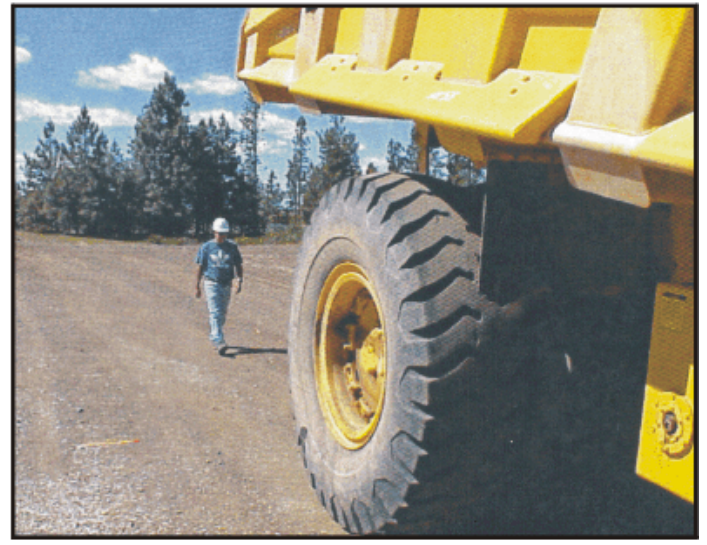

C
Range set to approximately $75 \%$.

Radar mounted near light bar at height of $1.7 \mathrm{~m}$ (68 in), offset of $46 \mathrm{~cm}$ (18 in), and. downward tilt of $5^{\circ}$. 


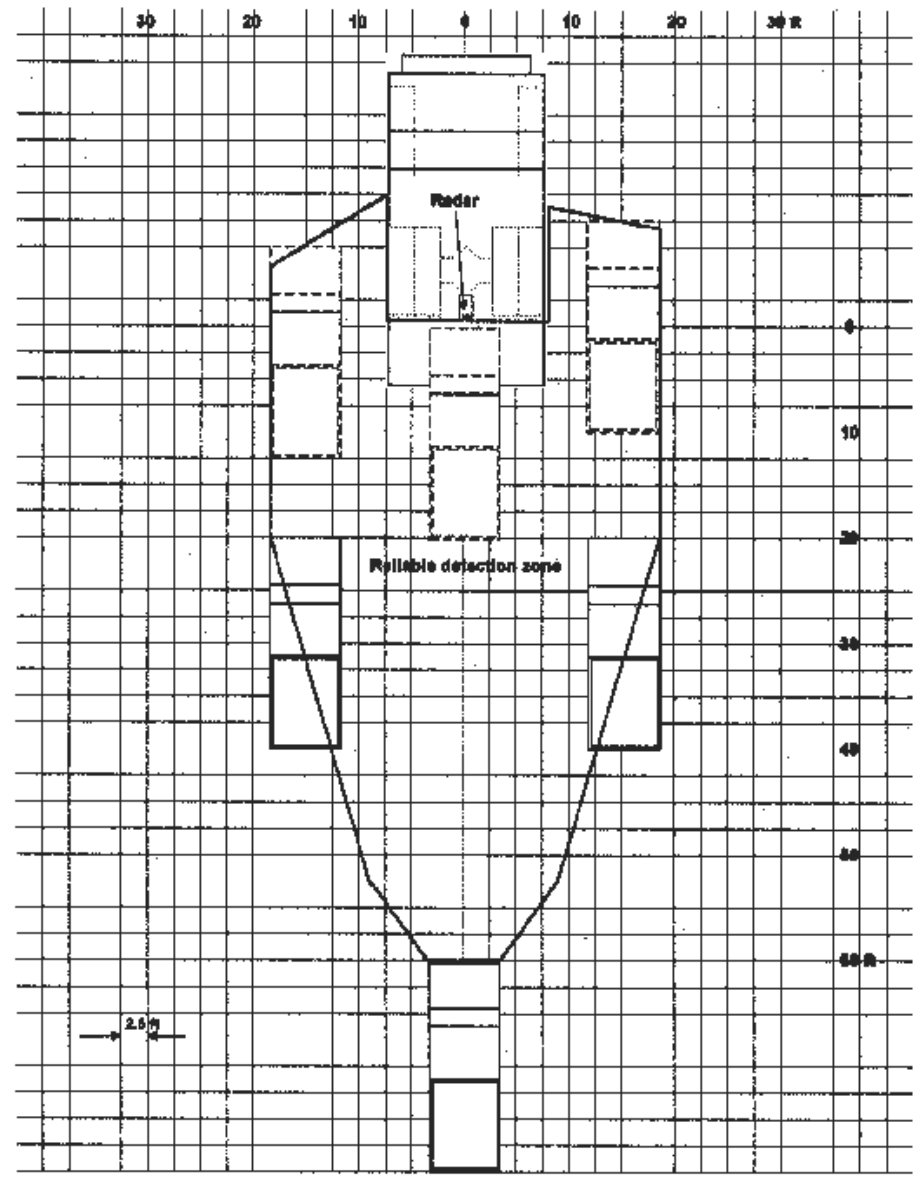

$\boldsymbol{A}$

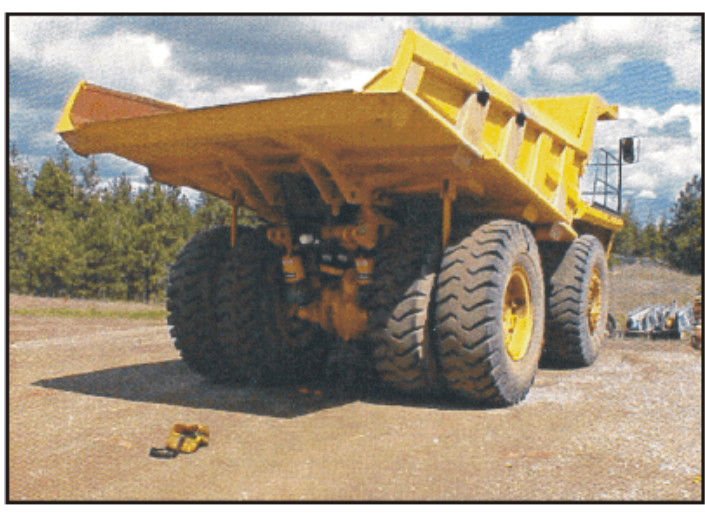

$B$

Settings:

Mounting:

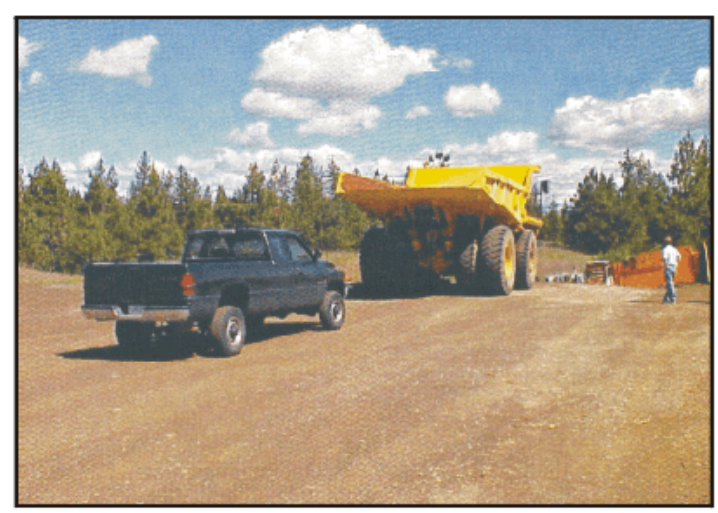

C

Target detected: Pickup detected if front bumper was within reliable detection zone.

Figure 12.-Test results for Knapp System 201, wide beam, and pickup. $A$, Detection zone; $B$, rear view of truck; $C$, view behind truck. 
The next set of tests, shown in figure 13, shows results when the truck was rotated $90^{\circ}$ or parallel to the back of the dump truck. This position resulted in the maximum amount of crosssectional area, and an increase in detection range was seen. The maximum distance was equal to $19.8 \mathrm{~m}(65 \mathrm{ft})$. Two scenarios were tested. In the first, the pickup was driven through the radar detection zone parallel to the back of the dump truck. In the second, the pickup was parked and the dump truck was driven in reverse. Both tests had similar results. The reliable detection zone indicates the point where the pickup was detected. The entire length of the pickup had to be contained in the zone indicated.

One disadvantage with this system (and radar technology in general) is that the maximum detection distance depends on the size and material of the obstacle. A person is detected up to a distance of $6.9 \mathrm{~m}(22.5 \mathrm{ft})$ and a truck to a distance of $19.8 \mathrm{~m}(65$ ft). Large, flat metal objects are easily detected by radar, but irregular-shaped objects with no metal or low water content are not good reflectors of microwave energy and may only be detected at close range.

\section{Front Blind Spot Test Results:}

The radar system was mounted level on the front of the dump truck under the front bumper (figure 14B) at a height of $61 \mathrm{~cm}(2$ $\mathrm{ft}$ ) and tested in a clear field. No false alarms were produced as the dump truck was driven forward.

Figure $14 A$ shows the detection zone when a person was the obstacle. The reliable detection zone extended to $6.9 \mathrm{~m}(22.5 \mathrm{ft})$.

Figure 15 shows the detection zone when a pickup, oriented to face the dump truck, was the obstacle. The reliable detection zone extended from the sides of the dump truck out to $19.8 \mathrm{~m} \mathrm{(65}$ $\mathrm{ft}$ ). Figure 16 shows the detection zone when the pickup was rotated $90^{\circ}$. In this case, the detection zone extended from the front bumper of the dump truck out to $24.4 \mathrm{~m}(80 \mathrm{ft})$. This is a dramatic example of the difference in the maximum detection range (i.e., a difference of $17.5 \mathrm{~m}$ [57.5 ft]) depending on whether a person or a pickup is being detected.

\section{Cinder Block Test:}

For this test, a standard $40-$ by 20 - by 20 -cm (16- by 8 - by 8 -in) concrete cinder block was laid on its side and put in the path of the dump truck (figure 8). Both rear and front blind spots were tested.

When the radar unit was mounted on the rear of the dump truck at a height of $1.7 \mathrm{~m}$. (68 in), the cinder block was detected if it was placed 6 to $12 \mathrm{~m}$ (20 to $40 \mathrm{ft}$ ) from the radar unit and the truck was driven in reverse. When the radar unit was mounted under the front bumper at a height of $61 \mathrm{~cm}(2 \mathrm{ft})$, the cinder block was detected 0 to $5 \mathrm{~m}(17 \mathrm{ft})$ away from the front of the truck. Whether the cinder block was detected or not depended on the radar's mounting height and tilt. While the mounting position could probably be adjusted so that the radar unit would ignore the cinder block, its sensitivity to a person or other obstacle would be decreased.

\section{SYSTEM 2 -OGDEN INTELLIGENT RADAR}

Manufacturer:

Ogden Safety Systems, Brodsworth, Doncaster, U.K.

Description of System:

This microwave radar system transmits a low-power $(5 \mathrm{~mW})$ signal and measures reflections from objects within the beam. It can calculate distance and relative speed of a detected object.

The system is shown in figure 2 and consists of a radar antenna and an electronics enclosure, an alarm display, and wiring. The alarm display is mounted in the equipment cab. It shows three range gates that indicate distance to the obstacle. LED's flash red in the appropriate range to indicate the presence of an obstacle. A beeper increases in frequency as the equipment gets closer to the obstacle.

This system had not been used in the United States at the time of this publication. It operates at a microwave frequency that is not allocated for this purpose, and it is not approved by Federal Communications Commission. The system may be approved for use in the United States at a later date.

Current Applications:

The system is used on front-end loaders at surface mines, quarries, and construction sites. It has also been used on articulated dump trucks.

Rear Blind Spot Test Results:

The system was mounted just below the light bar on the rear of the truck at a height of $1.5 \mathrm{~m}$ (58 in) (figure $17 B, C$ ). The electronics enclosure is mounted on a steel frame that can be easily tilted. For these tests, the enclosure was mounted level. For higher mounting positions, it may be necessary to adjust the tilt to pick up objects shorter than the mounting height. The alarm display was placed near the light bar so researchers could monitor the alarm's state.

There are various options for configuring the range and detection settings. Each of the three range gates indicated on the alarm display can be set for a particular distance. Also, velocity thresholds can be set to detect objects moving faster than 0.5 or $5 \mathrm{~km} / \mathrm{h}(0.3$ or $3.1 \mathrm{mi} / \mathrm{h})$. For these tests, the range gate settings were selected for the maximum total range of $9 \mathrm{~m}$ $(29.5 \mathrm{ft})$ and the slowest movements of $0.5 \mathrm{~km} / \mathrm{h}(0.3 \mathrm{mi} / \mathrm{h})$. 


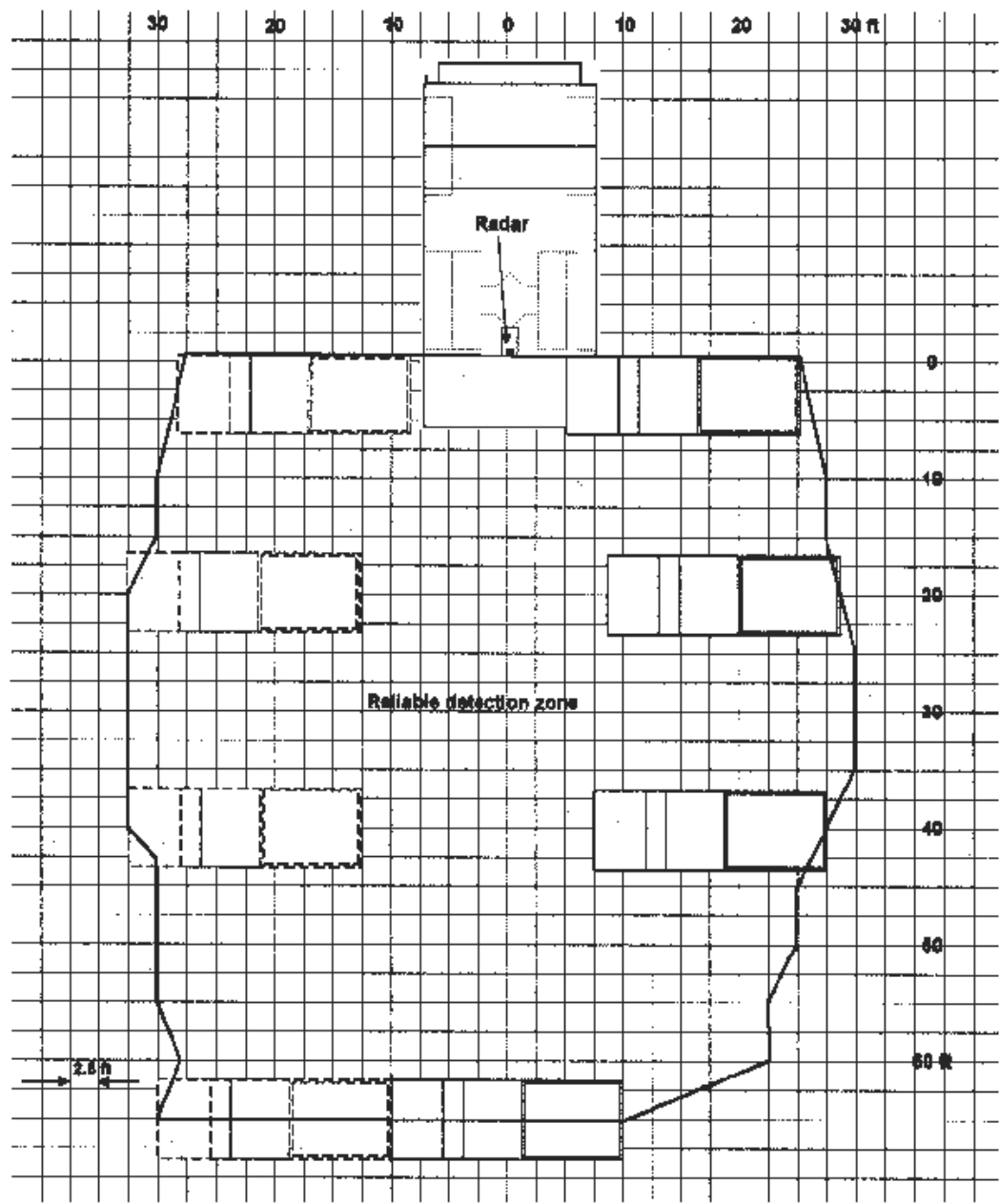

$\boldsymbol{A}$

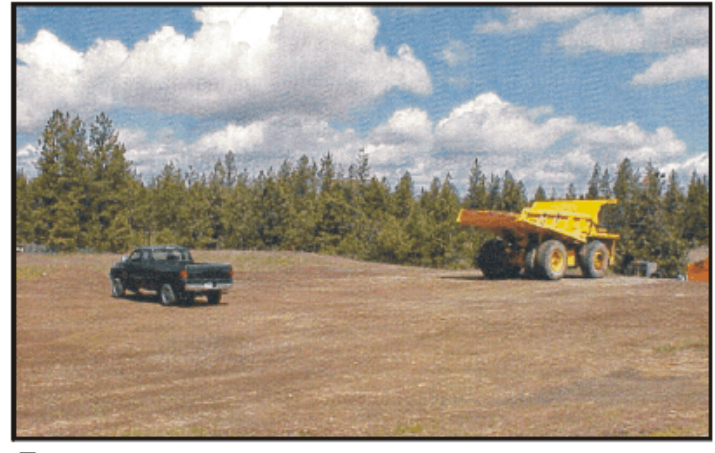

B

Settings:

Range set to approximately $75 \%$.

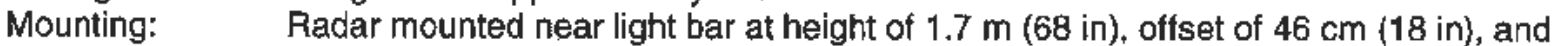
downward tilt of $5^{\circ}$.

Target detected: Pickup detected if vehicle was within reliable detection zone.

Figure 13.-Test results for Knapp System 201, wide beam, and pickup perpendicular to dump truck. A, Detection zone; $B$, view behind truck. 


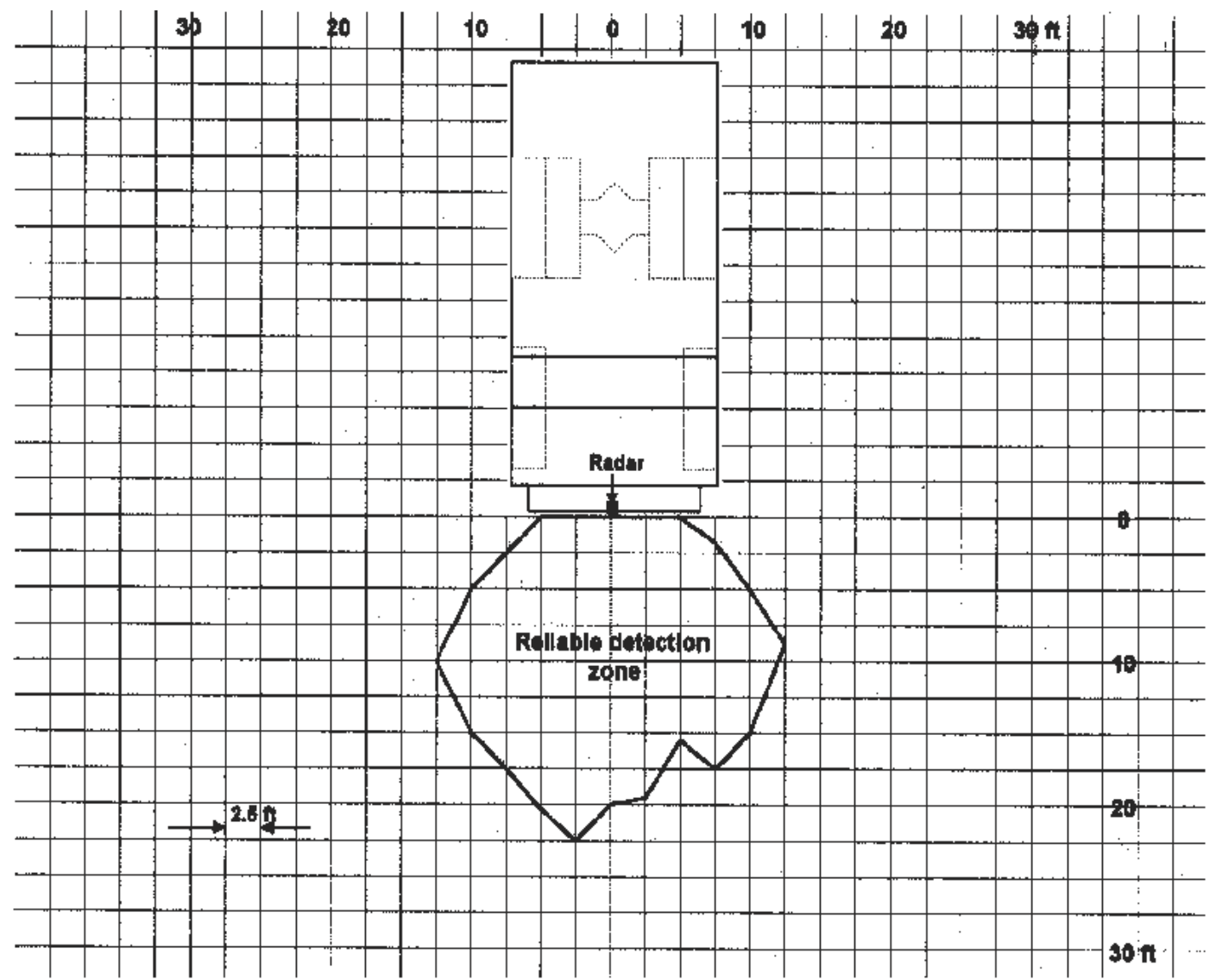

$\boldsymbol{A}$
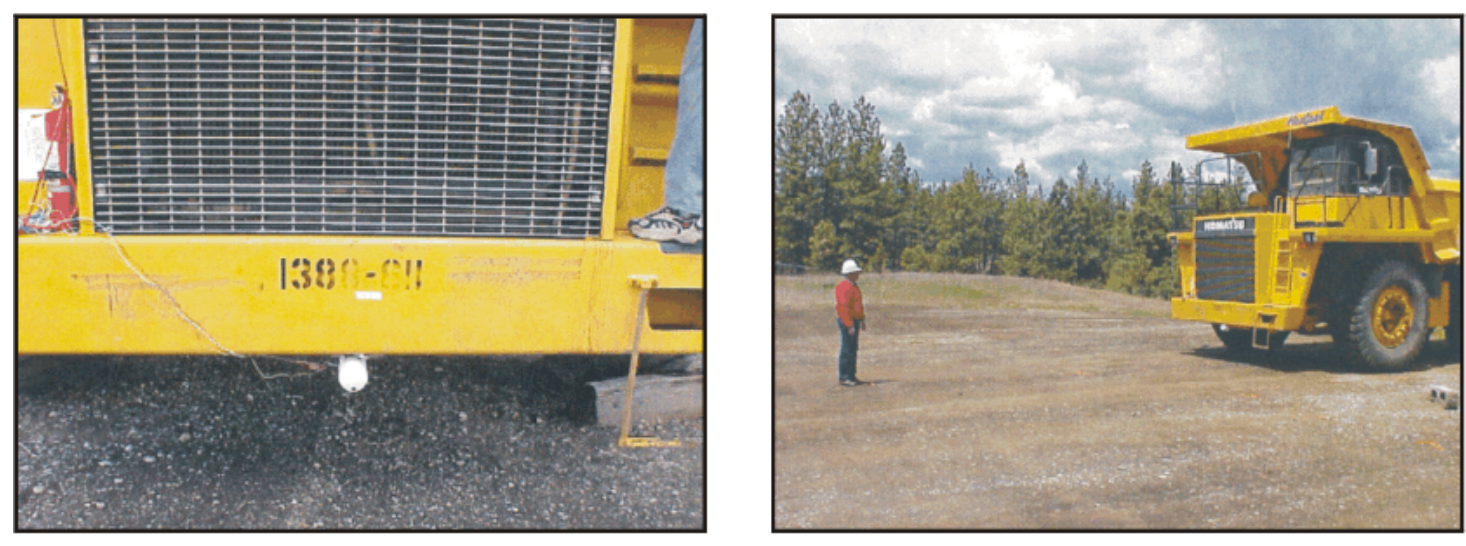

$B$

C

Settings: $\quad$ Range set to approximately $75 \%$.

Mounting: $\quad$ Radar mounted under front bumper at height of $61 \mathrm{~cm}(2 \mathrm{ft})$ and no downward tilt. Target detected: Person.

Figure 14.-Test results for Knapp System 201, wide beam, and person. A, Detection zone; $B$, mounting position; $C$, view in front of truck. 


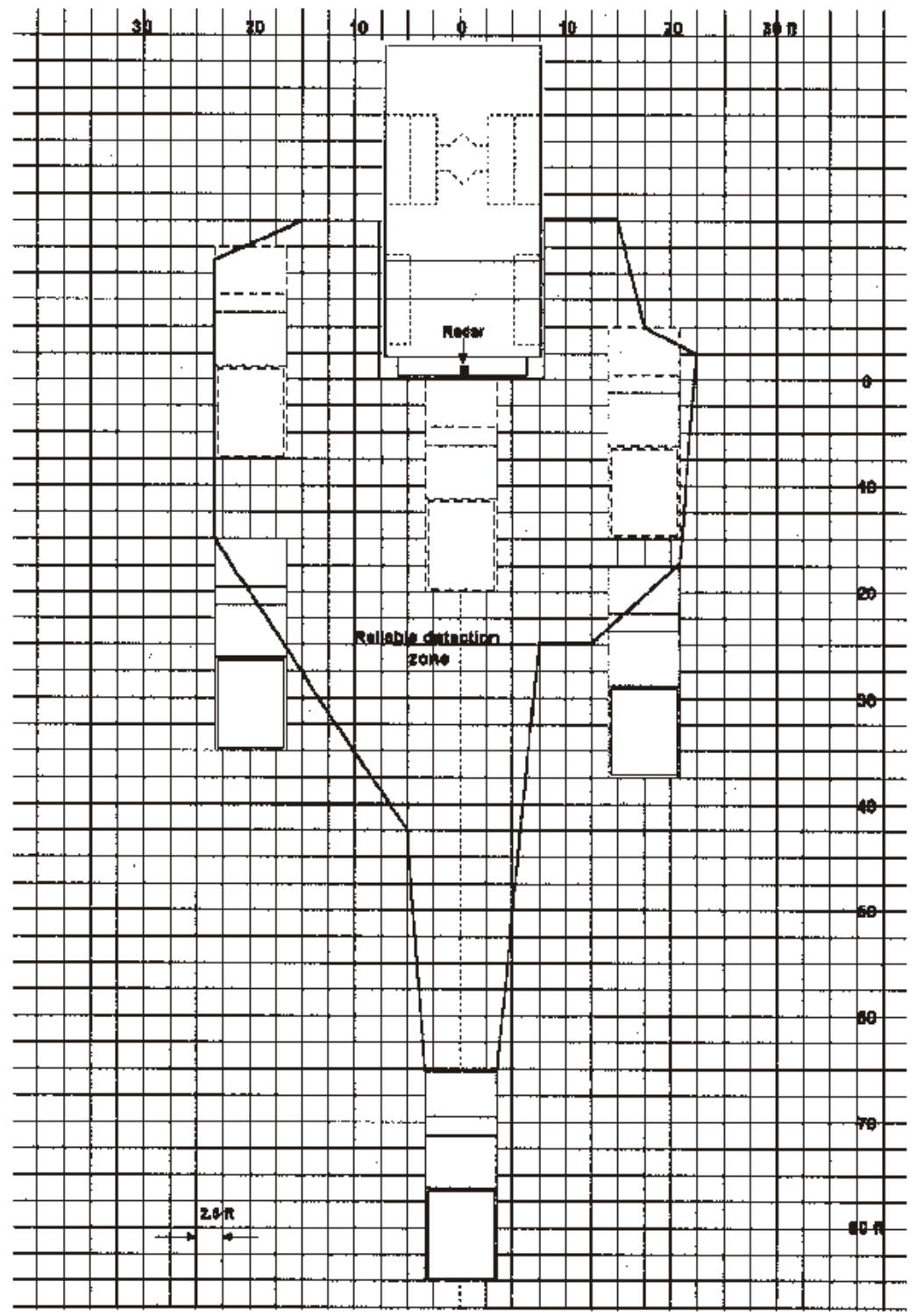

Settings: $\quad$ Range set to approximately $75 \%$.

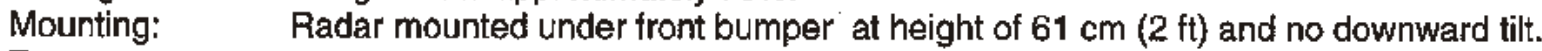

Target detected: Pickup detected if front bumper was within reliable detection zone.

Figure 15.-Detection zone for Knapp System 201, wide beam, and pickup. 


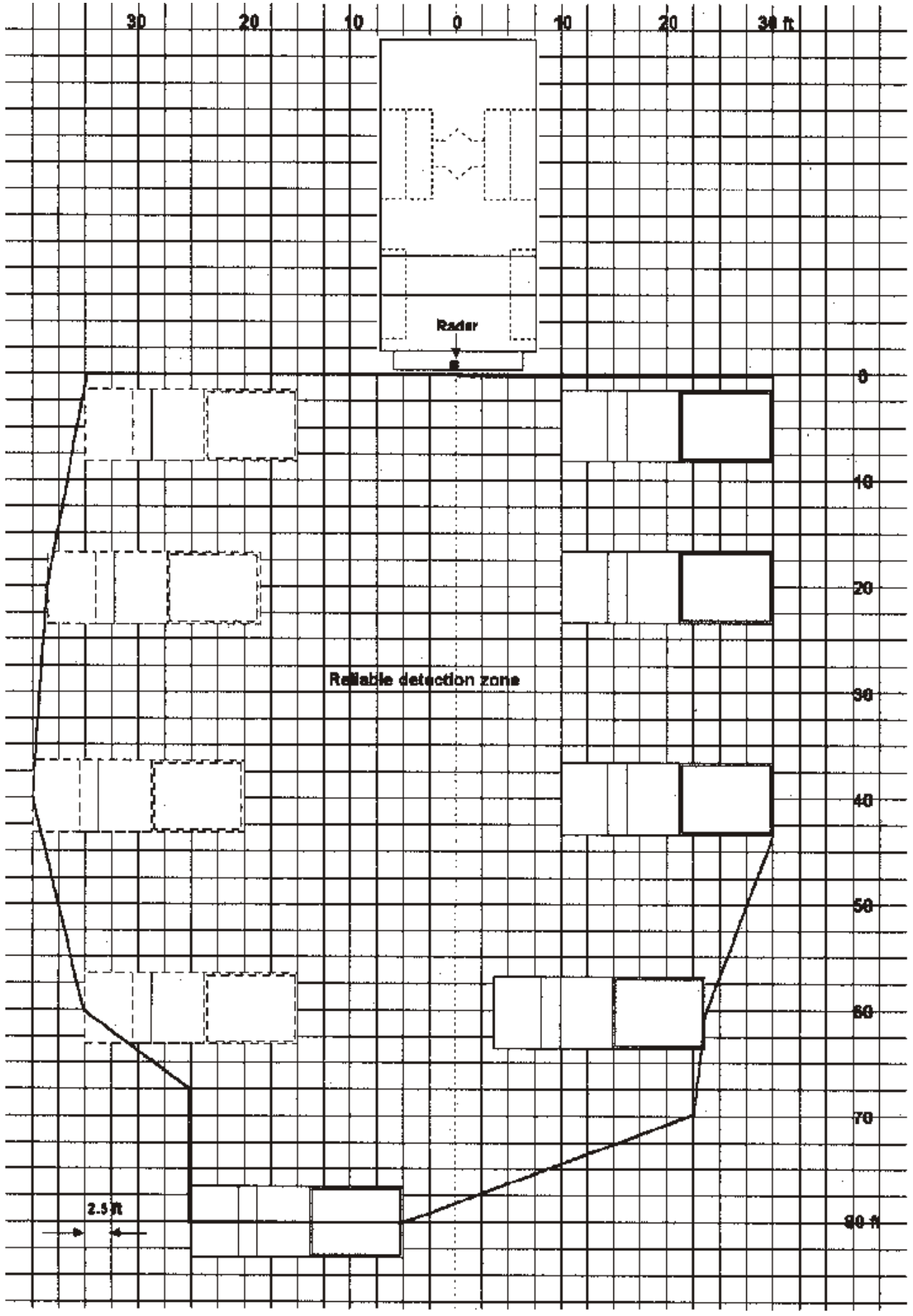

Settings: $\quad$ Range set to approximately $75 \%$.

Mounting: $\quad$ Radar mounted under front bumper at height of $61 \mathrm{~cm}(2 \mathrm{ft})$ and no downward tilt. Target detected: Pickup detected if vehicle was within reliable detection zone.

Figure 16.-Detection zone for Knapp System 201, wide beam, and pickup perpendicular to dump truck. 


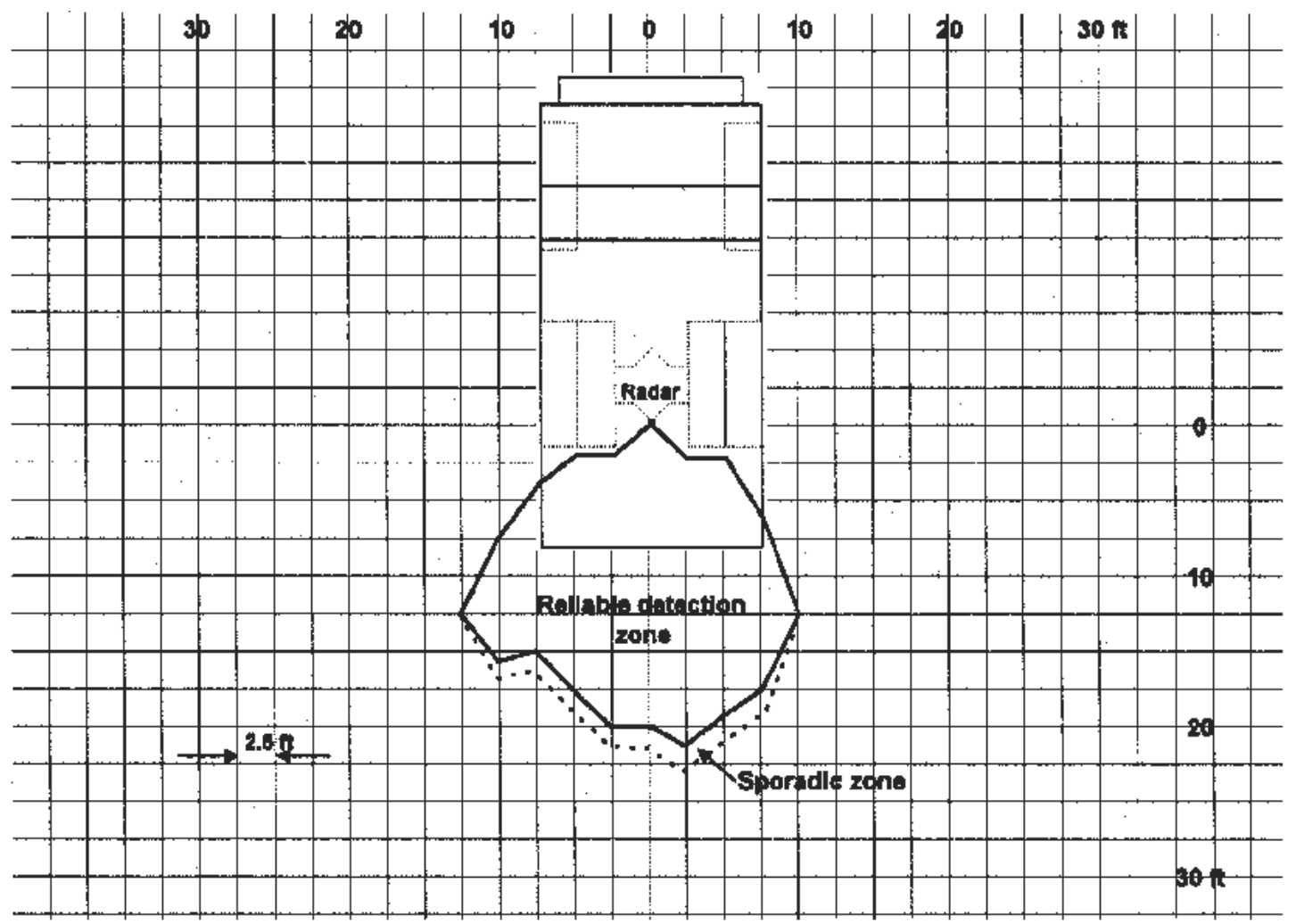

A

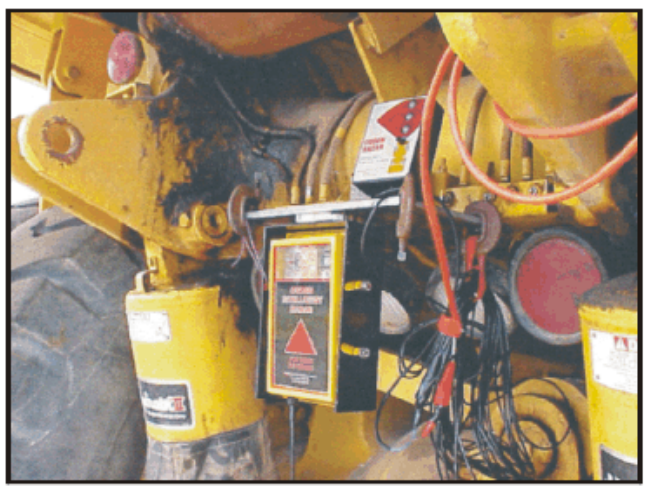

B

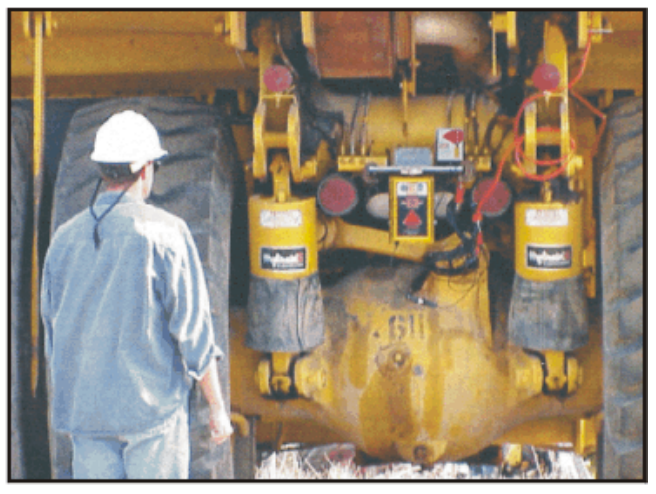

c

Settings: $\quad$ Range set to maximum.

Mounting: $\quad$ Radar mounted level under light bar at height of $1.5 \mathrm{~m} \mathrm{(58} \mathrm{in).}$

Target detected: Person.

Figure 17.-Test results for Ogden Intelligent Radar and person. A, Detection zone; $B$, mounting position; $C$, back view of mounting position. 
The system was first tested in a clear field. The dump truck was backed up several times, and the alarm state was noted. No false alarms occurred with a clear field. The radar unit did not detect the rotation of the tires even though it had been mounted as far back as possible near the light bar.

Figure 17A shows the results of the tests when a person was the obstacle. The reliable detection zone extended from near the radar unit to approximately $6.4 \mathrm{~m}(21 \mathrm{ft})$. The same results were obtained when either the person moved toward the stationary dump truck or the truck was driven toward the person. The beam width was sufficient to cover the area behind the dump truck's tires. However, the beam width may not be sufficient for larger trucks. A "sporadic detection zone" was noted in which the radar unit did not detect a person consistently. This zone was quite small and on the fringes of the detection zone, so no problems would result.

Figure $18 A$ shows test results when a pickup was the obstacle and faced the rear of the dump truck. If the front bumper of the pickup was within the indicated zone, detection was consistent to a maximum distance of $8.4 \mathrm{~m}(27.5 \mathrm{ft})$. The minimum distance occurred immediately in front of the sensor.

Additional tests with the pickup oriented sideways were not conducted with this or other systems because of time constraints. Tests with the pickup facing the dump truck are believed to be representative of a worst case (least amount of cross section) and are sufficient to evaluate the performance of a collision warning system. However, it is interesting to note the differences in detection range for the different pickup orientations, as was seen with the Knapp system.

These limited tests indicated that the Ogden radar unit does not have a dramatic increase or decrease in detection range, depending on whether a pickup or a person is the obstacle. This is an advantage in that the detection zone is well defined and consistent with any obstacle.

Front Blind Spot Test Results:

To test the front blind spot, the radar unit was mounted level on the front bumper at a height of $76 \mathrm{~cm}$ (30 in), as shown in figure $19 B, C$. The dump truck was driven forward in a clear field, and no false alarms occurred.

Figure $19 A$ shows the detection zone of the radar unit with a person as the obstacle. The reliable detection zone extended from about $76 \mathrm{~cm}(2.5 \mathrm{ft})$ away from the sensor out to $5.3 \mathrm{~m}(17.5$ $\mathrm{ft}$ ). A sporadic detection zone close to the radar unit was seen with this configuration. This could be a problem in that a person standing close to the bumper might or might not be detected as the truck was driven forward from a stopped position.

Figure 20 shows the detection zone when the pickup was the obstacle and oriented to face the dump truck. A small sporadic detection zone was seen close to the bumper of the dump truck. The reliable detection zone extended from the sides of the dump truck out to $8.8 \mathrm{~m}(29 \mathrm{ft})$. As seen in figure 19 , the rear of the pickup truck was detected as long as it remained in front of the sensor, accounting for the detection areas that extend down the sides of the dump truck.

\section{Cinder Block Test:}

The cinder block was not detected at any distance in the rear blind spot tests, but it was detected at distances between 3 and $6 \mathrm{~m}(10$ and $20 \mathrm{ft})$ in front of the dump truck. The lower mounting height on the front bumper of the dump truck made the radar unit more sensitive to smaller objects. Mounting the radar unit at a higher position would eliminate detection of the cinder block if desired.

\section{SYSTEM 3 - GUARDIAN ALERT}

Manufacturer:

Sense Technologies, Inc., Vancouver, BC, Canada

Description of System:

This motion-sensing radar unit operates at $10.525 \mathrm{GHz}$, which is a common frequency for police radar, intrusion alarms, and door openers. The radar unit does not require on-site licensing and is protected under U.S. patents 4803488 and 5028920 .

The radar unit uses frequency modulation of the microwave signal to determine the distance to an obstruction. The sensor is also pulse modulated so that it will not activate radar detectors or interfere with other similar devices. In fact, multiple sensors may be used on the same vehicle. The sensor will alert the operator to the nearest obstruction and, rather than requiring a fixed time between the moment it first detects an obstruction, it requires a fixed distance $(12 \mathrm{~cm}$ [5 in]) in order to react. This makes the sensor insensitive to the velocity of the vehicle and simplifies the analysis.

The system is shown in figure 21 and consists of the radar antenna and electronics enclosure, an alarm display, and wiring. The alarm display is mounted in the cab and provides range gates that indicate distance to the obstacle. Red, yellow, and green LED's flash to indicate an obstacle in a particular range gate, and a beeper increases in frequency as the obstacle gets closer to the equipment. This particular model was configured for three range gates: 0 to 3,3 to 6 , and 6 to $12 \mathrm{~m}$ ( 0 to 10,10 to 20 , and 20 to $40 \mathrm{ft})$. The total range, beam width, and range gates can be configured at the factory.

Current Applications:

The system is used on passenger cars, light trucks, and delivery vans. 


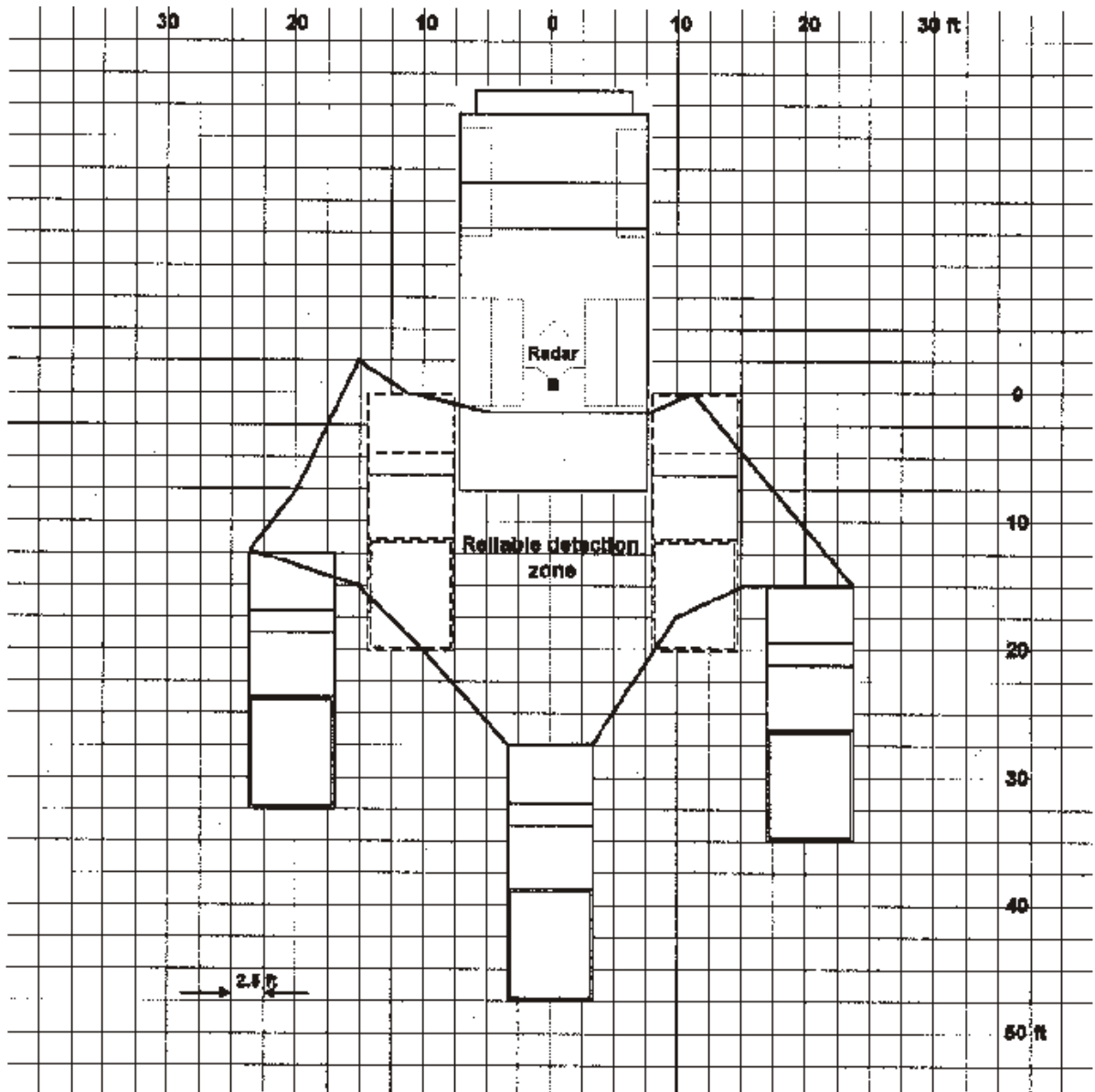

A
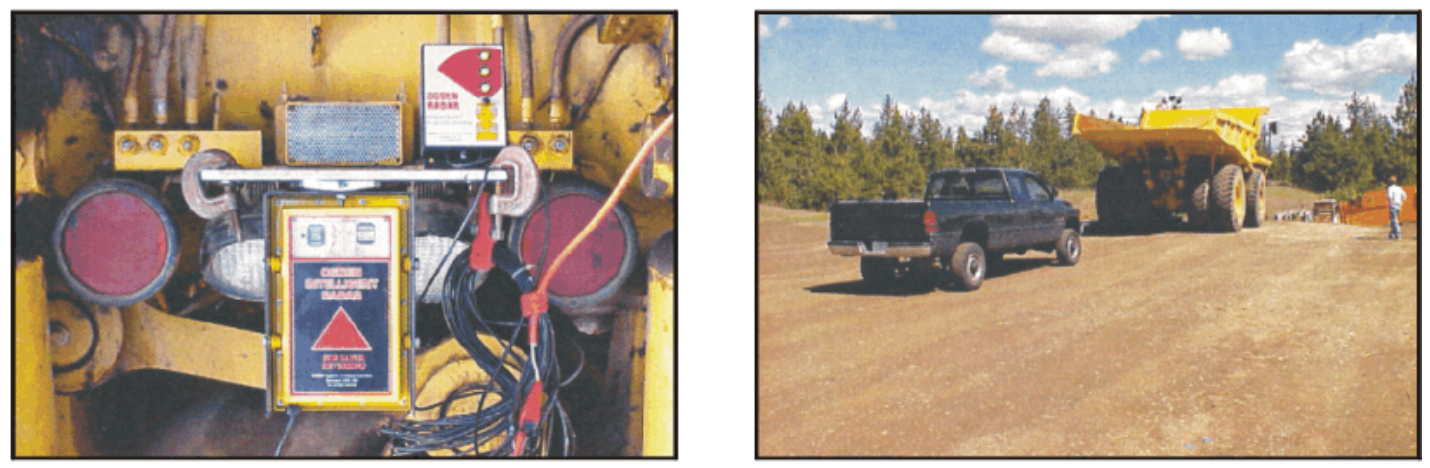

B

C

Settings: Range set to maximum.

Mounting: $\quad$ Radar mounted level under light bar at height of $1.5 \mathrm{~m}$ (58 in).

Target detected: Pickup detected if tront bumper was within reliable detection zone.

Figure 18.-Test results for Ogden Intelligent Radar and pickup. A, Detection zone; $B$, mounting position; $C$, view behind truck. 


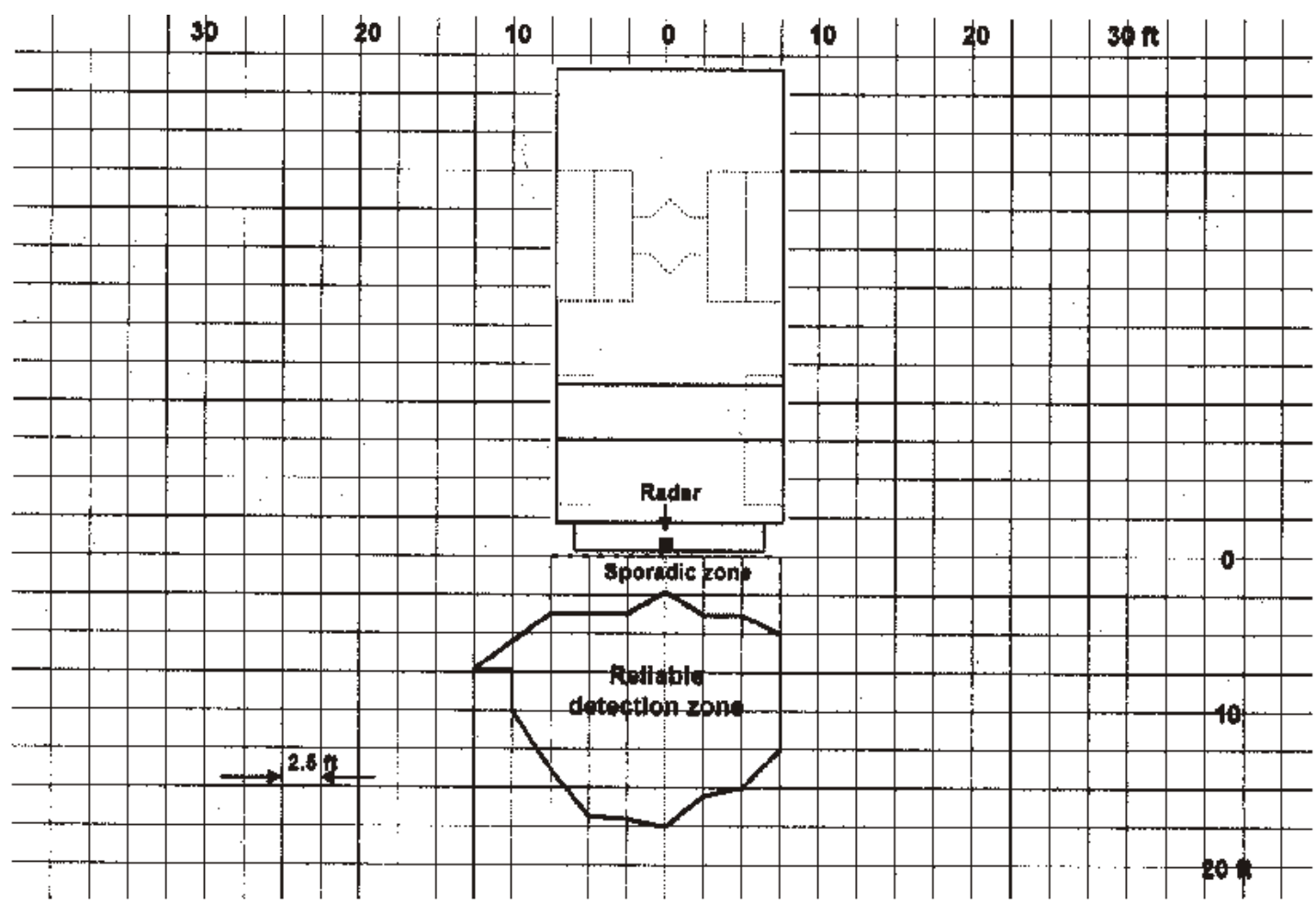

A

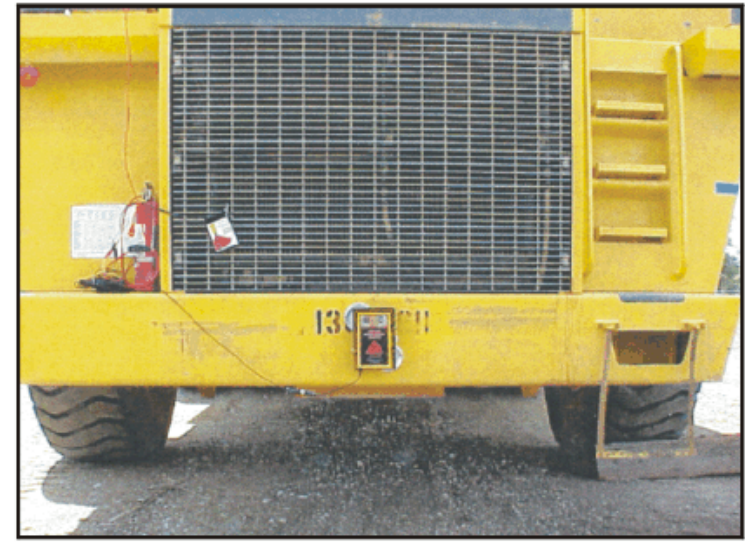

B

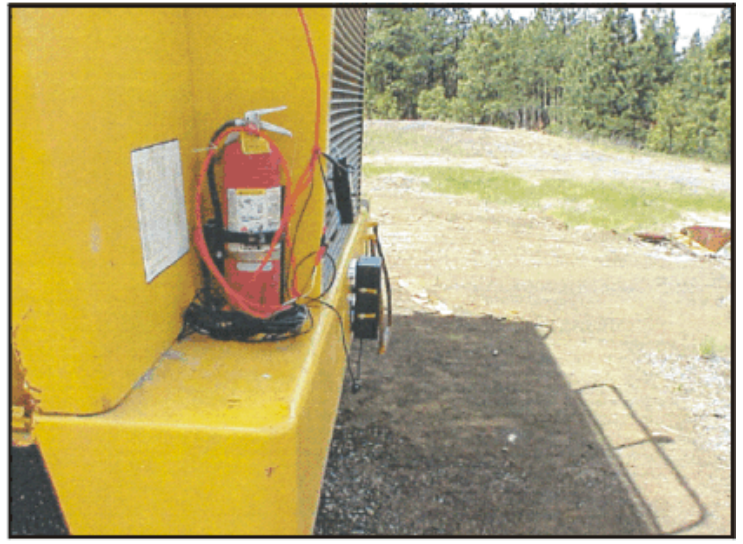

C

Settings: Range set to maximum.

Mounting: $\quad$ Radar mounted level on front bumper at height of $76 \mathrm{~cm}(30 \mathrm{in})$.

Target detected: Person.

Figure 19.-Test results for Ogden Intelligent Radar and person. A, Detection zone; $B$, mounting position; $C$, side view of mounting position. 


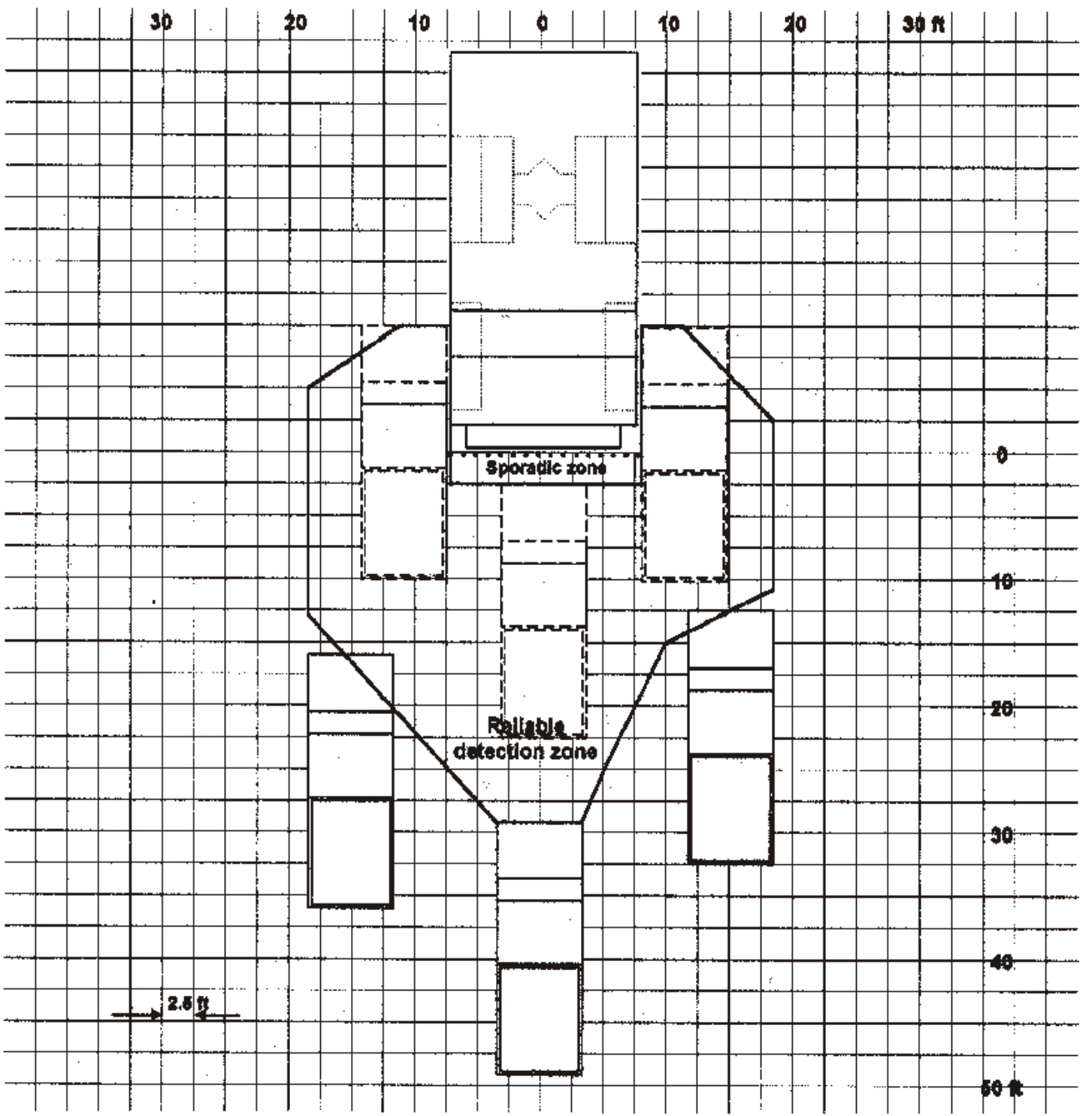

Settings: $\quad$ Range set to maximum.

Mounting: $\quad$ Radar mounted level on front bumper at height of $76 \mathrm{~cm}(30 \mathrm{in})$.

Target detected: Pickup detected if front bumper was within reliable detection zone.

Figure 20.-Detection zone for Ogden Intelligent Radar and pickup. 


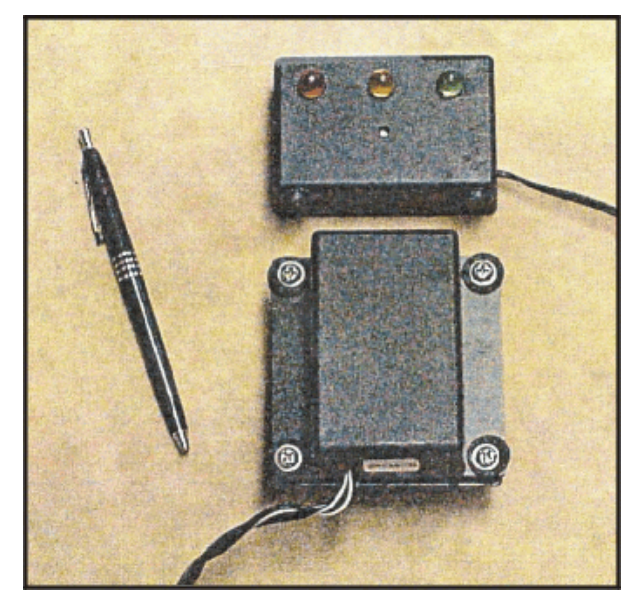

Figure 21.-Guardian Alert radar system showing antenna and electronics enclosure (bottom) and alarm display (top).

Rear Blind Spot Test Results:

The radar unit was mounted just below the light bar on the rear of the truck at a height of $1.7 \mathrm{~m}$ (68 in) (figure 22B, C). For these tests, the enclosure was mounted level, and the alarm display was placed near the light bar so researchers could monitor the alarm's state.

Previous tests on heavy mining equipment showed that the Guardian Alert radar unit malfunctioned because of equipment vibration. In an attempt to dampen the vibration, rubber vibration isolating grommets were used; on some mining equipment the grommets helped, but on others they did not. On the Komatsu dump truck, the grommets sufficiently dampened any errorcausing vibration. Because vibration seemed to depend on the particular piece of mining equipment, the need for vibration isolation would have to be determined during installation of the radar unit.

The system was first tested in a clear field. The dump truck was backed up several times, and the alarm state was noted. An occasional, short-duration (single beep), false alarm occurred in a clear field, but the source could not be determined. The radar unit did not detect the rotation of the tires even though it was mounted as far back as possible near the light bar. On a larger truck, the tires might be detected, and an alternative mounting configuration would be required.

Figure $22 A$ shows the results of the tests when a person was the obstacle. The reliable detection zone extended from near the radar unit to $7.6 \mathrm{~m}(25 \mathrm{ft})$. The same results were obtained when either the person moved toward the stationary dump truck or the truck was driven toward the person. The beam width was sufficient to cover behind the dump truck's tires and beyond. Figure $22 \mathrm{~A}$ also shows three internal zones that are the range gates of the alarm display within the reliable detection zone. When an obstacle is within zone 1, the first range gate is indicated by flashing LED's and the buzzer. In zone 2, the second range gate is indicated by different LED's and a higher frequency buzzer, and so on.
Figure $23 A$ shows test results when the pickup was facing the rear of the dump truck. If the front bumper of the pickup was within the indicated zone, detection was consistent. The maximum distance over which the pickup was detected was $13.7 \mathrm{~m} \mathrm{(45} \mathrm{ft).} \mathrm{The} \mathrm{minimum} \mathrm{distance} \mathrm{occurred} \mathrm{immediately} \mathrm{in}$ front of the sensor. As seen in figure 23A, the rear of the pickup truck was detected as long as it remained in front of the sensor, accounting for the detection areas that extend down the sides of the dump truck.

Front Blind Spot Test Results:

To test the front blind spot, the radar unit was mounted level above the front bumper at a height of $1.2 \mathrm{~m}$ (48 in), as shown in figure $24 B$. The dump truck was driven forward in a clear field, and again an occasional, short-duration false alarm was set off.

Figure $24 A$ shows the detection zone of the radar unit when a person was the obstacle. The reliable detection zone extended from the truck's bumper out to $9.1 \mathrm{~m}(30 \mathrm{ft})$. The alarm display range gates are indicated by zones 1,2 , and 3 .

Figure 25 shows the detection zone of the radar unit when the pickup was the obstacle and was oriented to face the dump truck. The reliable detection zone extended from the sides of the dump truck out to $11.4 \mathrm{~m}(37.5 \mathrm{ft})$.

\section{Cinder Block Test:}

The cinder block was detected at both the front and the rear at distances between 1.5 and $6.1 \mathrm{~m}$ ( 5 and $20 \mathrm{ft}$ ). The angle or tilt of the sensor was adjusted to approximately $10^{\circ}$ pointing upward. The cinder block was detected with this configuration also. This radar unit has a $45^{\circ}$ beam width in the vertical direction, so detection of the cinder block was expected.

\section{SYSTEM 4 - MINTRONICS BODY GUARD}

Manufacturer :

Mintronics Systems Corp., North Bay, ON, Canada

Description of System:

This system is classified as an RFID-based system. The tag reader consists of three separate enclosures: the processing electronics, the transmitting antenna, and the receiver antenna (figure 26). The transmitter constantly transmits a signal in the UHF band. The tags are passive and therefore do not require external power (figure 27). If a tag is within range of the transmitter, it receives the signal, doubles it, and transmits it back to the tag reader, which processes it to determine if the signal strength is such that an alarm should be generated.

The existing alarm display is an on/off-type alarm that provides both audible and visual signals. 


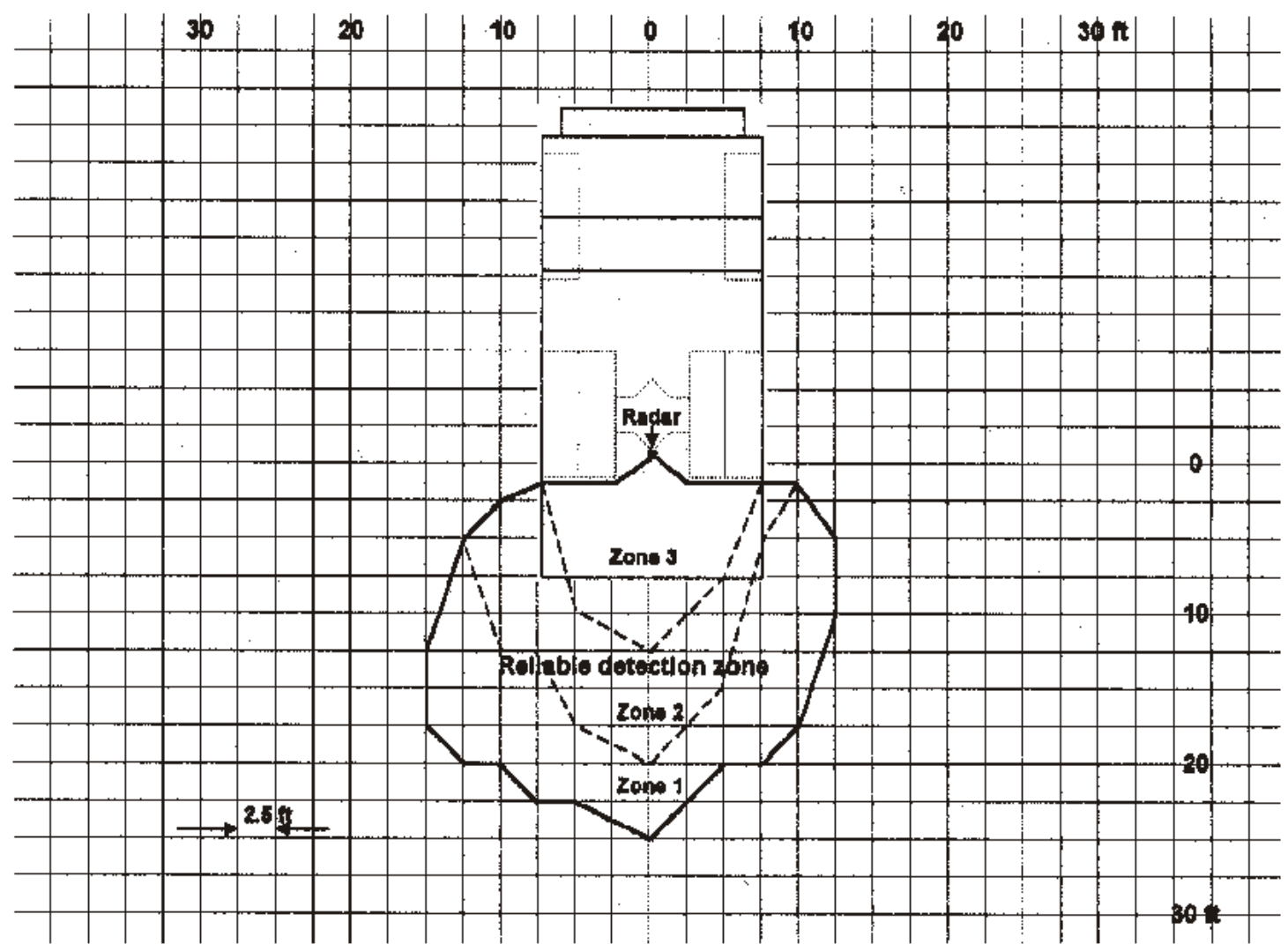

A
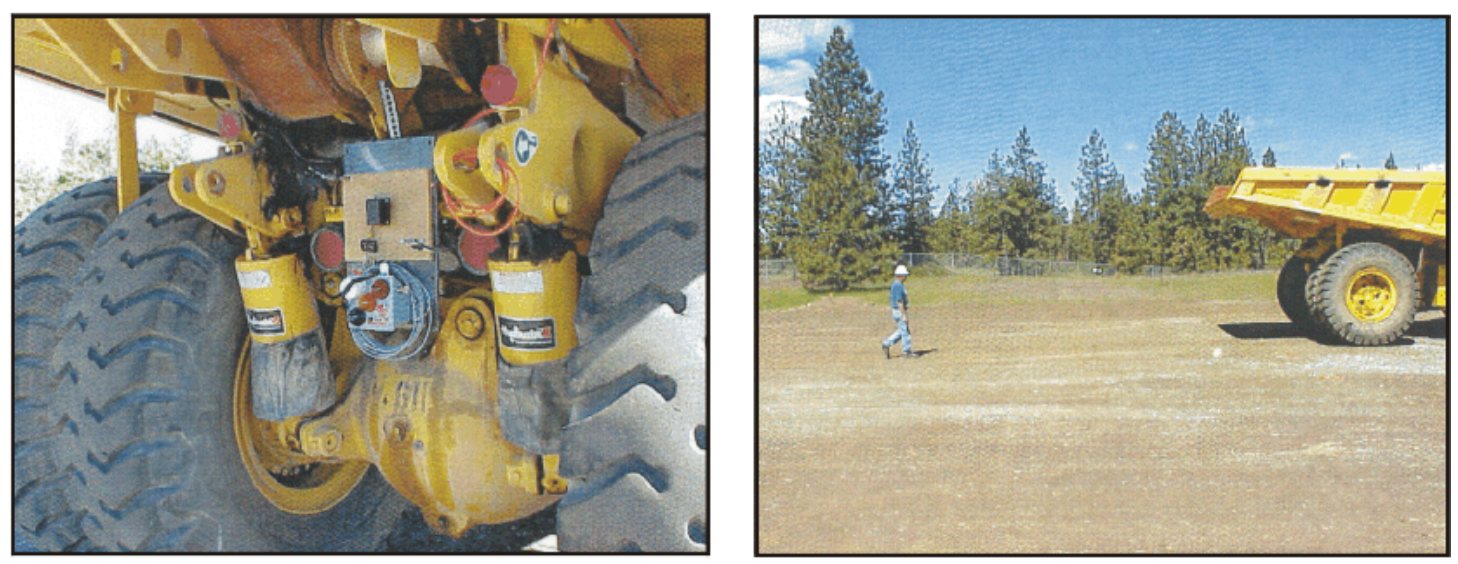

$\boldsymbol{B}$

C

Settings: $\quad$ No user-selectable settings.

Mounting: $\quad$ Radar mounted level under light bar at height of $1.7 \mathrm{~m} \mathrm{(68 \textrm {in } ) .}$

Target detected: Person.

Figure 22.-Test results for Guardian Alert radar and person. A, Detection zone; B, mounting position; C, view behind truck. 


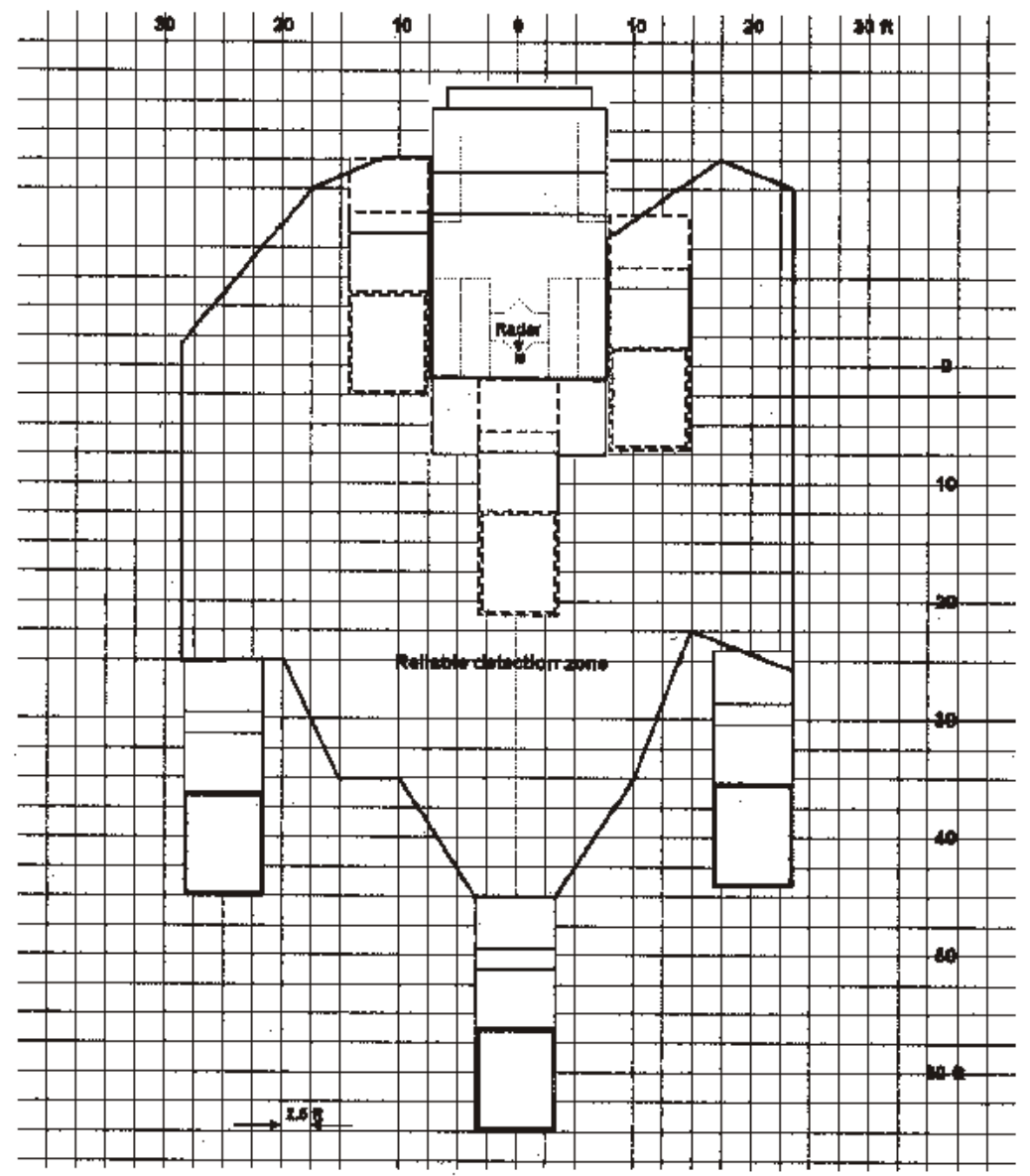

$\boldsymbol{A}$

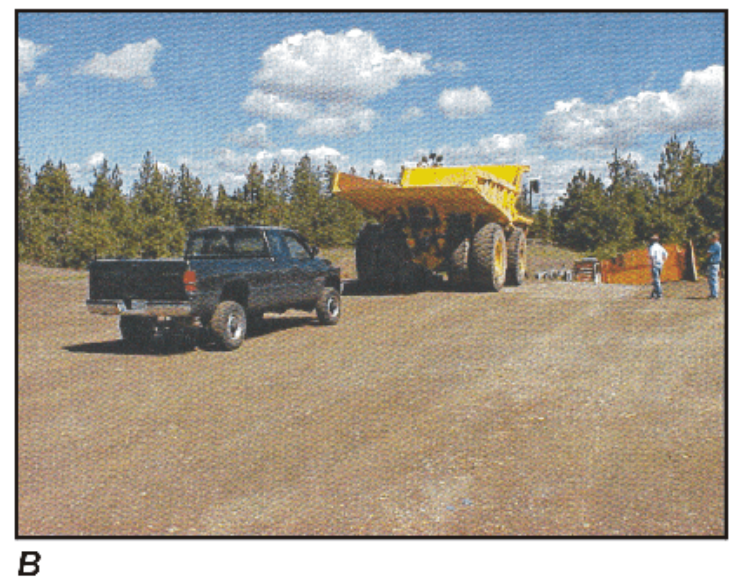

Settings: No user-selectable settings.

Mounting: $\quad$ Radar mounted level under light bar at height of $1.7 \mathrm{~m}$ (68 in). Target detected: Pickup detected if front bumper within reliable detection zone.

Figure 23.-Test results for Guardian Alert radar and pickup. A, Detection zone; B, view behind truck. 


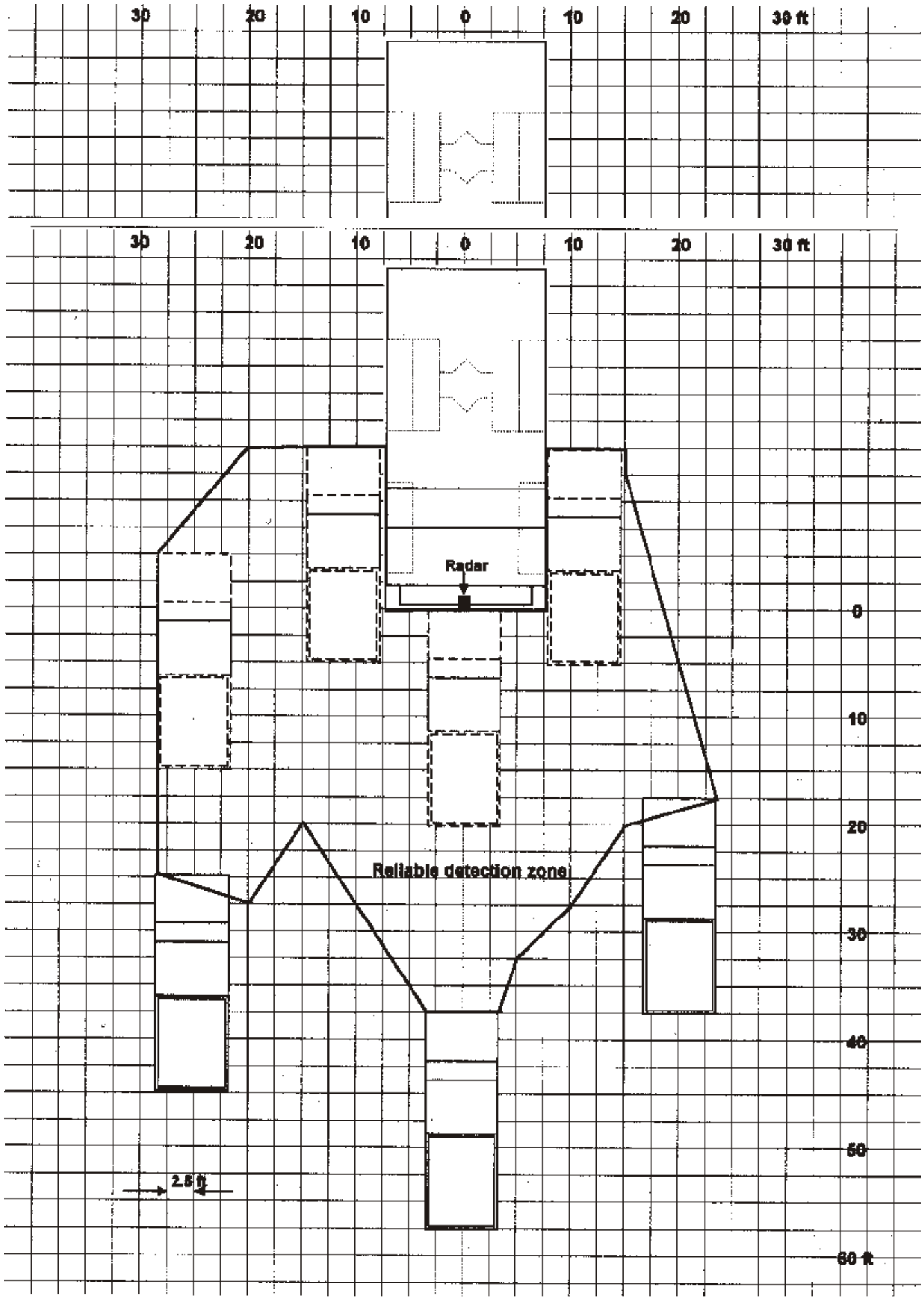

Settings: $\quad$ No user-selectable settings.

Mounting: $\quad$ Radar mounted level above front bumper at height of $1.2 \mathrm{~m}$ (48 in).

Target detected: Pickup detected if front bumper within reliable detection zone.

Figure 25.-Detection zone for Guardian Alert radar and pickup. 


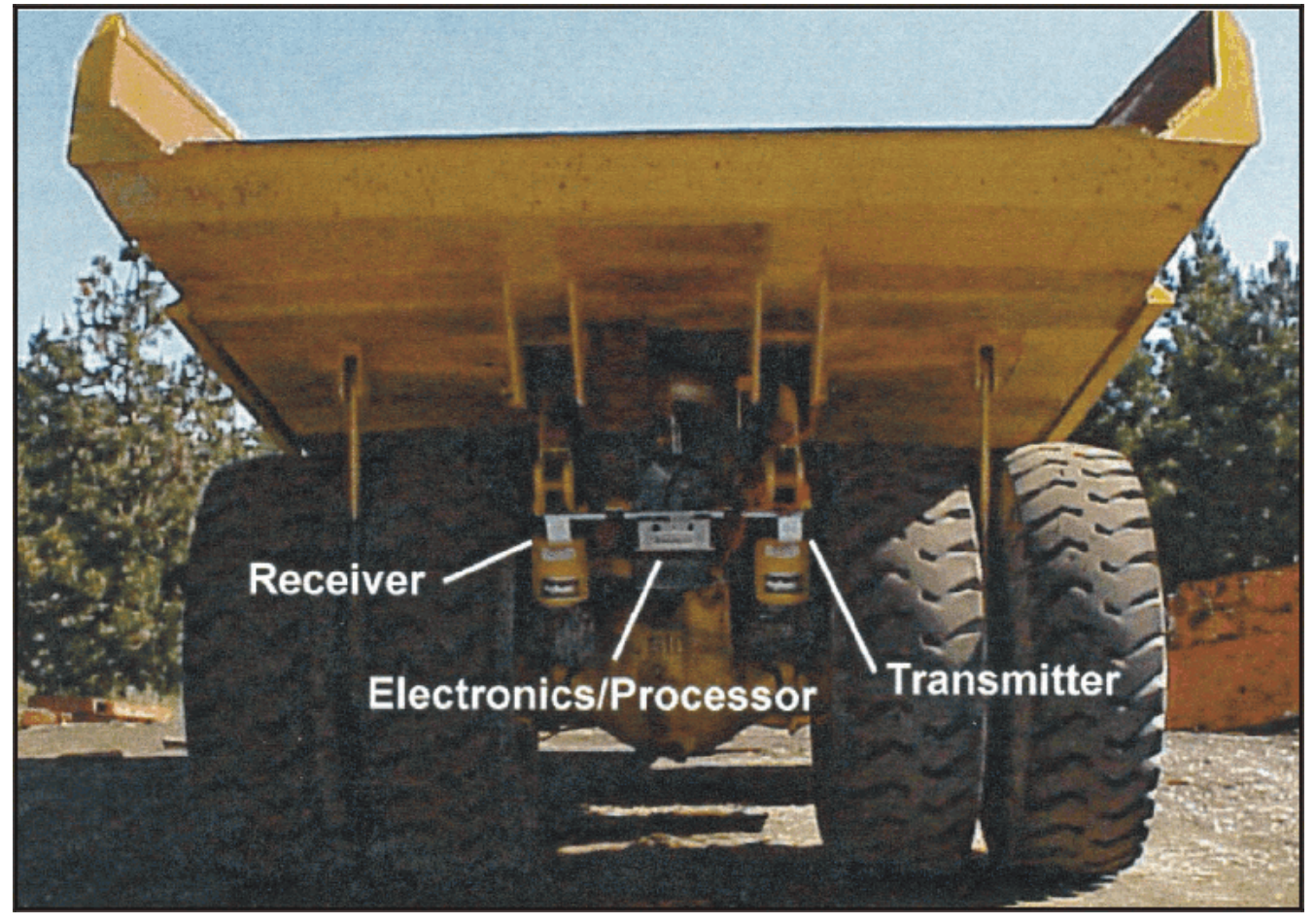

Figure 26.-Body Guard tag reader.

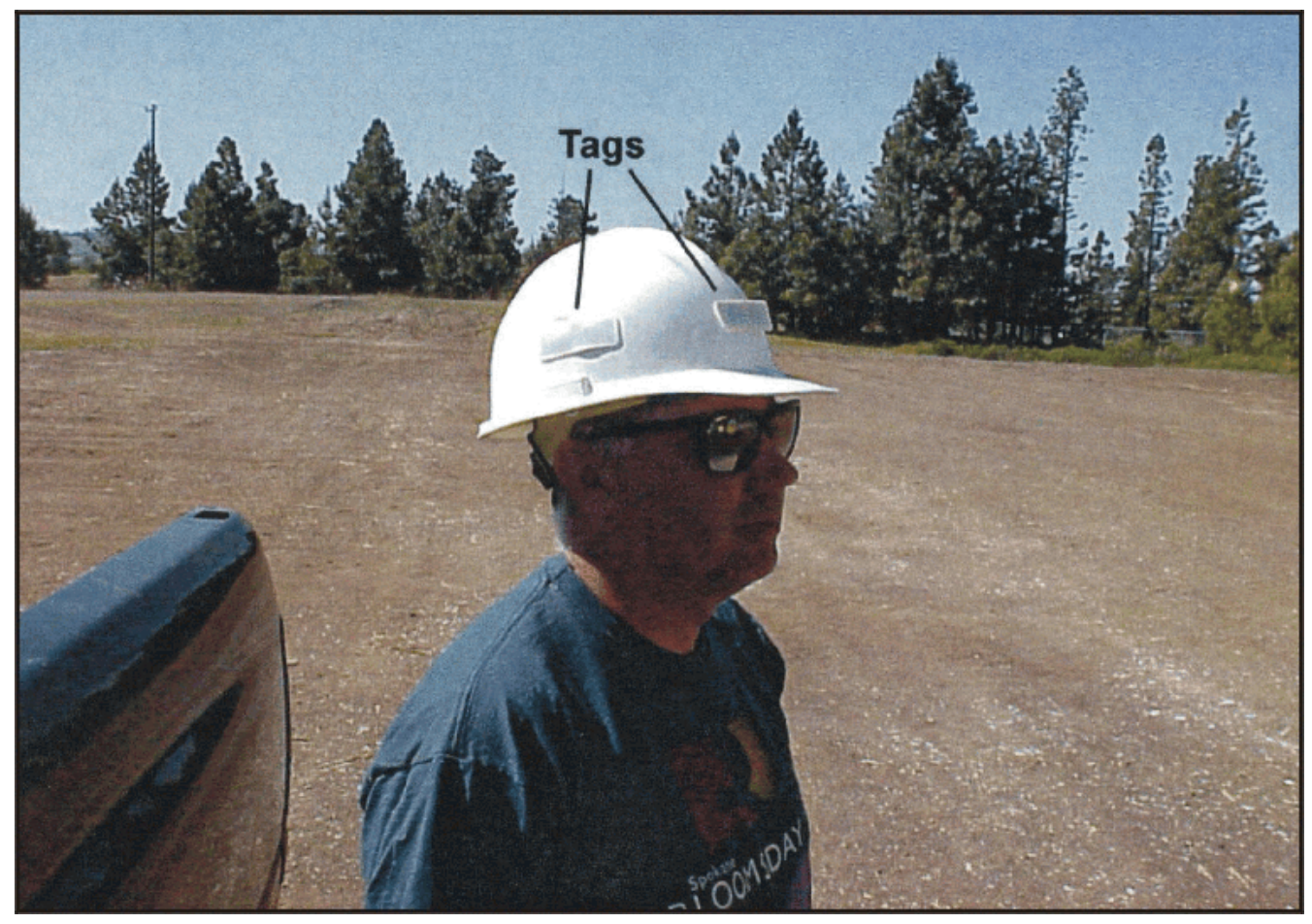

Figure 27.-Body Guard tags. 
Current Applications:

The system is used in underground mines on remotecontrolled LHD units. The system automatically stops the equipment if it gets too close to the remote-control operator.

\section{Rear Blind Spot Test Results:}

The transceiver unit or tag reader was mounted near the light bar on the rear of the truck at a height of $1.7 \mathrm{~m}$ (66 in) (figure 26). Because this system was a demonstration unit, the alarm display was integral to the tag reader enclosure. The receiver and transmitter antennas were in separate enclosures and on opposite sides of the tag reader enclosure. Extendable arms allowed the antennas to be separated by approximately $2 \mathrm{~m}(6.5 \mathrm{ft})$, which was about half the possible travel space. For permanent installations, the extendable arms are not needed, and the antennas would be attached to the dump truck at spacings to be determined by trial and error to optimize the detection zone. The electronics enclosure could be installed in a protected place inside the truck.

Two tags were mounted on the hard hat of the person acting as the obstacle (figure 27). While two tags were adequate for our tests, Mintronics recommends that a minimum of three tags be attached to the hard hat. This ensures that at least one tag will pick up and return a signal at any orientation. Figure $28 \mathrm{~A}$ shows the results of the tests when a person was the obstacle. The reliable detection zone extended from near the tag reader to 7.6 $\mathrm{m}(25 \mathrm{ft})$ away from the back of the dump truck. The same results were obtained when either the person moved toward the stationary dump truck or the truck was driven toward the person. The zone shown is a bit skewed, covering the left side of the truck more effectively than the right. This might be corrected by adjusting the position of the antennas.

A region in which a person was not detected $100 \%$ of the time extended to $13.7 \mathrm{~m}$ (45 ft) outside the reliable detection zone. However, if the person or dump truck moved approximately 61 to $152 \mathrm{~cm} \mathrm{(2} \mathrm{to} 5 \mathrm{ft}$ ), the person was detected, indicating that the area had signal nulls caused by multipath interference. Because this sporadic detection zone is, for the most part, on the outer edge of the reliable detection zone, intermittent detection would not be a detriment. However, an occasional alarm would be generated from objects out as far as $13.7 \mathrm{~m}(45 \mathrm{ft})$, which might not be desirable if the dump truck operator did not want alarms from tagged objects outside the reliable detection zone.

The detection range of this system is adjustable. Earlier tests showed a trade-off between increased range and an increase in the size of the sporadic detection zone. With a range setting of approximately one-half full scale, the reliable detection zone was adequate for this dump truck, and the sporadic detection zone's range was kept to a minimum. No false alarms occurred when the tags were kept outside of both zones.
Figure $29 A$ shows test results when a pickup was the obstacle. Two location schemes for the tags were tested. The first was to place two tags on the antenna of the pickup. The second was to place one tag on a plastic portion of the front bumper and the other one on the hood of the truck in an orthogonal direction to the first tag after mounting it on a piece of plastic. Both locations produced similar results. It is suspected that the detection zone could be lengthened by optimizing the location of the tags, providing better plastic insulators for the tags, and increasing the number of tags on the pickup. According to the manufacturer, five or more tags with plastic insulators should be mounted around the pickup.

This test was conducted with the pickup facing the rear of the dump truck, as shown in figure $29 B$. If the front bumper of the pickup was within the indicated zone, detection was reliable. The maximum distance over which the pickup was detected was $6.1 \mathrm{~m}(20 \mathrm{ft})$. No sporadic detection region was seen in this test.

\section{Front Blind Spot Test Results:}

To test the front blind spot, the tag reader was mounted

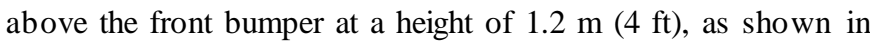
figure $30 \mathrm{~B}$. The extendable arms had sufficient clearance to be extended to their full travel length, providing maximum separation between the receiver and the transmitter. Range was set to one-half.

Figure $30 \mathrm{~A}$ shows the detection zone when a person was the obstacle. Tags were mounted on the hard hat as in previous tests. The reliable detection zone extended from the truck's bumper out to $7.6 \mathrm{~m}(25 \mathrm{ft})$. The sporadic detection zone extended to a maximum of $11.4 \mathrm{~m}(37.5 \mathrm{ft})$.

Figure 31 shows the detection zone when the pickup was the obstacle. Tags were placed on the front bumper and hood of the pickup, and the pickup was oriented to face the dump truck. The reliable detection zone extended from the bumper of the dump truck out to $5.3 \mathrm{~m}(17.5 \mathrm{ft})$. Again, no sporadic detection zone was seen.

\section{SYSTEM 5 - NAUTILUS BUDDY SYSTEM}

Manufacturer :

Nautilus International Control and Engineering, Ltd., Burnaby, BC, Canada

Description of System:

This system is classified as an RFID-based system. The tag reader consists of processing electronics and a loop antenna (figure $32 B, C$ ). It was mounted on the front deck of the dump truck, where it continuously transmitted a low-frequency signal that encompassed the entire truck. Only one loop antenna was needed to detect tags in blind spots at both the front and rear of 


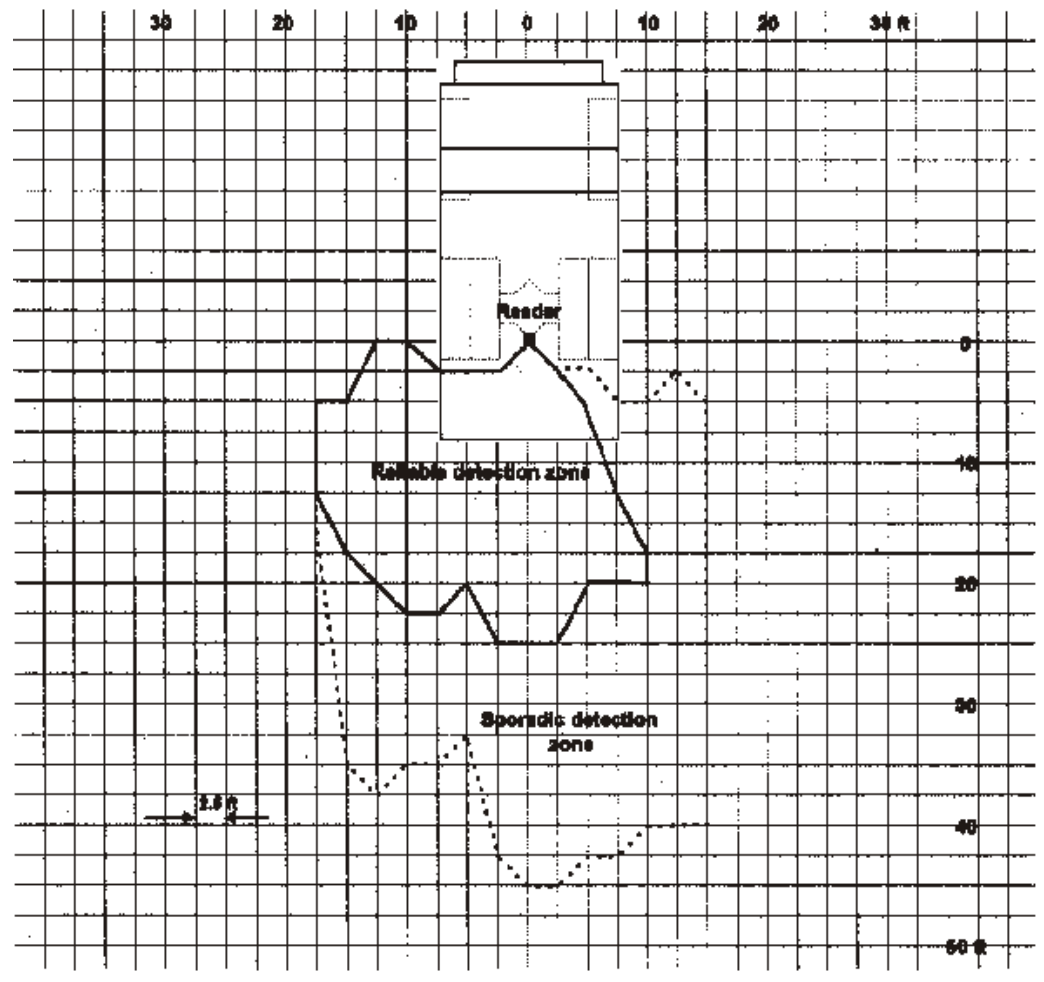

$\boldsymbol{A}$

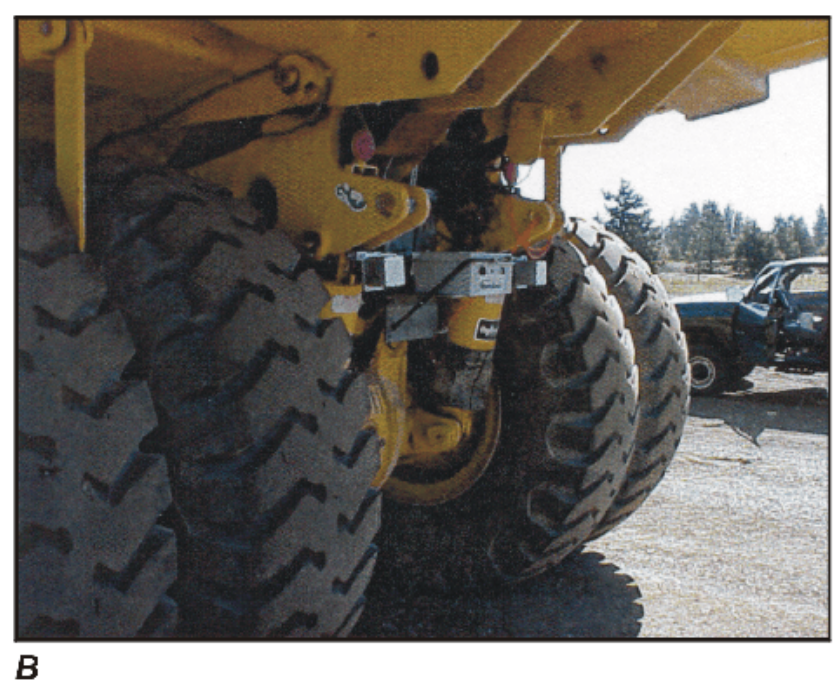

Settings: $\quad$ Range set to $50 \%$. Arms at half full travel.

Mounting: $\quad$ Mounted near light bar at height of $1.7 \mathrm{~m}$ (68 in).

Target detected: Person with tags on hard hat.

Figure 28.-Test results for Body Guard and person. A, Detection zone; $B$, mounting position. 


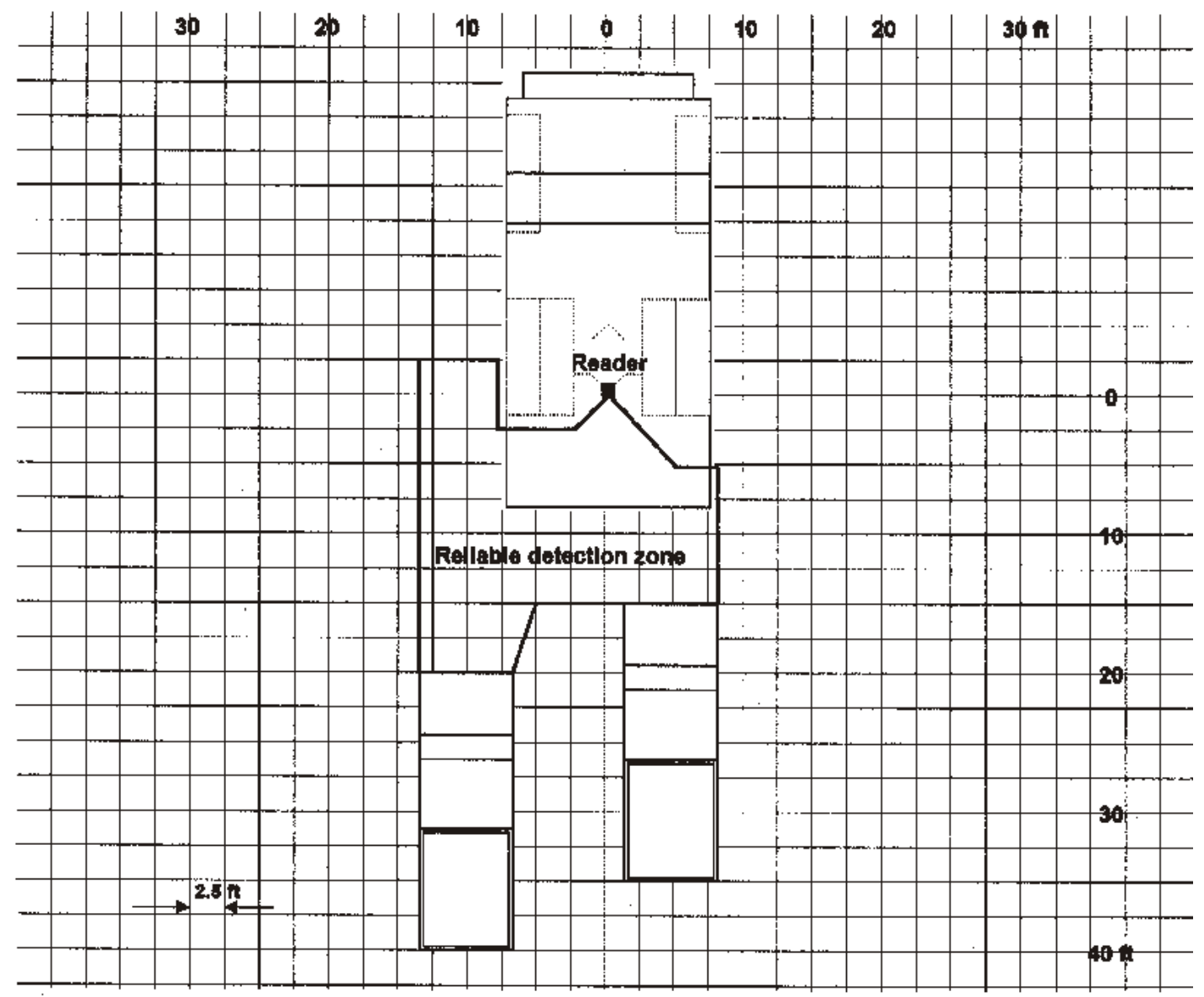

A

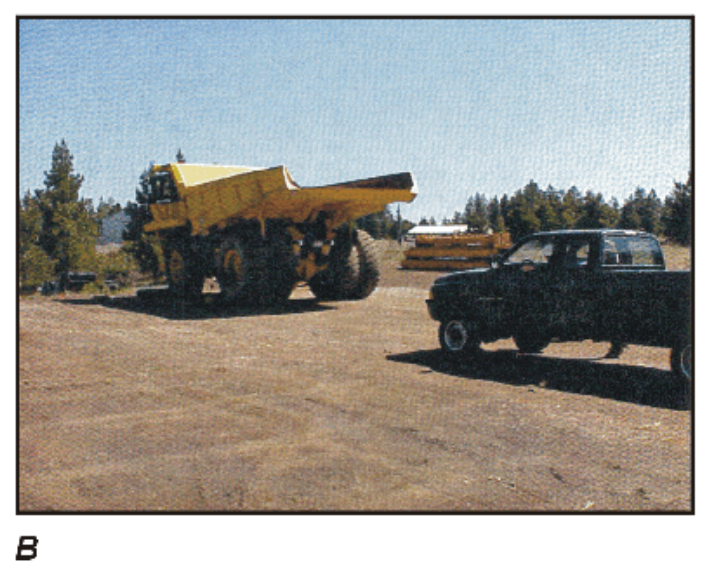

Settings: $\quad$ Range set to $50 \%$. Arms at half full travel.

Mounting: $\quad$ Mounted near light bar at height of $1.7 \mathrm{~m}$ (68 in).

Target detected: Pickup with tags on bumper and hood.

Figure 29.-Test results for Body Guard and pickup. A, Detection zone; B, view behind truck. 


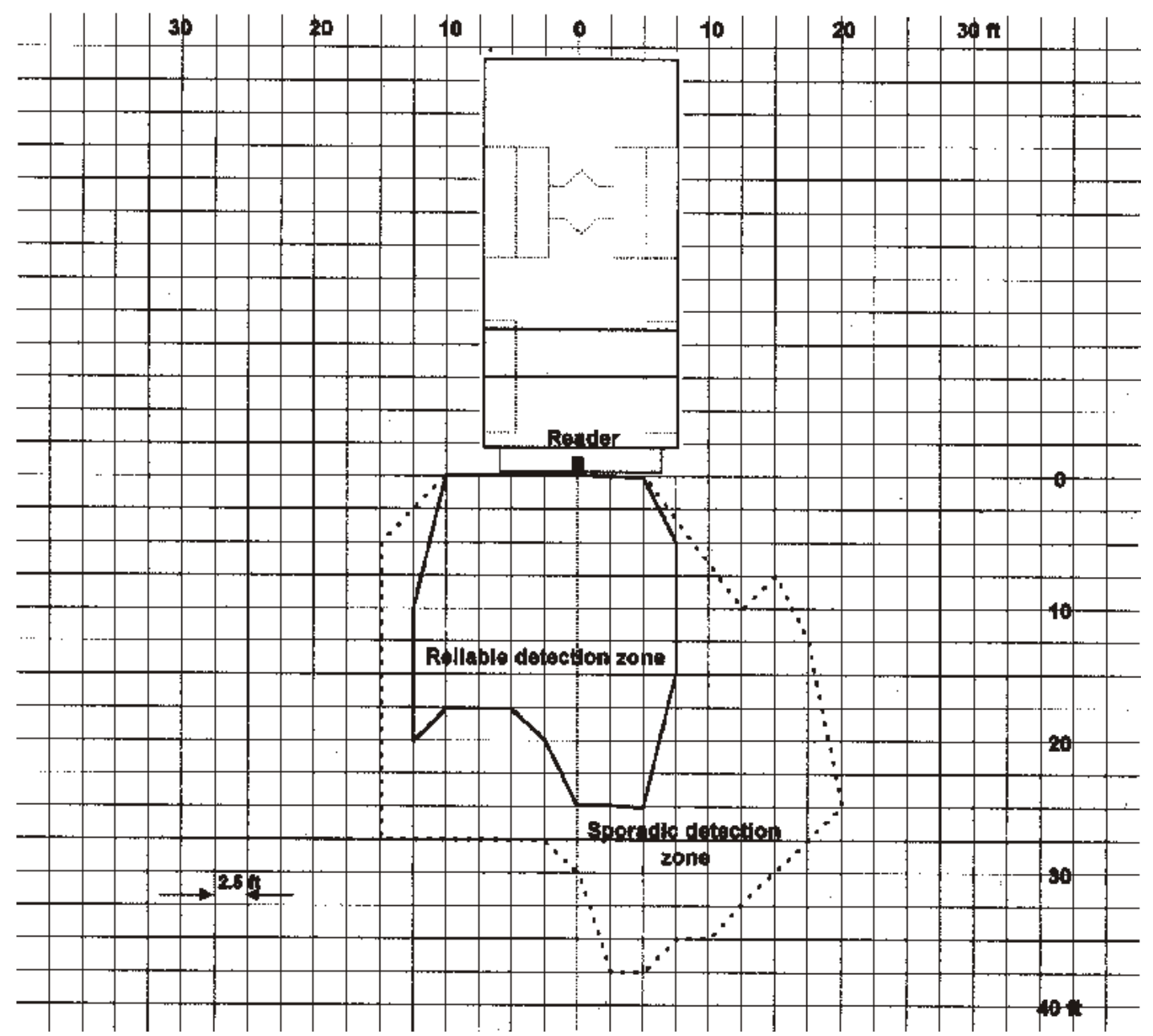

A

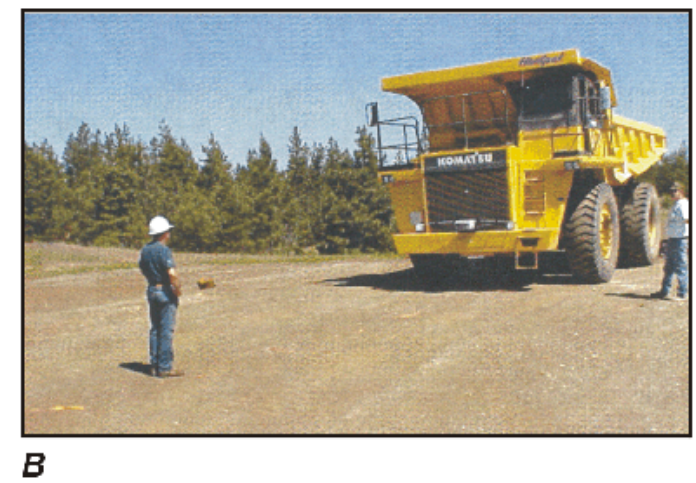

Settings: $\quad$ Range set to $50 \%$. Arms at full travel.

Mounting: $\quad$ Mounted on front bumper at height of $1.7 \mathrm{~m}(68 \mathrm{in})$.

Target detected: Person with tags on hard hat.

Figure 30.-Test results for Body Guard and person. A, Detection zone; B, view in front of truck. 


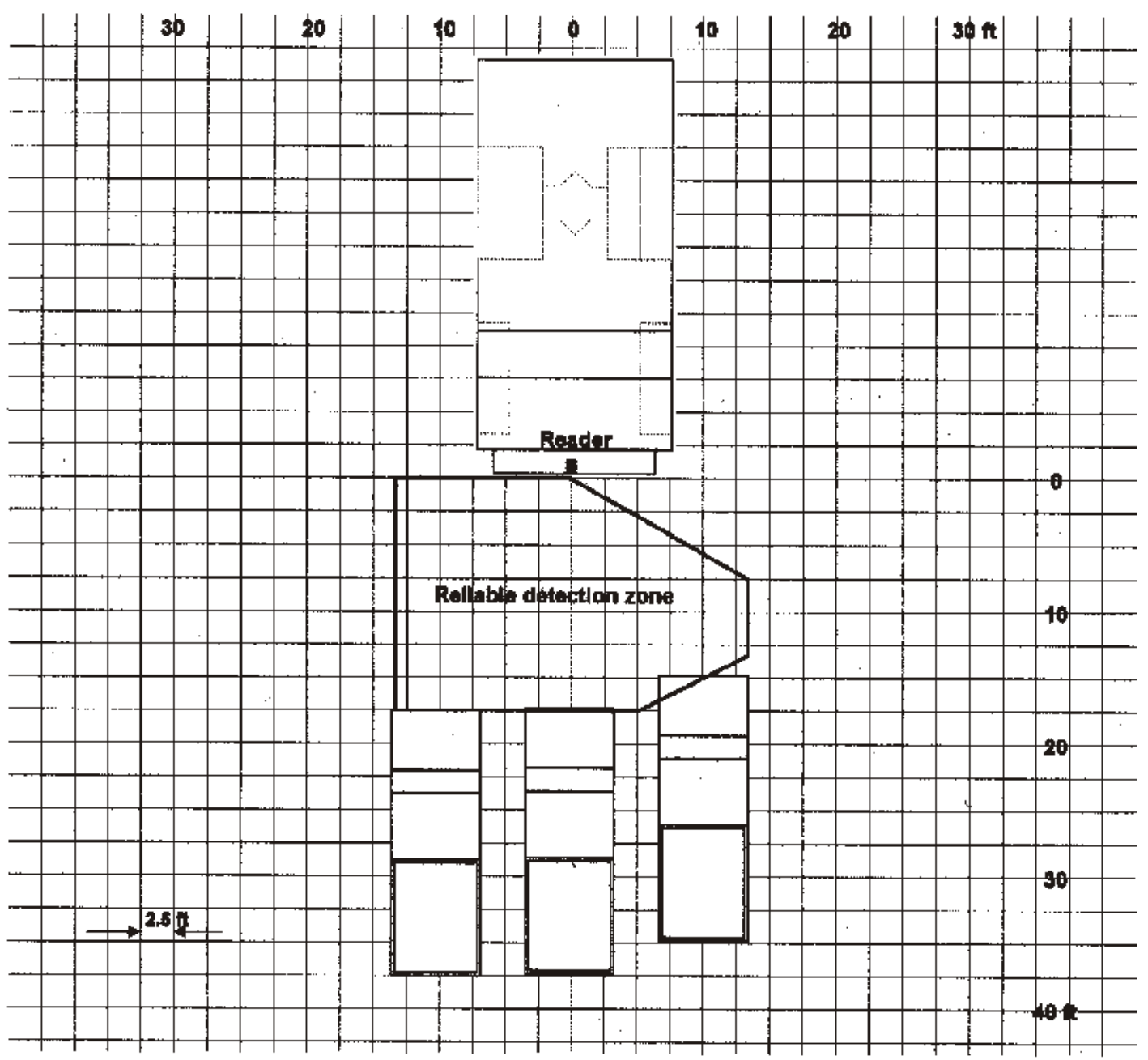

$\begin{array}{ll}\text { Settings: } & \text { Range set to } 50 \% \text {. Arms at full travel. } \\ \text { Mounting: } & \text { Mounted on front bumper at height of } 1.2 \mathrm{~m}(48 \mathrm{in}) \text {. } \\ \text { Target detected: } & \text { Pickup with tags on bumper and hood. }\end{array}$

Figure 31.-Detection zone for Body Guard and pickup.

the dump truck, although more antennas can be integrated into the system to determine in which blind spot the tag is located. The processing electronics also contain a separate high-frequency transceiver to communicate with the tags.

The tag tested on this system is considered active. It is contained in a remote-control pendant manufactured by Nautilus that is used in its radio-remote-control systems. Stand-alone tags are being developed at this time. Each tag contains a transceiver to communicate with the reader's processing electronics. The tag measures the field strength of the low-frequency signal generated by the loop antenna. The field strength increases as the distance between the tag and the loop antenna decreases. If the field strength exceeds a user-defined limit, this information is sent to the tag reader and an alarm is generated. On the system tested, the alarm state was normally used to set the brakes of the machine automatically. An alarm display for the dump truck operator is under development.

\section{Current Applications:}

The system is used in underground mines on remotecontrolled LHD's and trucks. The Buddy system automatically stops the equipment if it gets too close to the remote-control operator. 


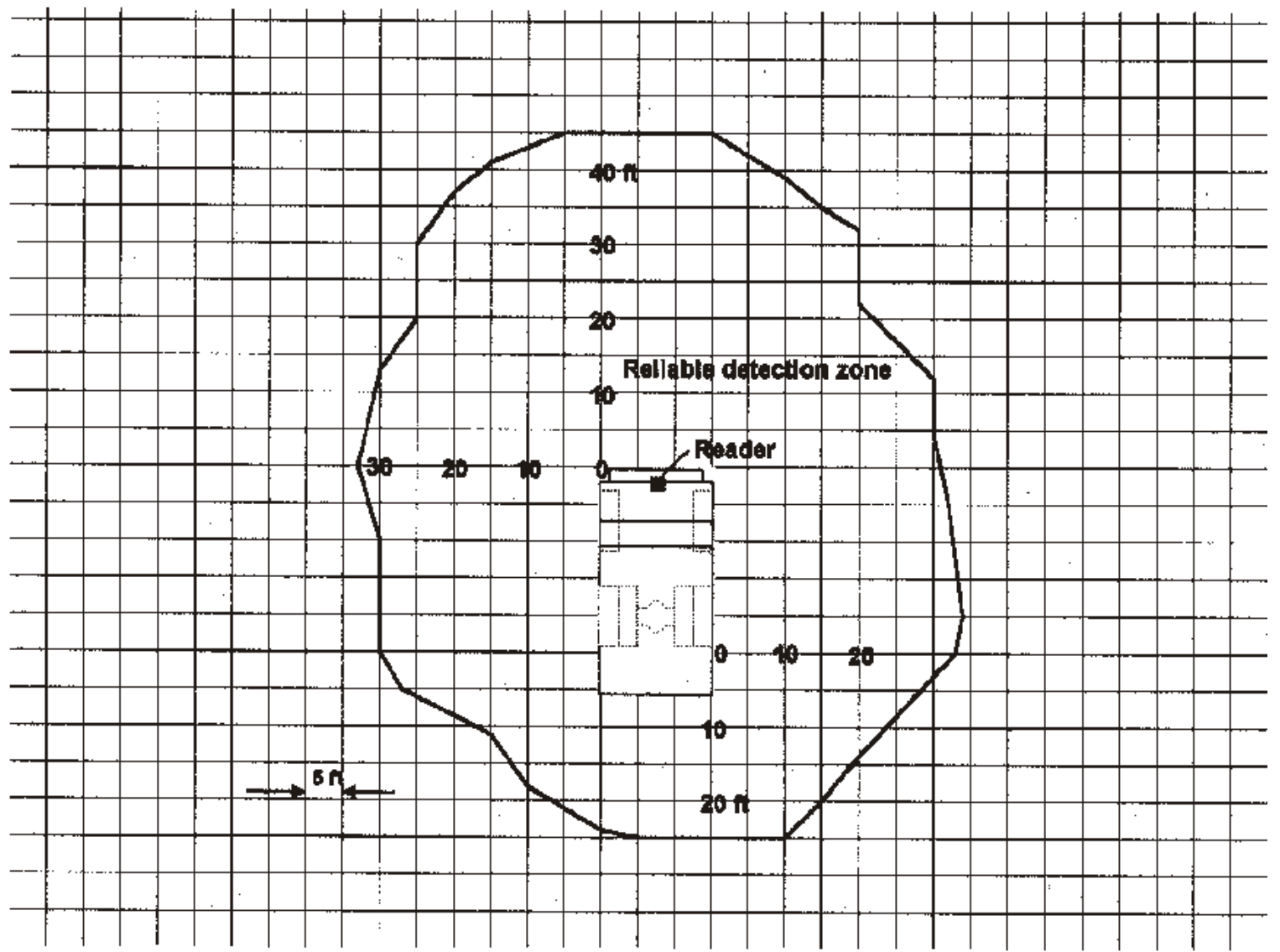

A

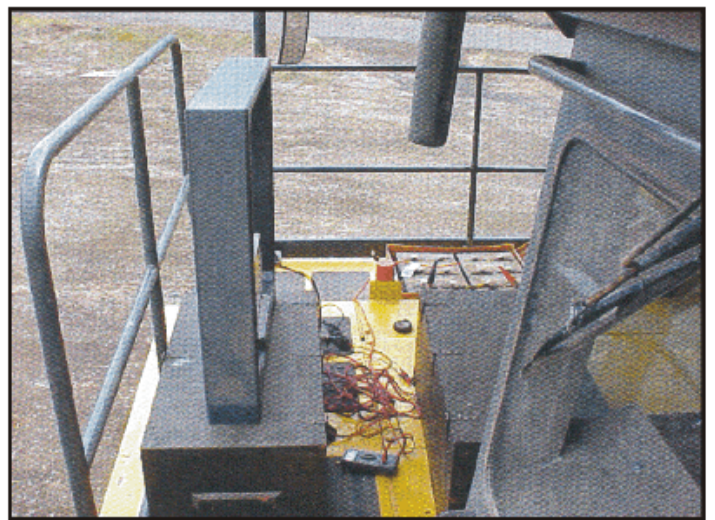

B

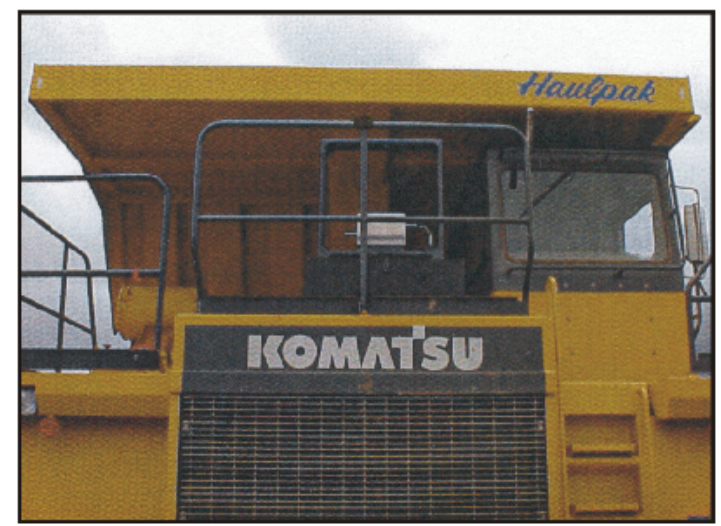

c

Settings: $\quad$ Warning zone of $18 \mathrm{~m}(59 \mathrm{ft})$.

Mounting: $\quad$ Mounted on front deck at height of $3 \mathrm{~m}(10 \mathrm{ft})$.

Target detected: Person carrying remote-control pendant.

Figure 32.-Test results for Buddy system and person. A, Detection zone; B, loop antenna; C, front view of truck. 
Blind Spot Test Results:

The front and rear of the truck were tested simultaneously. The tag reader was mounted on the front deck of the truck, next to the cab, at a height of $3 \mathrm{~m} \mathrm{(10} \mathrm{ft)} \mathrm{(figure} \mathrm{32C).} \mathrm{Because} \mathrm{the} \mathrm{unit}$ tested was a demonstration unit, the alarm display was integral to the remote-control pendant, and the alarm state was monitored from the pendant.

The size of the detection zone is set by inputting the desired detection radius. The field strength measured at this radius is then saved as the alarm threshold. As the tag is moved around the dump truck, the field strength is measured. Values of field strength above the alarm threshold trigger an alarm whereas values below this threshold do not.

The tests involved a person walking around the dump truck while holding the remote-control pendant containing the tag. The oval pattern shown in figure $32 \mathrm{~A}$ demonstrates the detection zone with a setting of $18 \mathrm{~m}(59 \mathrm{ft})$ for the detection radius. The actual detection zone extended $13.7 \mathrm{~m}(45 \mathrm{ft})$ from the front bumper, $7.6 \mathrm{~m}(25 \mathrm{ft})$ from the rear wheels, and $9.1 \mathrm{~m}(30 \mathrm{ft})$ from both sides. Note that the detection zone was larger in front of the truck than in the rear because of the forward position of the antenna. The detection zone can be adjusted using software to eliminate this offset, or it can be altered to compensate for forward or reverse movement of the truck. By adding an antenna at the rear of the machine, the position of the tag can also be determined, but this option is not yet available.

No sporadic detection zones or dead spots were seen near the truck. The tag was even detected underneath the chassis of the truck and in the wheel wells. No false alarms occurred when the tag was outside the detection zone.

No tests were conducted with a pickup because of the way the tag was packaged. Such tests should be conducted when a stand-alone tag is available in order to find the best mounting location for the tag.

\section{TEST RESULTS (PROTOTYPE SYSTEMS)}

Because of the initial difficulties in applying OTS collision warning systems to surface mine haulage trucks, NIOSH contracted out the development of two new systems specifically meant for mining equipment. This effort paralleled the testing of OTS systems to provide an alternative technology if needed. Another system currently being developed for continuous miners in underground coal mines was also tested.

\section{SYSTEM 6 - ULTRAWIDE-BAND RADAR}

Developer:

Multispectral Solutions, Inc. (MSSI), Gaithersburg, MD

Description of System (Fontana et al. 1998):

MSSI's radar system is based on ultrawide-band technology that uses nanosecond radar signal pulses to produce a wide, instantaneous bandwidth waveform. The radio frequency circuitry for a ultrawide-band system is minimal, consisting of a low-noise amplifier and broadband tunnel detector. In addition, most ultrawide-band system designs are digital, further lending to lowcost modular designs and small-sized packages.

A transmitter module emits ultrawide-band radar pulses at a fixed repetition rate from the transmitting antenna. A receiver antenna picks up both the transmitted pulse and pulses reflected from the environment and/or targets of interest. A radiofrequency module amplifies and filters the pulses and sends them to a processing board. The transmitted pulse is picked up by one detector of a dual short-pulse detector (initialization pulse) while the second detector picks up target and clutter information. A high-speed time-detector circuit measures the relative positions of the two pulses and passes this information to a digital signal processor. The digital signal processor then performs calculations to control detector sensitivity and to convert the time difference to a precise measurement of distance for display as a target.

The advantages of using the ultrawide-band width approach are as follows:

- An ultrawide-band-based radar unit operates as a presence sensor, i.e., it does not depend upon relative motion or Doppler information.

- Because of the extremely short (nanosecond to subnanosecond) duration of the pulse widths and very low energy densities, ultrawide-band systems are immune to interference from other communication devices, electronic equipment, or motors.

- With ultrawide-band radar, range gates can be established at user-selected distances at a precise cutoff of several centimeters and thereby eliminate object detection beyond certain distances. - The wide bandwidth of an ultrawide-band radar unit also enhances the probability of detecting small targets, such as suspended wires, poles, etc.

The prototype radar system consists of the antenna and electronics enclosure, a liquid crystal alarm display (LCD), and necessary wiring (figure 33). Repackaging the antenna and electronics enclosure will be necessary if the unit goes to 
production. The display shows an icon for the equipment along with zones in the radar beam that represent the range gates. If an obstacle is detected by the radar unit, the location of the obstacle is highlighted in the appropriate range on the LCD. An audible alarm is provided that can be shut off for each range gate, e.g., if no alarm is desired for the farthest range, the alarm can be turned off for that particular range.

\section{Current Applications:}

A similar version of this radar unit is being used by the military, specifically in collision avoidance for unmanned helicopters [Mulloy 1999].

\section{Blind Spot Test Results:}

The radar antenna enclosure was mounted near the light bar at the rear of the truck at a height of $1.5 \mathrm{~m}(5 \mathrm{ft})$. Horizontal polarization of the antennas gave the best results with the least number of false alarms. Figure $34 B$ shows the radar unit mounted on the back of the truck with vertical polarization, which is achieved by just turning the unit $90^{\circ}$.

The radar unit was tested for false alarms by driving the dump truck in a clear field. No false alarms were heard after the radar unit's sensitivity was adjusted to correct levels.

Figure $34 A$ shows the detection zone when a person was the target. Because of the timing of the transmitted and received pulses, this version of the radar unit had difficulty detecting a person nearby, as evidenced by the sporadic detection zone from

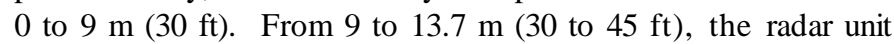
detected a person reliably.

Modifications to the radar unit are in progress. The modifications are expected to alleviate the close-range detection problem, and the reliable detection zone will be extended to cover both detection areas shown in figure $34 A$.

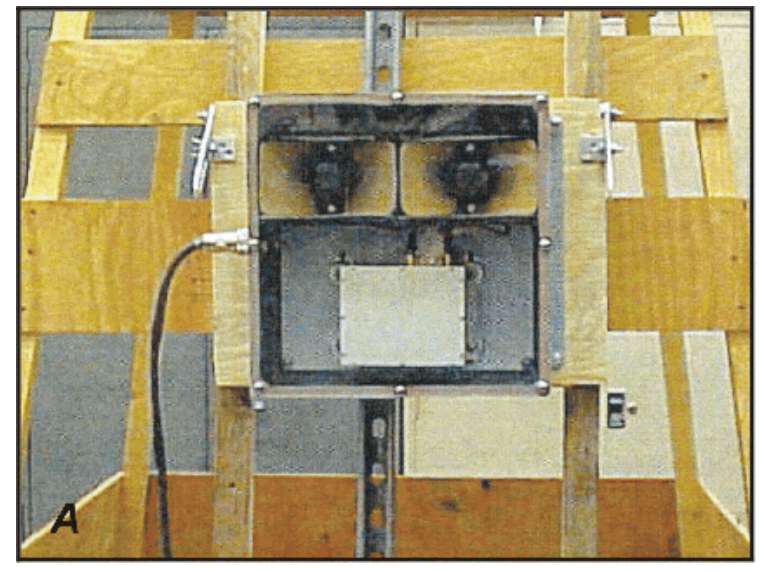

Figure 35 shows the results of tests when a pickup was the target. The reliable detection zone extended from $4.6 \mathrm{~m}(15 \mathrm{ft})$ to $24.4 \mathrm{~m}(80 \mathrm{ft})$. Detection was also seen around the sides of the truck as long as part of the pickup remained in front of the radar unit. As with most of the other radar systems, reliable detection and maximum range of detection depend on material composition and cross section of the target. For this system, the sporadic detection zone was also affected by the type of target; the zone was significantly decreased with the pickup.

The dump truck was driven around the test area to determine the radar unit's reaction to various objects. The radar unit detected large berms (bigger than $0.5 \mathrm{~m}[1.6 \mathrm{ft}]$ ) while ignoring smaller ones. It detected bushes and trees, but ignored small foliage such as grass and weeds. The system also detected and provided correct range information for wood power poles, buildings, and chain-link fences as long as they were at least $6 \mathrm{~m}(20 \mathrm{ft})$ away from the truck.

\section{SYSTEM 7 - ID INTERNATIONAL, RFID SYSTEM}

Developer:

ID International Holdings (IDI), LLC, Concord, MA.

Description of System:

This RFID-based system consists of active tags, a tag reader mounted on the mining equipment, and an alarm display mounted in the operator's cab and connected to the reader via cable (figure 3). Each pedestrian worker and any smaller vehicles in a work area or job site are outfitted with tags. If a tag is detected within range of a tag reader, an alarm is activated, warning the equipment operator.

The first version of the tags were housed in high-impact, sealed plastic cases approximately 6 by 7 by $2.5 \mathrm{~cm}(2.4$ by 2.7 by

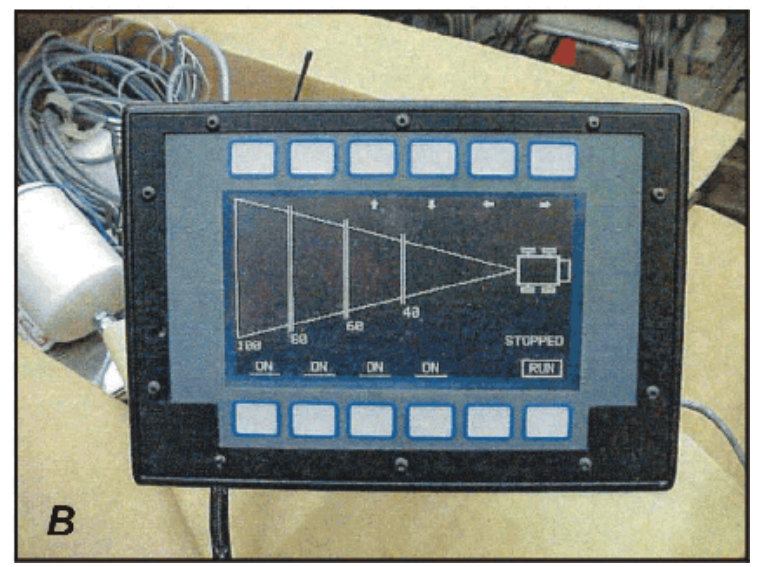

Figure 33.-Prototype radar system. $A$, Antenna and electronics enclosure; $B$, operator display showing range gates. 


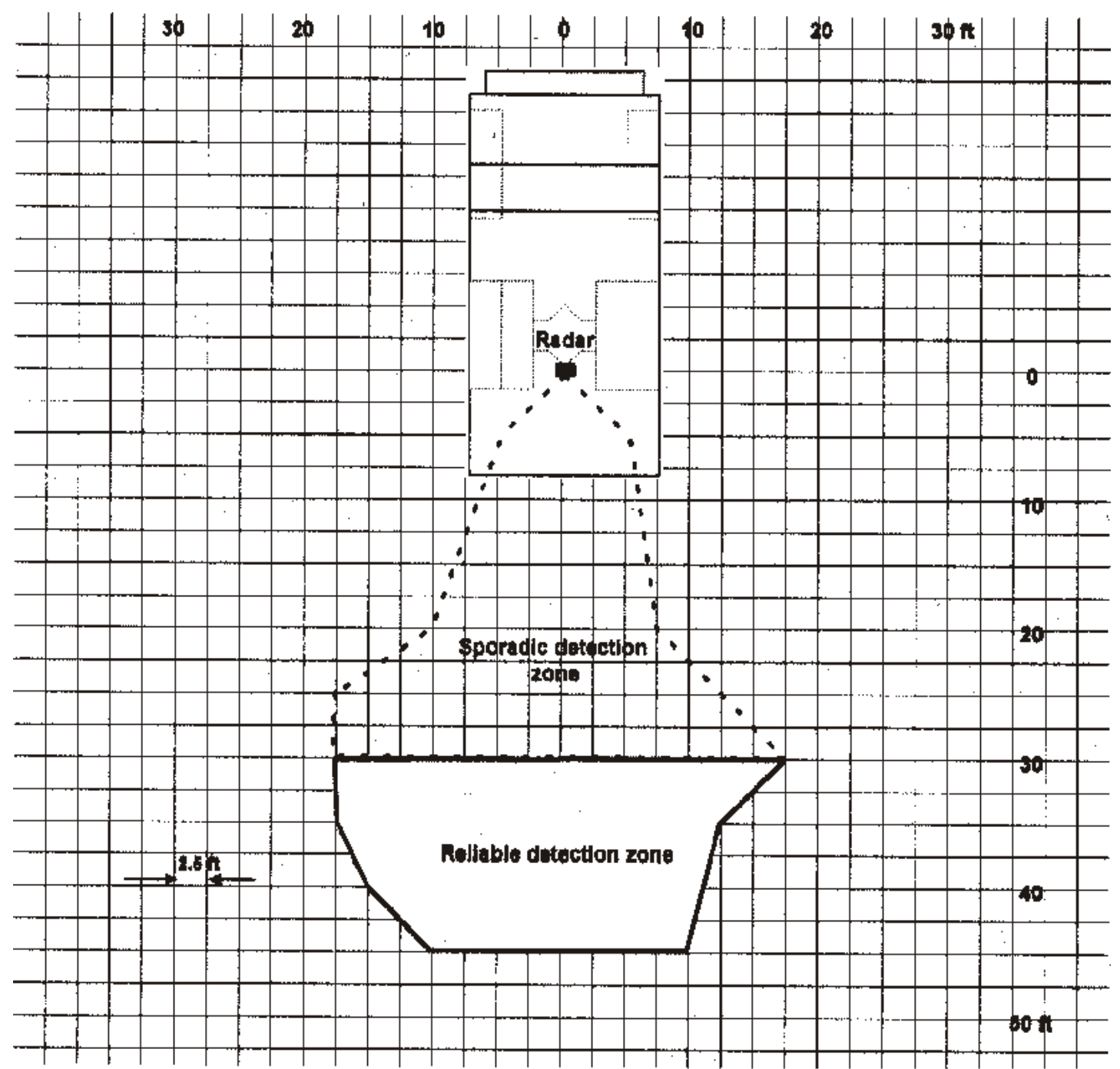

A

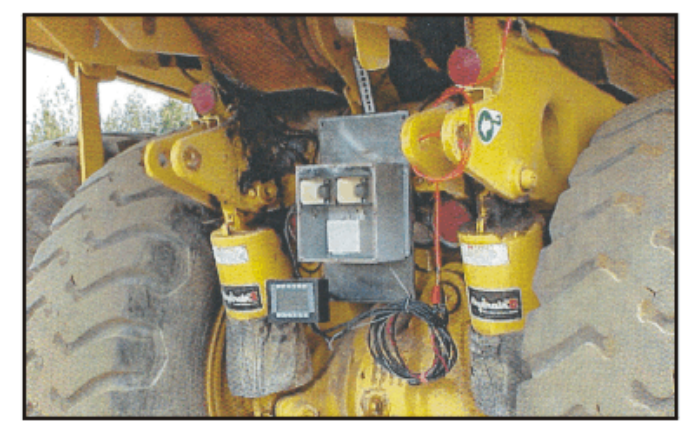

B

Mounting: $\quad$ Radar mounted near light bar at height of $1.5 \mathrm{~m}(60 \mathrm{in})$.

Target detected: Person.

Figure 34.-Test results for Multispectral ultrawide-band radar prototype and person. A, Detection zone; $B$, mounting position. 


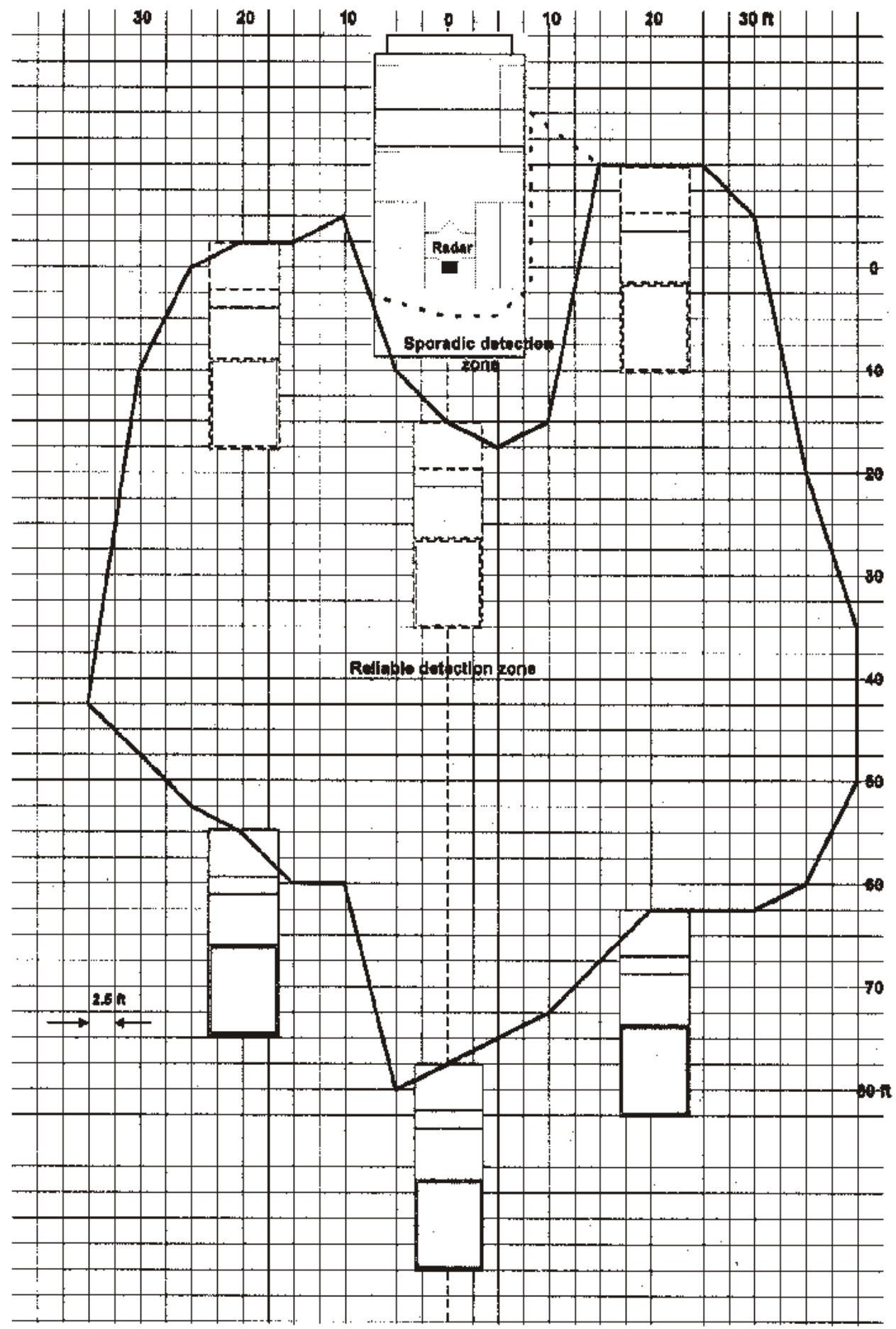

Mounting: $\quad$ Radar mounted near light bar at height of $1.5 \mathrm{~m}$ (60 in).

Target detected: Pickup facing rear of durnp truck.

Figure 35.-Dectection zone for Multispectral ultrawide-band radar prototype and pickup. 
1 in). A single whip-style antenna was used to transmit a lowpower, 315-MHz signal. These antennas were highly directional, making detection dependent on orientation of the tags. Presently, the tags are much smaller and are mounted inside a hard hat. Two dipole antennas are used to alternately transmit the signal. This modification improved detection, making it independent of tag orientation. Components include a microprocessor, a 315$\mathrm{MHz}$ transmitter, and an on-board battery (figure 36 ).

Tag reader components include a receiver, signal conditioning electronics, and a microprocessor. The reader and a partial-coil whip antenna are housed in a 10 - by 10 - by $15-\mathrm{cm}$ (4- by 4- by 6-in) NEMA-type enclosure. These sealed, grounded steel boxes are mounted with bolts and brackets to the host vehicle, powered by the vehicle's 12 - or $24-\mathrm{V}$ dc system, and connected to the alarm unit in the operator's cab. The sealed alarm unit has a light and 105-dB audible alarm.

For testing and development purposes, the readers have two external switch-controlled adjustments for range and sensitivity. There are three selectable distance ranges, (near, middle, and far) and a continuously adjustable sensitivity setting that controls the software's signal discernment characteristics.

Each tag transmits an "I'm here" signal three to four times per second, alternating between the two sets of orthogonal antennas. The reader receives and processes the signal. If a valid signal is detected within the selected range, an alarm condition is sent to the alarm unit, which flashes the light and buzzes the alarm. If two tags are detected in the reading range, a discernable "double buzz" alerts the driver to the presence of two or more tags [Ruff and Hession-Kunz 1998]. Currently, the tags are powered by lithium coin cells, which have a projected working life of 2 years.

\section{Current Application:}

This system has not been used in any other application.

Blind Spot Test Results:

The tag reader was mounted on the rear of the dump truck near the light bar. The range of the reader was adjusted to the low setting. No false alarms were seen in a clear field.

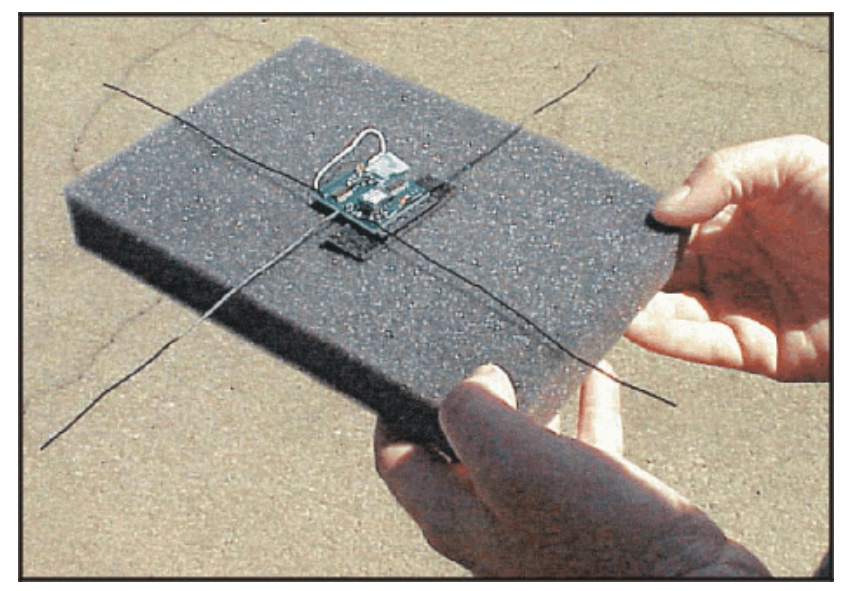

Figure 36.-Prototype ID International tag.
The detection zone was interspersed with small nulls where the tags were not detected. This was not seen as a function of tag orientation, and it is suspected that multipath interference from the dump truck and ground caused these nulls. An improved antenna design and possible relocation of the reader are currently being studied.

The range of the system extended from immediately next to the reader out to approximately $24 \mathrm{~m}(80 \mathrm{ft})$. The width of the detection zone extended between 12 and $15 \mathrm{~m}$ (40 and $50 \mathrm{ft}$ ) on either side of the truck. More work is needed to obtain a betterdefined detection zone that contains no nulls and is limited to $15 \mathrm{~m}(50$ $\mathrm{ft}$ ) behind the truck and a total width of 6 to $9 \mathrm{~m}$ (20 to $30 \mathrm{ft}$ ).

\section{SYSTEM 8 - PITTSBURGH RESEARCH LABORATORY HASARD SYSTEM}

Developer:

Pittsburgh Research Laboratory, NIOSH, Pittsburgh, PA.

Description of System:

Even though this system has some significant differences, it could be classified as an RFID-based system because it is based on radio-frequency signal detection. The system consists of a loop antenna that transmits a low-frequency signal and a receiver or signal detector that receives this signal. The receiver measures and displays signal strength and can produce an alarm. The system was originally designed to protect remote-control operators of mobile mining equipment. The loop antenna(s) is mounted on the machine, creating a low-frequency halo or field around the perimeter of the machine. The receiver is worn by the remote-control operator and warns when the operator enters this field. The system also has the option of automatically setting the brakes if a collision is imminent. This device was based on U. S. Patent 5,939,986, "A Mobile Machine Hazardous Working Zone Warning System," which was granted on August 17, 1999 [Schiffbauer 1999].

A variation of this system was tested on the dump truck. For this application, the transmitter and receiver locations were reversed, i.e., the object to be avoided was outfitted with the transmitter and the dump truck was outfitted with one or more receivers. A $60-\mathrm{kHz}$ sine wave at $40 \mathrm{~V}$ peak-to-peak was transmitted through a loop antenna $135 \mathrm{~cm}$ wide by $124 \mathrm{~cm}$ long (49 by 53 in). The antenna consisted of seven turns of 14-gauge wire encased in PVC pipe so that a donut-shaped electromagnetic field was generated. Different sizes of antennas or multiple antennas can be used to vary the size and shape of the field.

The receiver for the system incorporated a simple LED bar graph that indicated signal strength from 1 to 10,10 indicating the strongest signal. The receiver's indication of signal strength was recorded to define the detection area of the system. 
Applications:

This system is currently being tested on continuous coal mining equipment used in underground mines.

Blind Spot Test Results:

With the current configuration, a worker would have to wear a large, high-power antenna to generate the required field, which would not be practical. Thus, unless alternative transmitters are developed, the current system could not be used to protect a person. For these tests, only a pickup was used as the target.

Two configurations were tested in which the loop antenna was mounted on top of the pickup cab (figure $37 B$ ). In the first, the antenna was mounted directly on top of the cab against the steel body. In the second, the antenna was mounted with a $15-\mathrm{cm}$ (6-in) offset to hold it away from the cab. The offset increased the range of the antenna, so this configuration was used during the final tests.

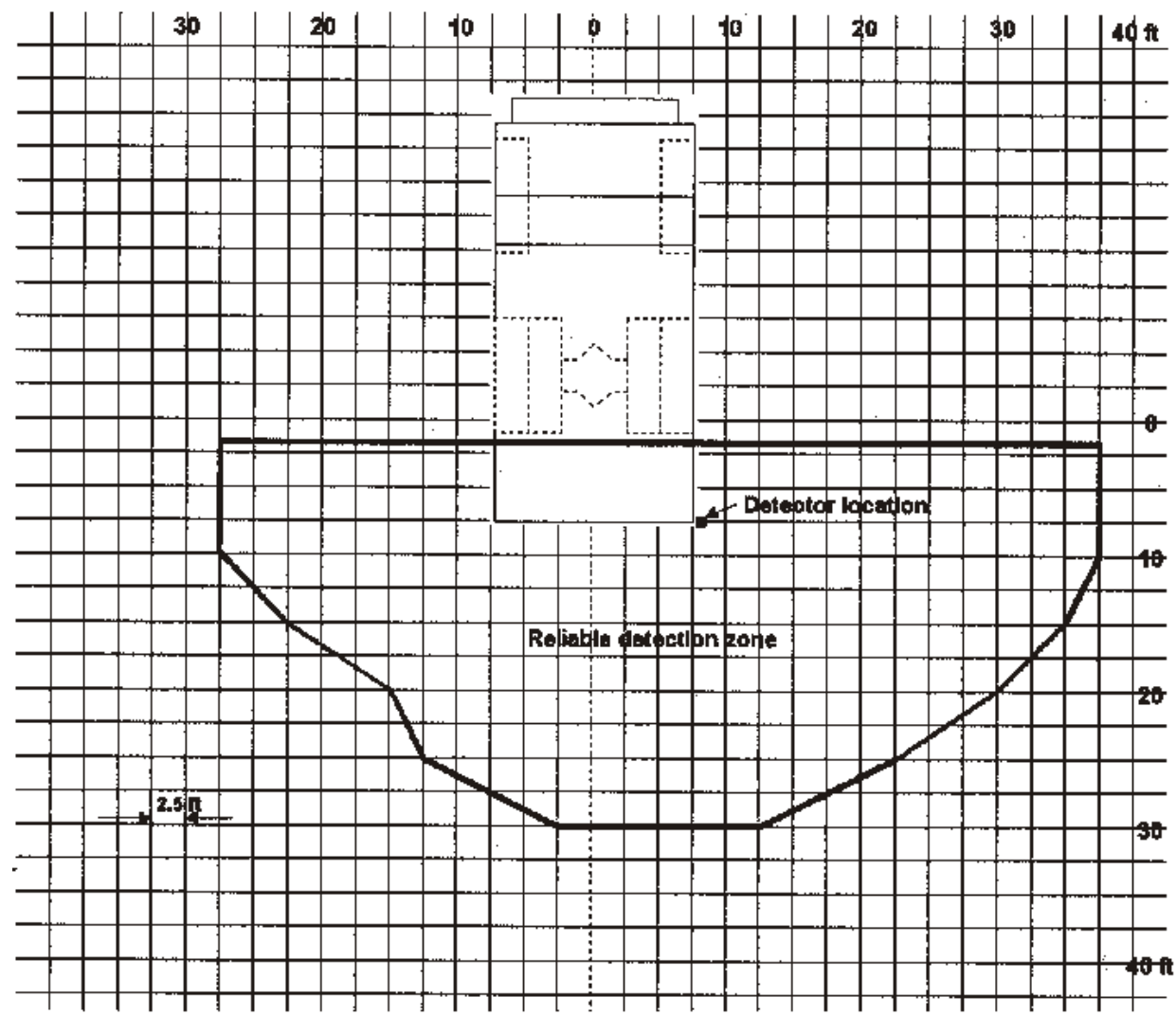

A

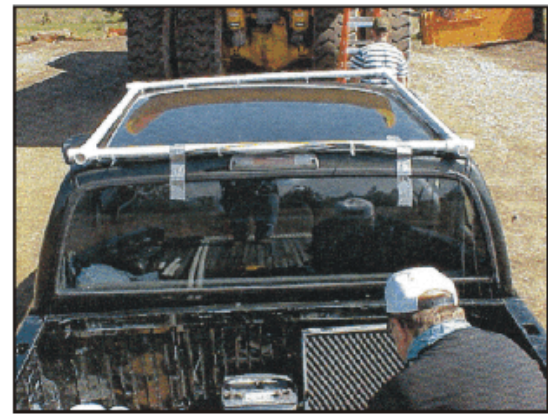

B

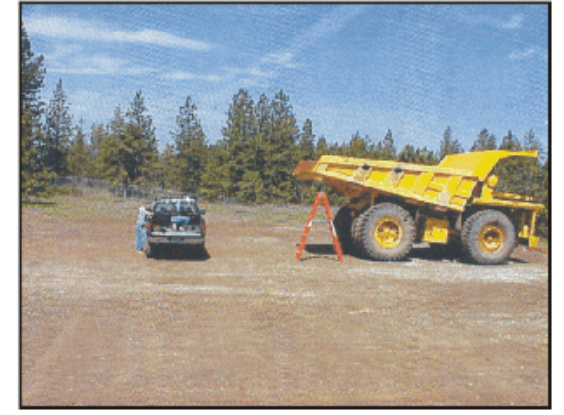

c

Mounting: $\quad$ Radar mounted near light bar at height of $1.5 \mathrm{~m}(60 \mathrm{in})$.

Target detected: Pickup facing rear of dump truck.

Figure 37.-Test results for PRL's HASARD system and pickup. A, Detection zone; $B$, loop antenna on truck; $C$, view behind truck. 
The receiver was mounted near the light bar at the rear of the dump truck. Interference from the surrounding metal significantly attenuated the signal, and a better location was found at the outside corner of the dump truck bed (directly above the ladder in figure $37 C$ ). While this location was used in the tests, it would be difficult to install a final system receiver here. If this difficulty can be overcome, a receiver could be mounted near each corner of the dump truck to monitor all blind spots simultaneously.

Figure $37 A$ shows the test results for a single receiver at the corner of the dump truck bed. The detection zone extended

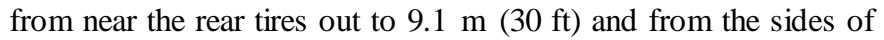
the dump truck to $11.4 \mathrm{~m}(37.5 \mathrm{ft})$. This zone should extend along the sides toward the front of the dump truck, but this area was not tested.

This system showed promise for the dump truck; however, more development is needed to make it suitable for surface mining. A full description of the system as it applies to underground coal mining equipment can be found in Schiffbauer's report (1999).

\section{CONCLUSIONS}

\section{RADAR SYSTEMS}

Radar-based collision warning systems are the least expensive of the technologies tested. Ranging from $\$ 500$ to $\$ 2,000$, radar systems are affordable to install on the front and rear of every dump truck in a mining operation. They also require the least amount of equipment - an enclosure for the radar unit, alarm display, and wiring between the two.

However, false alarms are inevitable with radar systems. In the worst case, false alarms are short and frequent. They can be caused by rocks or uneven terrain that would not be considered hazardous and from abrupt truck movements and shocks. At best, false alarms are infrequent, but still occur because of rocks or uneven terrain. Alarms are also caused by objects that the truck driver is aware of, such as a highwall, berm, buildings, or another dump truck. This characteristic could also mask the presence of an object such as a person standing between a dump truck and a berm. False alarms are a major concern with collision warning systems because the equipment operator may, understandably, start ignoring alarms.

Mounting a radar unit can be time consuming, and a suitable location can be difficult to find. Radar will detect nearby objects, such as the rear tires of the machine, if the radar unit is mounted near the rear axle, so care must be taken in selecting beam widths and ranges to minimize false alarms caused by parts of the truck itself. On some systems, finding the correct height and mounting angle can be difficult and must be done on a trialand-error basis for each size of dump truck and for each type of obstacle to be detected. The mounting angle of radar is especially important when trying to detect shorter objects or people (or a person laying down). Because of the fan-shaped beam, low-profile objects near the radar may not be detected. Examples of this are found in the sections describing the cinder block tests. Mounting the radar unit on the front of the truck is likely to be less complicated, but mounting angle and height still must be considered.

The detection zone of a radar unit can change depending on the object to be detected. The mounting scheme and radar settings for effectively detecting a pickup at a given distance might not be the same as for detecting a person. This is atradeoff that must be considered when adjusting the settings on the radar unit.

None of the radar systems evaluated in this study had been developed for, or previously tested on, large, rigid-frame dump trucks. Thus, there are some concerns about the durability of the enclosures and the effectiveness of the alarm displays. More data are needed from actual tests at a surface mine before any conclusions or recommendations can be made.

Although much was learned from testing the systems on a 50ton-capacity Komatsu, the results are not necessarily transferable to larger trucks. In fact, the systems tested may have to be modified if they are to work on larger trucks because of differences in physical dimensions.

There is potential for significantly reducing accidents by employing radar technology if the above concerns can be addressed adequately. This calls for further development and testing by collision warning system manufacturers and close cooperation with the mining industry.

\section{RFID SYSTEMS}

Although no RFID-based collision warning systems are commercially available for use on surface mining equipment at this time, some of the systems tested show promise for this application. One advantage of these systems is that they do not generate false alarms. Either a tag is in the reading range of the tag reader or it is not. If the system detects a tag and sets off an alarm, the dump truck operator can be sure that there is an obstacle in his or her blind spot. Attaching tags to objects that are to be avoided assures that only objects of interest will generate an alarm. Rocks, berms, or a highwall will not cause the system to alarm.

The disadvantage to RFID systems is that a large number of tags must be purchased and attached to pickups, graders, pedestrian workers, and any other object to be avoided. On one hand, a simple and cheap tag would make it easy and affordable to tag many objects. On the other, intelligent and complex tags can provide more functionality and improved performance.

RFID-based systems tend to be more expensive than radar systems. Tags can range from $\$ 2$ to $\$ 500$ each, and the cost of 
a tag reader with an alarm display can range from $\$ 6,000$ to $\$ 20,000$, depending on the quantities purchased.

The OTS systems tested were easy to mount. However, because the detection zone can change depending on the location of the tag reader, some care must be taken in finding a proper mounting location. Trial-and-error in mounting is required to optimize the detection zone for a particular dump truck. Also, range settings must be adjusted to optimize the detection zone for both people and vehicles because the quality of the tag transmissions can be affected by the object to which they are attached.

Durability will also be an issue for these systems. Tests at an actual surface mine will be required before any of the systems examined can go into production.

\section{RECOMMENDATIONS}

These tests show that both RFID and radar technology show potential in reducing accidents involving people or smaller vehicles in the blind spots of mining equipment. More development and testing are needed in order to meet the unique conditions encountered in surface mining. Other specific recommendations follow.

Because of false alarms (or real alarms from objects that pose no danger), it is recommended that radar systems be used in conjunction with another, secondary collision warning system, such as video cameras. This duplication will give an operator a warning about an object in the blind spot and a method to check out the warning without leaving the cab. If the reliability of radar systems increases so that false alarms are rare and multiple objects can be distinguished, a secondary system may become optional.

For systems using radar, the distance to a detected obstacle should be presented in a simple way to an equipment operator. This can be accomplished with LEDs, a graphic LCD, distinguishable audible alarms that indicate the presence of an obstacle in a certain range gate, or an actual distance readout. This is especially helpful when multiple targets are in a detection zone or cameras are not used as a back-up system. It also provides a method of determining the closer of two objects, such as in the case where a person is in between the equipment and the detected highwall.
Systems based on RFID are not prone to false alarms because of the positive nature of tag detection and therefore may not require redundancy. However, the addition of a secondary system, such as cameras, may be helpful by allowing the operator to verify the location of an obstacle, especially when multiple tags are in the detection zone. A method of indicating the position or distance to detected tags would also be helpful. Finally, extra precaution is needed to as sure that all vehicles and pedestrian workers at a mine are outfitted with a working tag.

When evaluating the reliability of a collision warning system, it is important to test the system on the actual mining equipment and while the equipment moves toward the obstacle to be detected. This is the only way to determine if equipment vibration and signal reflections are adversely affecting the system. Also, it is important to verify the reliability of a system by using the actual objects that need to be detected. Many collision warning systems, especially radar, are sensitive to the composition and size of the object to be detected.

No collision warning system can replace common sense and the caution needed when operating mobile mining equipment. However, technology can aid in reducing some of the guesswork required when operating vehicles that have extensive blind spots.

\section{REFERENCES}

Boldt, C. M. K., and R. R. Backer. Surface Mine Truck Safety - Where Are We? Proceedings, 28th ann. Institute on Mining Health, Safety and Research, Salt Lake City, UT, August 25-27, 1997.

Fontana, R. J., J. F. Larrick, J. E. Cade and E. Rivers. An Ultrawide-Band Synthetic Vision Sensor for Airborne Wire Detection. Proceedings Enhanced and Synthetic Vision 1998, Orlando, FL, April 1998, 9 pp.

Harpster, J. L., R. W. Huey, N. D. Lerner, and G. V. Steinberg. Backup Warning Signals: Driver Perception and Response. U.S. Department of Transportation, Technical Report, DOT HS 808 536, 1996, 62 pp.

Huey, R. W., J. L. Harpster, and N. D. Lerner. In-Vehicle Crash Avoidance Warning Systems: Human Factors Considerations. U.S. Department of Transportation - Summary Report, DOT HS 808 531, 1997, 35 pp.

Johnson, G. A., R. E. Griffin, and L. W. Laage. Improved Backup Alarm Technology for Mobile Mining Equipment. Bur. of Mines Inform. Cir. 9079, 1986, 19 pp.

Mine Safety and Health Administration (MSHA). Accident Data. Accessed July 1999 at http://www.msha.gov.
Code of Federal Regulations 30, Parts 56-57, 77, 1998.

Mulloy, R. W. T. Development of an Autonomous Flight Capability for the Hummingbird Unmanned Air Vehicle. In Proceedings AUVSI '99, Baltimore, MD, July 13-15, 1999.

Ruff, Todd M., and Drew Hession-Kunz. Application of Radio-Frequency Identification Systems to Collision Avoidance in Meta1/Nonmetal Mines. Presentation at IEEE Industry Applications Society, St. Louis, MO, Oct. 12-16, 1998. (Available on CD-ROM.)

Schiffbauer, W. H. A Workplace Safety Device for Operators of RemoteControlled Continuous Mining Machine. Am. J. of Ind. Med., Suppl. 1. Sept. 1999, pp. 69-71.

Society for Automotive Engineers (SAE). Discriminating Back-Up Alarm System Standard J1741. 1998, 11 pp.

Skolnik, Merrill. Radar Handbook, 2nd ed. McGraw Hill, 1990. 


\section{APPENDIX A: COLLISION WARNING SYSTEM TEST DESCRIPTION}

\section{INTRODUCTION}

Researchers at the Spokane Research Laboratory of NIOSH are testing various sensor systems to be used on surface mine dump trucks to avoid collisions with objects in the truck's blind spots. This document outlines the procedure that will be used to test each system. Part of the directions for the tests was taken from SAE J1741 Discriminating Back-up Alarm System Standard. ${ }^{1}$

\section{PURPOSE}

The purpose of these tests is to determine which sensor technologies are effective in warning a dump truck operator that there is a person or vehicle in the blind spot of the equipment. The results of the tests may be documented in a paper to be published at a later date. The results of the tests are not meant to be used for approval purposes or endorsements.

\section{DEFINITIONS}

3.1 Obstacle: Object that must be avoided by the moving dump truck. For these tests the obstacles will consist of either a person or a pickup truck.

${ }^{1}$ Meeting SAE, OSHA, or MSHA standards and testing for compliance are the responsibility of the collision warning system manufacturer and end user.
3.2 Blind Spot: The areas that a truck driver cannot see while seated in the cab

3.3 Collision Warning System: A system consisting of a sensor and operator interface that detects nearby objects and provides an alarm. In the case of radio-frequency-based systems, the total system would also include the radio-frequency tags.

3.4 Sensor: The part of the system that senses nearby objects or radio-frequency transmissions from tags.

3.5 Alarm Display: The part of the system that is located in the cab of the truck and provides a visual and/or audible alarm indicating that an obstacle is in the system's detection zone.

3.6 False Alarm: An alarm indicating the presence of an obstacle in the detection zone of the sensor when no obstacle exists or an alarm from any object that is at a sufficient distance to pose no danger.

3.7 Reliable Detection Zone: The area in which an obstacle is detected $100 \%$ of the time regardless of obstacle orientation.

3.8 Sporadic Detection Zone: The area in which an obstacle is detected some of the time but not always, i.e., less than $100 \%$ detection, but more than approximately $10 \%$.

3.9 Zone Depth: The distance of the detection zone measured from the mounting location of the sensor to where detection no longer occurs (figure A-1).

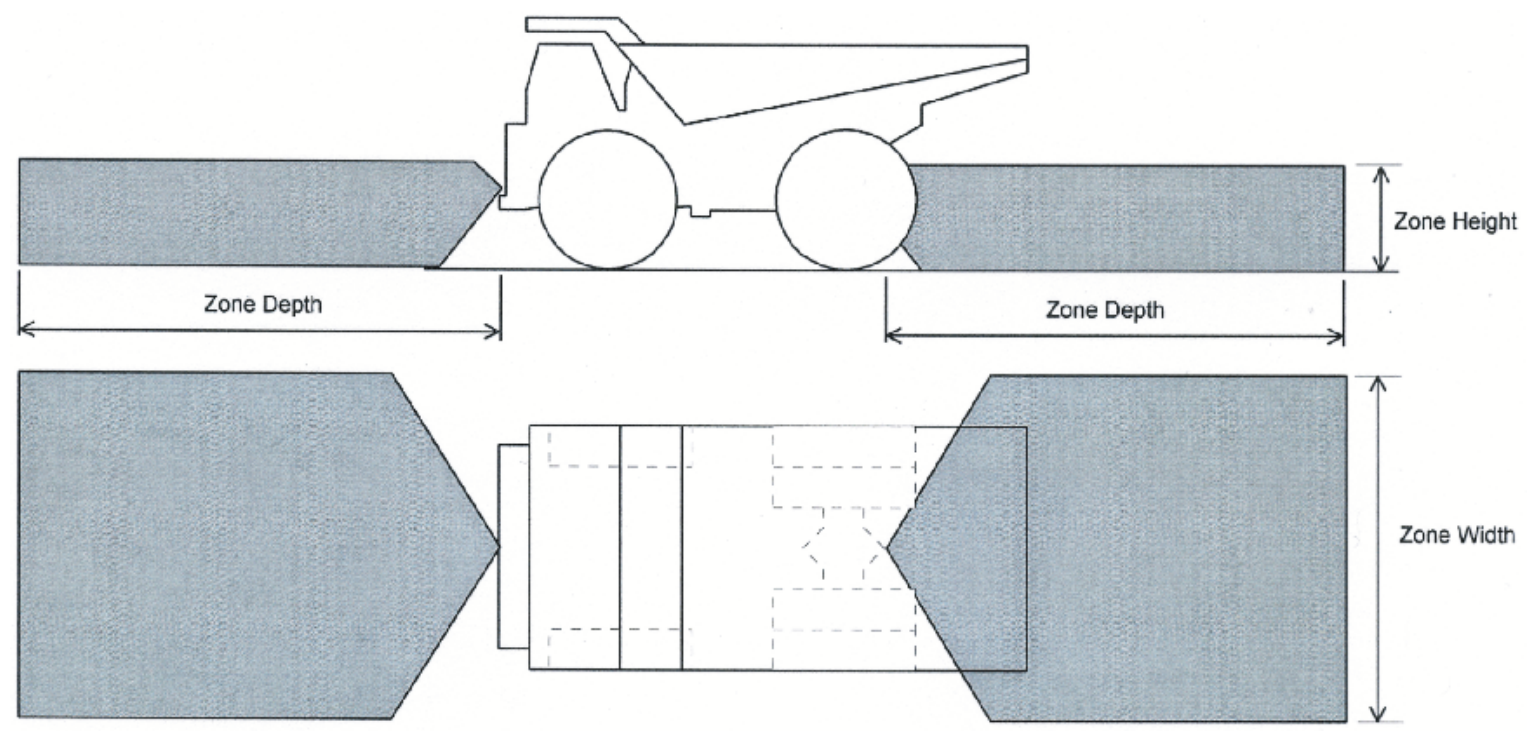

Figure A-1.-Example of size of detection zones for sensors mounted on front bumper and rear axle of off-road dump truck. 


\section{TEST OBSTACLES}

The obstacles that must be detected by the sensor consist of those obstacles most commonly involved in dump truck accidents, i.e., pedestrian workers (persons) and pickup trucks.

\subsection{Person}

For tests to detect a person in the detection zone of a sensor, an SRL researcher will stand in the area of interest near the truck. The person will be wearing a hard hat and will be between $165 \mathrm{~cm}(65 \mathrm{in})$ and $191 \mathrm{~cm}$ (75 in) tall. The orientation of the person will be varied as to which direction he or she is facing. A mannequin, in a sitting position, is recommended by the SAE J1741 standard.

Because of time constraints for the testing procedure, this was not practical. Also, some of the technologies tested are sensitive to the composition of the test obstacle, and a mannequin may not be an accurate representation.

\subsection{Pickup Truck}

For tests to detect a smaller vehicle in the detection zone of a sensor, a three-quarter-ton, full-sized pickup truck will be parked in the area of interest near the dump truck. Several tests should be run with the pickup truck parked in different orientations to determine the effect on detection range. At a minimum, one test is required in which the pickup truck faces the sensor system, giving the minimum cross-sectional area.

\section{DUMP TRUCK DESCRIPTION}

Make: Komatsu (figure A-2)

Model: 210M

Type: Rigid frame, off-highway

Capacity: 50 tons

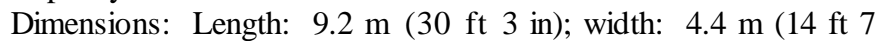
in); height: $4.6 \mathrm{~m}$ (15 ft)

Turning diameter: $21 \mathrm{~m}(69 \mathrm{ft})$

Tire diameter: $2 \mathrm{~m}$ (77 in)

Electrical system: $24 \mathrm{~V}$ (access to $12 \mathrm{~V}$ at batteries).

\section{DETERMINING THE DETECTION ZONE}

\subsection{Test Area}

During tests all personnel, except whoever is acting as the obstacle, shall remain a significant distance away from the potential detection zone. The test area will be an open space on flat terrain with a sand or gravel base. No rocks, foliage, or debris larger than $15 \mathrm{~cm}$ (6 in) in diameter will be in the test area. No large objects such as buildings or berms will be within approximately $61 \mathrm{~m}(200 \mathrm{ft})$ of the front or rear of the truck.
No large objects will be within $30 \mathrm{~m}$ (100 ft) from the sides of the truck.

\subsection{Test Procedure for Rear-Looking Sensors}

6.2.1 False Alarms: Tests of the collision warning system will start with no obstacles near the dump truck as defined by section 6.1 entitled "Test Area." With the potential detection zones totally clear, the truck will be moved several times in reverse to determine the frequency of false alarms.

6.2.2 Obstacle Detection: The detection zones for the rear sensor will be determined by placing the obstacle at various distances and locations behind the truck and recording whether or not an alarm was activated when the truck is moved in reverse at slow speeds (less than $8 \mathrm{~km} / \mathrm{h}[5 \mathrm{mi} / \mathrm{h}]$ ). Test points behind the truck will be defined by a grid with a spacing of no more than $1.5 \mathrm{~m}(5 \mathrm{ft})$ between test points. Note: When testing the detection zone for a person, it may be unsafe to move the truck in reverse when determining detection at grid points that are very near the truck. In this case, the person may move toward the stationary truck to determine if detection occurs.

6.2.3 Detection Zones: The reliable detection zone will be recorded as the area in which the obstacle is detected $100 \%$ of the time regardless of the orientation of the obstacle. The obstacle must be detected and an alarm indicated immediately ( $<200 \mathrm{~ms}$ ) after the truck starts moving.

The sporadic detection zone will be recorded as the area in which the obstacle is detected less than $100 \%$ of the time but more than approximately $10 \%$. Less than $10 \%$ detection will be considered outside both detection zones, but may be noted as false alarms.

\subsection{Test Procedure for Forward-Looking Sensors}

The false alarm rate and detection zones for the forwardlooking sensor will be determined in the same way as the rear sensor, but with the dump truck moving forward.

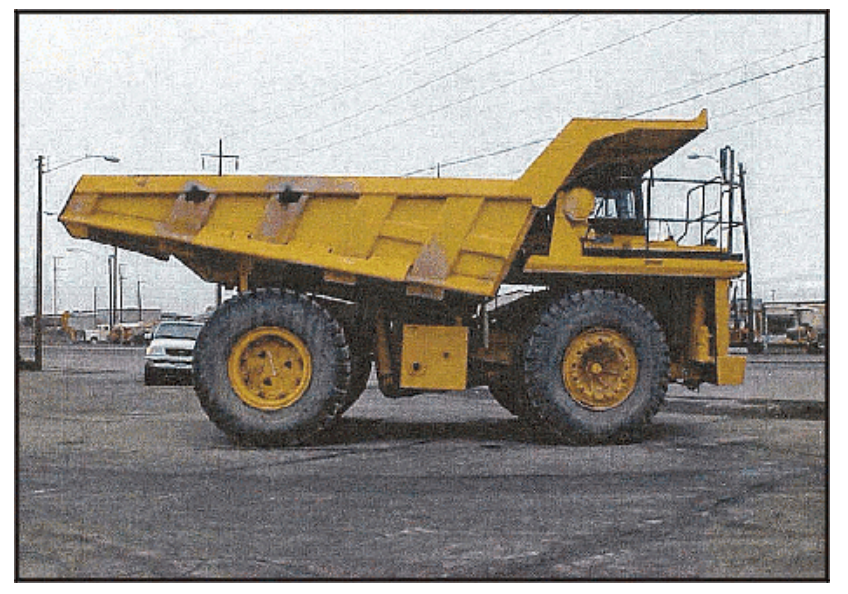

Figure A-2.-Fifty-ton-capacity Komatsu dump truck. 
bumper or grill. For rear sensing, the sensor will be mounted near the light bar above the rear axle (figure A-3). Other locations may be acceptable depending on the individual sensor's installation instructions. If a sensor is not working to specifications, the mounting location may be changed, but must be in a location that does not require modifications to the dump truck.

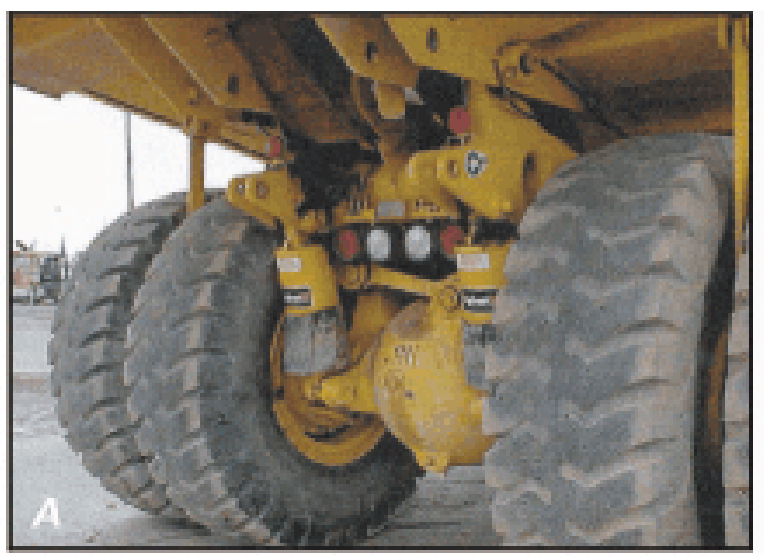

\section{RECORDING THE DETECTION ZONES}

The reliable and sporadic detection zones will be recorded on a graph that will approximate the depth, width, and general shape of the detection zone as seen from a top view. The zones will be determined by placing the obstacle on a grid spacing of no more than $1.5 \mathrm{~m}(5 \mathrm{ft})$. The height of the detection zone, as measured from the ground, will not be recorded in these tests except when it is necessary to investigate a sensor that is not detecting test obstacles (figure A-1).

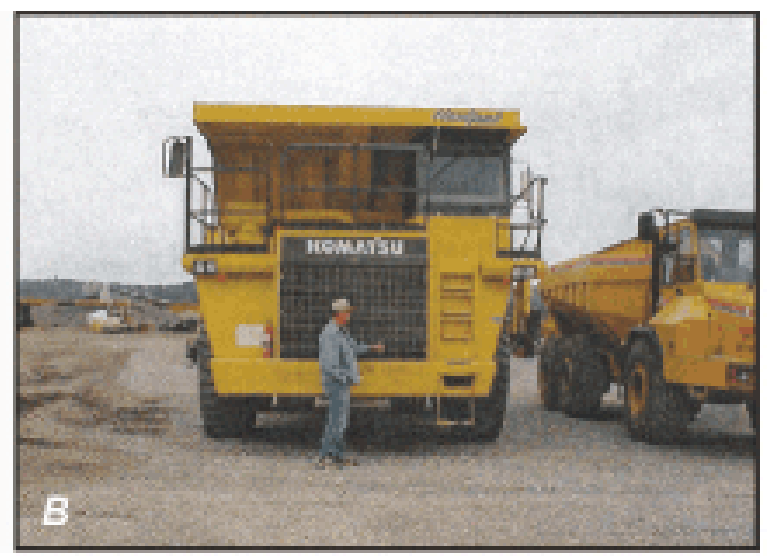

Figure A-3.-Mounting positions for RFID sensors.

A, Rear axle or light bar for rear-leoking senser; B, front bumper or grill for forward-leoking sensor. 
To receive other information about occupational safety and health problems, call

1-800-35-NIOSH (1-800-356-4674), or

visit the NIOSH Home Page on the World Wide Web at http://www.cdc.gov/niosh
DHHS (NIOSH) Publication No. 98-

1998 